\title{
Etiopía, historias de vida de mujeres tigriñas: causas y consecuencias de la fístula obstétrica
}

Investigadora: Liher Bakaikoa Erro

Directora principal: Prof. Ana Alcázar Campos. Instituto Universitario de Estudios de la Mujer. Universidad de Granada

Directora de apoyo: Prof. Chirstine Quinan. Utrecht University

Departamento: Instituto Universitario de Estudios de la Mujer. Universidad de Granada Fecha: 2014 


\title{
Etiopía, historias de vida de mujeres tigriñas: causas y consecuencias de la fístula obstétrica
}

Investigadora: Liher Bakaikoa Erro

Directora principal: Prof. Ana Alcázar Campos. Instituto Universitario de Estudios de la Mujer. Universidad de Granada

Directora de apoyo: Prof. Chirstine Quinan. Utrecht University

Departamento: Instituto Universitario de Estudios de la Mujer. Universidad de Granada Fecha: 2014

Fdo.: Doctora Ana Alcázar Campos. Instituto Universitario de Estudios de la Mujer. Universidad de Granada

\author{
(20)
}




\section{Resumen}

Este trabajo de investigación se centra en el análisis de las vivencias de mujeres que han sufrido la fistula obstétrica en el estado regional de Tigray, Etiopía. La fístula obstétrica es una rotura entre la vejiga y la vagina o entre el recto y la vagina, provocada normalmente por un parto prolongado y obstruido. En la mayoría de los casos, este problema de salud se produce en embarazos a edades tempranas, comprendidas entre trece y dieciocho años, cuando el cuerpo no está suficientemente desarrollado para dar a luz. Debido a ello, provoca a las mujeres incontinencia de los orines o de las heces, desprendiendo un olor fuerte y desagradable, viviendo avergonzadas, escondidas en sus propias casas por el miedo a que el vecindario las discrimine y sintiéndose culpables por pensar que no han sido buenas esposas y madres y que por ello reciben un castigo divino. Esta exclusión de los cuerpos se justifica con que los desechos del cuerpo, como la orina, las heces o la menstruación se consideran materia marginal y, por lo tanto, el cuerpo de las mujeres será considerado repugnante, asociándolo con la parte animal de los seres humanos y excluyéndolos de la sociedad. Desde mi punto de vista y para entender mejor esta problemática hay que ir más allá del discurso médico y tener en cuenta factores culturales, tradicionales y religiosos. Para llevar a cabo esta investigación etnográfica feminista, he realizado trece entrevistas con las mujeres intervenidas de la fístula en la zona rural del estado regional de Tigray, Etiopía, con el fin de conocer sus historias de vida, las cuales durante años han sido marginadas y homogenizadas. Mediante la observación participante, he podido mirar el día a día de estas mujeres y cómo las tradiciones desempeñan un papel importante en sus vidas. En las entrevistas exploro el proceso de estas mujeres desde que toman conciencia de su incontinencia urinaria y piensan que solamente les afecta a ellas hasta que se dan cuenta de que no es un problema individual y privado, sino que se trata de una problemática social con tratamiento médico y que otras mujeres también sufren el mismo problema. Por lo tanto, lo que quiero conseguir con este trabajo es traer sus vivencias desde la esfera privada a la pública para dar a conocer sus realidades en los discursos públicos. La reflexión última derivada de este trabajo me lleva a plantear el diseño de un programa de sensibilización y prevención para ser implementada en escuelas públicas del estado regional de Tigray en torno a los derechos sexuales y reproductivos y, específicamente, la prevención de la fistula $y$ del prolapso uterino. 


\section{Abstract}

This research focuses on the experiences of women who have been living with obstetric fistula in the regional state of Tigray, Ethiopia. Obstetric fistula is a tear between the bladder and the vagina or between the rectum and the vagina caused by a long and obstructed labor. Often, this health problem is due to early-age pregnancy, ranging from thirteen to eighteen, when girl's body is not yet mature enough to give birth. As a result, women suffer of incontinence of urine or feces, emitting a strong and unpleasant odor. These women become stigmatized by society; ashamed of themselves, hidden in their houses and in continual fear of being discovered by family and neighbors. In rural areas fistula is explained as a divine punishment for not being "good" wives and mothers. Exclusion of women's bodies could be justified taking into account that matter expelled from the body, such as urine, feces, sweat, menstrual fluid, etc., is considered to be marginal, polluting and dangerous. Therefore, the bodies of women will be considered disgusting and associating it with the animal part of the human being and so excluded from the society. Fistula goes beyond biological factors. In addition to the assessment of biological aspects, we must take into account social and cultural factors as well. To carry out this study, I use feminist ethnography; I have interviewed thirteen women who had surgical intervention because of obstetric fistula conducted in rural areas of the regional state of Tigray, Ethiopia, to explore their life stories during the years that have been marginalized and homogenized. Through the participant observation, I have observed the day-to-day lives of informants at home, the dynamics of their relationships in a family context, etc., and how the tradition plays an important role in Ethiopian women's life. With these interviews I gather information about the process of becoming aware of their urine or feces incontinence and that this problem goes beyond of individual issue; instead of thinking it is an individual and privet problem and that happens only to them, they realize it is a social problem which has medical treatment. The main objective of the research is to bring experiences of these women from the private to the public sphere, to get to know their realities in public discourses. Finally, the last reflection derivative from this work leads me to raise the design of a prevention programs to provide information and resources on women's rights and health care, with a special focus on sexual and reproductive rights, including issues relating to non-discrimination against women suffering from obstetric fistula for high school students. 


\section{Agradecimientos}

A mi amona Mari Azurmendi y a mi aitona Martin Erro, aunque no estén desde hace años este trabajo no sería posible sin su ayuda.

A mi ama Maite Erro, por su incondicional apoyo durante todos estos años y especialmente estos últimos meses, también a mi aita Baleren Bakaikoa, porque siempre tiene las palabras indicadas para tranquilizarme en los momentos más duros. Gracias a ambos por transmitirme la pasión por la investigación en las ciencias sociales.

También agradezco a mi gran amiga Zufan Ababe, por todas esas risas y horas que hemos compartido juntas en Mekelle, tanto caminando bajo el sol etíope como celebrando los pequeños logros. A Hagos Godefay, por las cenas y largas charlas que tanto echo de menos, y a Tirfu, por su cálida acogida en su casa. Sin la ayuda de estas tres personas mi trabajo no hubiera sido posible. También agradecer a Kinfe Abraha y todo el equipo de la Asociación de Mujeres de Tigray, por todo el trabajo tan importante que están haciendo por las mujeres.

Por supuesto, gracias a Takien, Ascual, Berhane, Abba Maharon, Letekiros, Tesfai, Abrehat, Hatsed, Hailu, Aregawit, Tesfay, Gidey y Abrehet, por hacer posible este trabajo y por abrir las puertas de su casa con tanta generosidad.

Y, finalmente, agradezco sinceramente los sabios consejos de Ana Alcázar Campos, mi directora de este trabajo, y que a lo largo de mi vida profesional estarán presentes.

\section{Gracias, eskerrik asko, thank you, yekenyeley}




\section{Resumen}

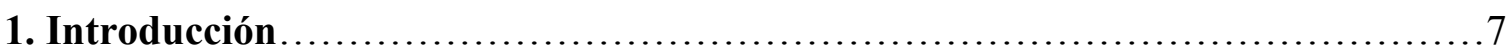

1.1. La problemática de la fístula .......................................... 10

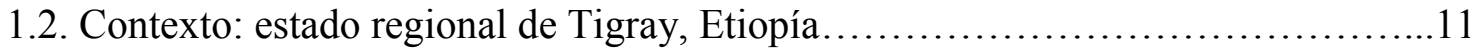

1.3. Interés personal en esta investigación.................................... 13

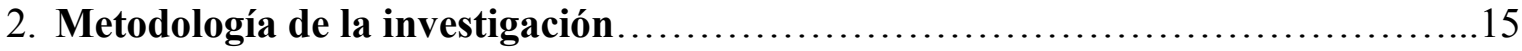

2.1. Objetivo y preguntas de la investigación.................................. 16

2.2. Cuestiones a tener en cuenta durante la investigación feminista.................17

2.3. Mujeres con las que he trabajado........................................ 21

2.4. Método de recogida información.........................................23

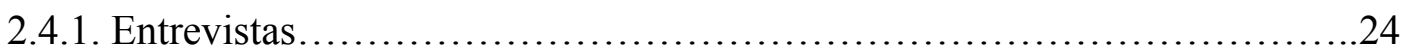

a) Mujeres que han vivido con la fístula ..................................25

b) Directora de la ODWACE.............................................26

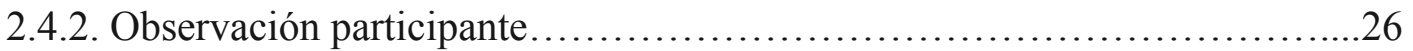

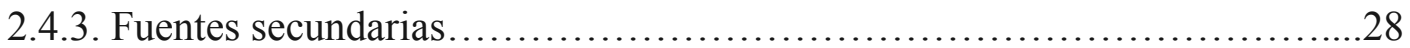

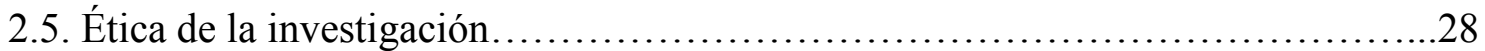

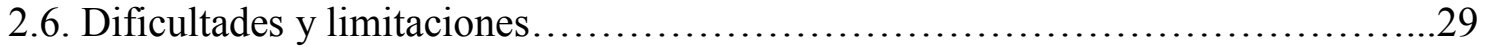

3. Marco teórico de análisis de la fístula como problema social, más allá de lo biomédico........................................................................ 31

3.1. Derechos sexuales y reproductivos........................................ 31

3.2. Antropología médica o de la salud...................................... 37

3.3. Repugnancia hacia los cuerpos de las mujeres................................ 39

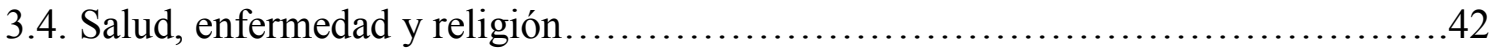

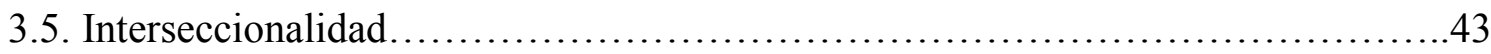

4. Vivencias en torno a la fístula: partos obstruidos, rechazo, castigo y

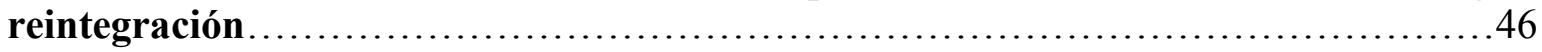

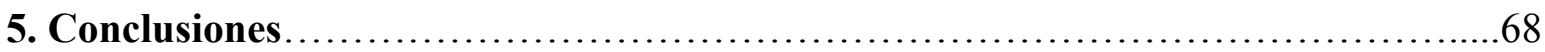

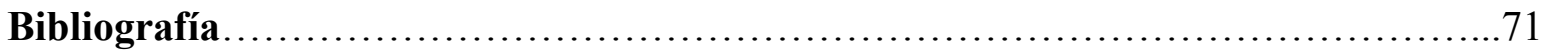

Anexo I: Guion de entrevistas.......................................................

Anexo II: Transcripciones de las entrevistas.................................... 80 


\section{Introducción}

La fístula obstétrica es una rotura entre la vejiga y la vagina (vesico-vaginal) o entre el recto y la vagina provocada por la presión ejercida por la cabeza del bebé en el momento de su nacimiento. Debido a ello, la vejiga, la uretra o el recto quedan comunicados con la vagina o el cuello del útero provocando incontinencia de los orines o de las heces, desprendiendo un olor fuerte y desagradable. Según el ginecólogo Robert F. Zacharin, muchas mujeres sufren la fístula en países en desarrollo de África y Asia, hoy en día todavía se considera una enfermedad propia de mujeres pobres (Zacharin, 1988:2). La fístula es un problema ginecológico debido a un parto obstruido y de larga duración (de entre dos y tres días), estando considerada como uno de los problemas más devastadores y debilitadores para las mujeres (Ahmed y Holtz, 2007:S10).

Reiteradamente se subraya que una de las consecuencias de la fístula es un proceso aniquilador para las mujeres, puesto que conlleva como reacción inicial el aislamiento total como ciudadanas en actividades sociales que se desarrollan en el barrio y en la comunidad. Esto hace, además, que sea, difícil identificar a las mujeres con este problema con el fin de informarles sobre su tratamiento médico. A este comportamiento se añaden las dificultades para mantener estándares mínimos de higiene personal por la escasez de agua (los pozos de agua se encuentran generalmente alejados del hogar, su transporte es una tarea de las mujeres y requiere de mucha fuerza física para acarrear los bidones de agua durante largas caminatas). También este problema de salud conlleva, en muchas ocasiones, que los maridos se divorcien o las abandonen, quedando desprovistas de recursos económicos mínimos para la subsistencia y con frecuencia abocadas a la mendicidad (Ahmed y Holtz, 2007:S10). Todas estas realidades inciden negativamente en su nivel de autoestima, favorecen la depresión y representan traumas emocionales para estas mujeres (Wall, 2006:1203).

La OMS (2010) estima que en el mundo hay dos millones de casos y que el mayor número de los mismos se dan en África y Asia, debido a las dificultades existentes en ambos continentes al acceso a la información y a servicios de salud, y también por el etiquetaje negativo atribuido a la fístula y el alto número de mujeres que dan a luz en sus hogares con la asistencia de familiares o vecinas que carecen de formación. En el caso de Etiopía resulta difícil encontrar datos específicos sobre el número de mujeres que sufren de fístula debido a que las estadísticas oficiales no visibilizan este problema de salud que afecta específicamente a niñas y mujeres. Hay estimaciones que indican que el número de mujeres afectadas por la fístula puede aproximarse a 250.000. La OMS calcula que en Etiopía hay 8.000 nuevos casos de fístula cada año (WHO, 2010). Una particularidad de Etiopía es que desde 1975 hay varios 
hospitales especializados (que pertenecen a una fundación privada) para el tratamiento de la fístula. El hospital principal se encuentra en Addis Ababa (Addis Ababa Fístula Hospital), puesto en marcha por la ginecóloga Dra. Catherin Hamlin y su esposo Dr. Reginald Hamlin. Más tarde, en 2006, abrieron otros cinco hospitales en cuatro estados regionales de Etiopía: Mekelle (Tigray), Bahir Dar (Amhara), Yirgalem (SNNPR), Harar y Metu (Oromia).

Destacar que el problema de la fístula no solo afecta a la productividad del país, de la comunidad y del hogar, sino que esta realidad impacta negativamente en la vida personal y social de las mujeres que la sufren. No pueden hacerse cargo de los roles personales y sociales de esposa, madre y ciudadana, principalmente porque son excluidas o se excluyen de la vida cotidiana y en algunos casos porque no pueden realizar los trabajos del hogar por su condición física, tampoco participan de las dinámicas comunitarias o de la vida comunitaria, como ir a misa, a reuniones, etc. Son mujeres que sufren durante años las severas consecuencias derivadas de este problema de salud pero, además, son estigmatizadas por la sociedad y viven con el "miedo" continuado a ser descubiertas por la familia y el vecindario (Ahmed y Holtz, 2007:S11).

La prevención y el tratamiento de la fístula, según la OMS (2010), son intervenciones necesarias para alcanzar la meta del quinto Objetivo para el Desarrollo del Milenio 2015 (mejorar la salud materna). Las fístulas pueden prevenirse, por ejemplo, retrasando la edad de matrimonio acordados y del primer embarazo, terminando con las prácticas tradicionales dañinas ${ }^{1}$, etc., así como garantizando el derecho de acceso al cuidado obstétrico y a la planificación familiar (WHO, 2010).

Basándome en lo anterior, considero que llevar a cabo investigaciones etnográfica sobre la fístula obstétrica es interesante para enriquecer el conocimiento sobre sus características y consecuencias y, también, para identificar las barreras sociales existentes en la actualidad: el estigma y la exclusión social que afectan a estas mujeres, las dificultades que encuentran en su reincorporación a la vida social después de haber sido intervenidas en un centro hospitalario, etc. En este trabajo, mediante entrevistas y observación participante en el contexto familiar, exploro aquellos factores culturales, sociales y económicos que han incidido en las vidas de catorce de estas mujeres. Su finalidad es identificar los puntos débiles del problema y desarrollar en un futuro un proyecto de prevención mediante la

\footnotetext{
${ }^{1}$ Las prácticas tradicionales dañinas o nocivas, según la ONG etíope ODWACE (Organization for Development of Women and Children of Ethiopia) son: la mutilación genital femenina, extracción de la úvula a niñas y niños, extracción de los dientes de leche, los masajes abdominales a las mujeres embarazadas, casamientos concertados por los padres antes de los quince años, los casamientos por secuestro, incisión en los cuerpos o en las caras de mujeres y hombres, la discriminación alimenticia hacia las mujeres, etc.
} 
sensibilización y educación de la juventud.

Las razones que me han llevado a investigar este problema han sido diferentes. Por una parte, las garantías que tenía, a través de los contactos que hice en el año 2013 en la Asociación de Mujeres de Tigray, WAT, en Mekelle, para poder llevar a cabo la investigación y esto me daba cierta seguridad para hacer los contactos necesarios para recabar información. Y, por otra, también porque conocía un poco la cultura y sociedad etíope. Hubiera sido muy diferente y más problemático si hubiera tenido que empezar de cero, desconociendo la cultura rural de la región de Tigray y sin contactos previos. A mi regreso de Etiopía, después del verano de 2013, empecé a revisar bibliografía sobre este problema de salud y me di cuenta que había pocas investigaciones cualitativas publicadas sobre la fístula obstétrica; además, las publicaciones revisadas eran muy homogéneas, generalizando determinadas características de casi dos millones de mujeres con esta problemática en todo el mundo. Por lo tanto, teniendo en cuenta el Máster que estaba realizando, tomé la decisión de analizar las experiencias individuales de estas mujeres y ponerlas en valor.

Para llevar a cabo este trabajo, he realizado una revisión de la literatura especializada en la revista médica electrónica "International Journal of Gynecology and Obstetrics" (Revista Internacional de Ginecología y Obstétrica), que publica investigaciones de diferentes autores y autoras sobre la fístula. En la mayoría de estos artículos se menciona que entre los principales factores causales de la fístula obstétrica se encuentran los matrimonios y los embarazos a edad temprana (el desarrollo del cuerpo de estas mujeres es prematuro), así como los obstáculos existentes en el acceso a la atención sanitaria y la escasez de personal sanitario con formación cualificada para la atención en el parto en el caso de dar a luz en el propio hogar. Por supuesto, sin olvidar que la mayoría de las chicas y mujeres desconocen y no pueden ejercer sus derechos sexuales y reproductivos, y que los gobiernos tampoco los garantizan. A mi juicio la desprotección en la que se encuentran estas mujeres es verdaderamente lamentable en el siglo XXI.

Señalar que este trabajo se sustenta en la información recabada mediante catorce entrevistas realizadas a mujeres de zonas rurales del estado regional de Tigray, Etiopía, que han sufrido las consecuencias devastadoras de la fístula durante años, hasta que fueron intervenidas en el Mekelle Hamlin Fístula Center (capital del estado regional de Tigray). Considero que, en términos generales, sus relatos no aportan información divergente con publicaciones especializadas en esta temática, sin embargo, opino que las voces de estas mujeres son de incalculable valor porque relatan vivencias personales entorno a las causas y consecuencias 
de la fístula, aunque el objetivo de esta investigación no es generalizar sus discursos sino que, al revés, se quiere rescatar sus experiencias individuales y poder darles el valor que merecen.

Finalmente, indicar que este trabajo de investigación consta de cinco secciones: seguidamente a la introducción, en la segunda sección, expongo aspectos relacionados con la metodología; a continuación, en la tercera sección, abordo cuestiones teóricas como la fundamentación de los derechos sexuales y reproductivos, cuestiones relacionadas con la antropología médica o de la salud, la repugnancia hacia el cuerpo de las mujeres, incluyendo también planteamientos de la teoría de la interseccionalidad; en la cuarta sección me refiero al análisis de experiencias y vivencias relatadas por las mujeres entrevistadas; y, finalmente, recojo en la quinta sección las conclusiones más relevantes extraídas de las secciones anteriores así como reflexiones sobre las posibles futuras líneas de investigación y de intervención dirigidas a la sensibilización y toma de conciencia en derechos sexuales y reproductivos de las mujeres y niñas, y sobre la prevención de la fístula obstétrica y el prolapso uterino ${ }^{2}$.

\subsection{La problemática de la fístula}

A mi juicio, las causas de la fístula obstétrica no siempre han sido relatadas e interpretadas de manera adecuada sino que utilizando explicaciones reduccionistas en la mayoría de los casos, por ejemplo, cuando se plantea este problema desde un punto de vista médico: una lesión que se produce cuando una mujer padece la obstrucción prolongada del parto. Sin embargo, si se tienen en cuenta la cultura y la tradición, como en el caso de mi investigación, la interpretación que las mujeres hacen de la obstrucción prolongada del parto es que ésta castigo divino o de los espíritus de antepasados por una conducta censurada y reprobada por la sociedad (Wall, 2007:86). Así mismo, tanto las dificultades para identificar este problema de salud como los obstáculos en el acceso a cuidados obstétricos en caso de emergencia (por motivos económicos, distancia, accesos problemáticos y creencias tradicionales y religiosas) son realidades que afectan negativamente.

La fístula obstétrica es un trastorno debilitante que ha causado, y continúa causando, vergüenza y sufrimiento en soledad a centenares de miles de mujeres. Es uno de los ejemplos más evidentes de la falta de equidad en el acceso a la atención de la salud materna y, hasta hace poco, uno de los trastornos más ocultos y más descuidados por la salud pública. Entre

\footnotetext{
${ }^{2}$ El prolapso uterino se debe a que el útero cuelga elásticamente de los ligamentos de la pelvis y se estabiliza desde abajo por el suelo pélvico. Es una problemática de salud que se está diagnosticando desde hace poco tiempo. Las consecuencias sociales del prolapso uterino son muy parecidas a los de la fístula y está generando gran preocupación al sistema de salud etíope.
} 
sus causas se encuentran la pobreza, embarazos a edad temprana, malnutrición, recursos de salud insuficientes, determinadas prácticas tradicionales-nocivas, escasez de personal cualificado, limitado acceso a cesáreas en casos de emergencia, relaciones de desigualdad entre mujeres y hombres, etc.

El aislamiento y la lejanía en la que se encuentran las aldeas rurales son impedimentos importantes en el acceso a centros hospitalarios y, también, en el acceso a la información. Es común que las mujeres, familiares y comunidad ignoren que la fístula tiene reparación, que existen centros especializados y organizaciones encargadas de ofrecer apoyo económico. También, desconocen que hay Organizaciones No Gubernamentales y Fundaciones que trabajan en el campo de la prevención y reintegración, por ejemplo, la ODWACE (Organization for Depelopment of Women and Children of Ethiopia) ${ }^{3}$ y la Fundación Healing Hands of $\mathrm{Joy}^{4}$.

\subsection{Contexto: estado regional de Tigray, Etiopía}

La República Democrática Federal de Etiopía está ubicada al este de África y al sur de la región del Mar Rojo. Este país limita al oeste con Sudán y Sudan del Sur, al norte con Eritrea, Djibouti y Somalia al este, y al sur con Kenia. La Constitución etíope (1995) reorganiza este país en base a nueve regiones étnicas: Afar; Amhara; Banishangul-Gumez; Gambela; Harar; Oromiya; Somali; Southern Nations, Nationalities and People's Region; y Tigray. En 1998, Addis Ababa se establece como capital federal y Dire Dawa como distrito administrativo. Cada una de las nueve Regiones Nacionales tiene su propio Parlamento y Congreso, y autonomía para establecer y regular los impuestos y su propio presupuesto.

\footnotetext{
${ }^{3}$ La ODWACE (Organization for Development of Women and Children of Ethiopia), conocida con anterioridad como EGLDAM durante los años 2010-2013, trabaja en el área de la erradicación de las prácticas tradicionales nocivas para las mujeres, como la mutilación genital, amputación de la úvula, extracción de los dientes de leche, etc. También facilita micro préstamos a las mujeres tratadas de prolapso uterino con el fin de que puedan iniciar con pequeños negocios, cría de ganado menor o para cultivar la tierra.

${ }^{4}$ Healing Hands of Joy (HHoJ) es una Fundación creada en 2010 para la prevención de la fístula. Desde esta organización imparten formación a las mujeres tratadas de fístula con el fin de que se ocupen de educar a la comunidad para que las mujeres realicen las cuatro visitas ginecológicas durante el embarazo y den a luz en los centros sanitarios. También trabajan en el empoderamiento de las mujeres a través de la educación, concesión de micro préstamos y en asesoramiento espiritual. La finalidad última de estas actividades es transformar la vida de estas mujeres y, también, la vida de las familias y de la comunidad.
} 


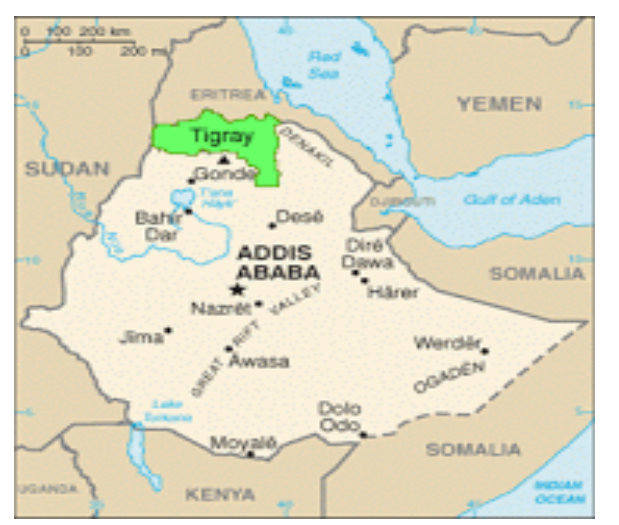

Imagen 1: la República Democrática Federal de Etiopía y paises conlindantes

Este país es uno de los más pobres de África. Su economía se basa principalmente en la agricultura de subsistencia, la cual se ve fuertemente afectada en épocas de sequía. Etiopía está clasificado por el Banco Mundial como un país de bajos ingresos. El 90\% de las exportaciones son productos procedentes de la agricultura, principalmente café, representando el $60 \%$ de las exportaciones. Otros productos exportados por este país son piel, cuero, aceites esenciales y miel de abejas. En el sector agrícola trabaja el 85\% de los 30 millones de la población activa. No obstante, la mayoría de sus habitantes vive de la economía agrícola de subsistencia. El Índice de Desarrollo Humano de Etiopía (IDH 2013) es 0,396, lo que coloca a este país en la posición 173 de los 187 países clasificados por el PNUD.

El estado regional de Tigray se encuentra al norte de Etiopía. Limita al norte con Eritrea, al oeste con Sudán, al sur con la Región de Amhara y al oeste con la Región de Afar. Este estado regional se encuentra organizado en siete zonas (Oeste, Noroeste, Central, Este, Noreste, Sur y zona metropolitana de Mekelle). El 95,5\% de la población informa que pertenece a la Iglesia Ortodoxa Cristiana, el 4\% a la Musulmana/Islámica y el 0,1\% a la Iglesia Protestante.

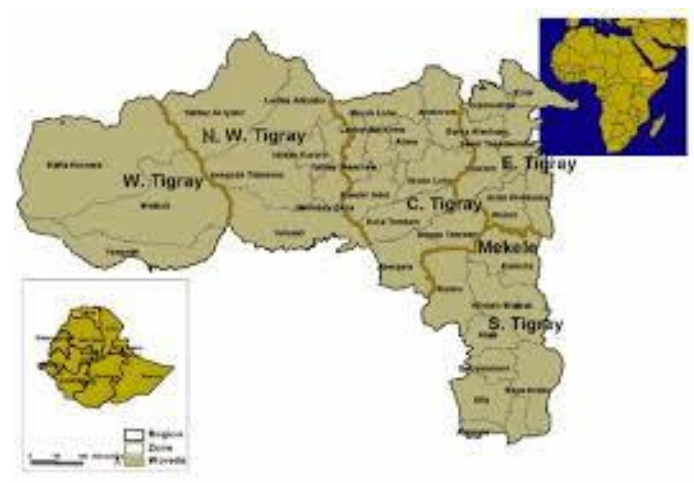

Imagen 2: estado regional de Tigray 
La cultura y la tradición tienen un peso importante en la sociedad etíope y también son factores causales de la fístula obstétrica. Por ejemplo, el modo tradicional de dar a luz es en el propio hogar y, generalmente, con la ayuda de la madre o de la hermana o, en otros casos, con la ayuda de una partera tradicional que, en la mayoría de los casos, tiene experiencia pero carece de formación oficial específica. Generalmente, es el marido, también la madre del marido, quienes deciden dónde la embarazada dará a luz y quién atenderá el parto. Por esta razón, los Grupos de Mujeres para el Desarrollo ${ }^{5}$ organizan encuentros en las aldeas para discutir sobre estos temas, para informar sobre las consecuencias y complicaciones que pueden suceder en caso de dar a luz en el hogar. En caso de que determinadas mujeres decidan dar a luz en un servicio de salud son consideradas como "malas mujeres" (Tigray Regional Health Bureau, 2013).

Algo similar sucede en los casos de matrimonios acordados a edades tempranas. Estos matrimonios, que en muchos casos van en contra de la regulación vigente, se consienten por miedo a que las niñas se queden embarazadas fuera del matrimonio, para garantizar la virginidad de las jóvenes hasta su matrimonio y para poder encontrar el mejor marido posible. Además, según la tradición etíope, las mujeres pueden participar de la vida social plena a partir del casamiento. La familia ahorrará durante años para la celebración de la boda de las hijas. El rol o destino de las mujeres es ser esposa y madre.

Finalmente, según el estudio realizado por Sibhatu Biadgilign, Yihunie Lakew, Ayalu Reda y Kebede Deribe, la prevalencia de la fístula en el estado regional de Tigray es la más alta de Etiopía (1,6\%), la mayoría de los casos no habían sido tratados (68\%), y las mujeres de entre quince $\mathrm{y}$ diecinueve años $\mathrm{y}$ que han sufrido la mutilación genital tenían mayores probabilidades de desarrollar este problema de salud (Biadgilign, Lakew, Reda y Deribe 2013: 3-4).

\subsection{Interés personal en esta investigación}

He llevado a cabo esta investigación en zonas rurales del estado regional de Tigray. Su realización, además de enriquecer mi conocimiento, me ha posibilitado tomar conciencia

\footnotetext{
${ }^{5}$ Son mujeres que a nivel de distritos, municipios y barrios se implican, voluntariamente, en múltiples y variadas cuestiones que afectan negativamente a las mujeres y a sus familias. Además, las integrantes de los Grupos de Mujeres para el Desarrollo son un pilar fundamental en la estructura sanitaria de la región, son elegidas por sus propias comunidades por ser personas de confianza por su trayectoria de compromiso con las problemáticas de la comunidad. Cada una de ellas tiene a su cargo cinco o seis familias que visita con cierta regularidad. El trabajo que llevan a cabo estos grupos está supervisado por las trabajadoras o promotoras para la salud.
} 
sobre situaciones personales, familiares, sociales, de estigmatización y exclusión que sufren estas mujeres. En ocasiones, he llorado con ellas cuando escuchaba sus relatos, he sentido su sufrimiento y he admirado su fuerza de voluntad y su capacidad para "reiniciar" con dignidad sus vidas. Una de las reacciones que más me ha impactado ha sido su generosidad, quieren formarse en temas relacionados con la fístula, con los recientes casos detectados de prolapso uterino y en derechos sexuales y reproductivos para sensibilizar, concienciar e informar a otras mujeres y hombres de sus aldeas.

Entre los motivos que me han llevado a realizar el trabajo de campo en Etiopía se encuentran, por una parte, que conozco la región de Tigray, había estado en este país el verano de 2012 realizando trabajo de voluntariado, concretamente en el municipio de Wukro. Estuve en la misión de St. Mary, una misión de padres blancos y el hogar del Padre Ángel Olaran (de Hernani, País Vasco) desde hace veintidós años. Colaboré en la escuela de verano con niñas y niños que perdieron a sus padres, madres o a ambos a consecuencia de la guerra entre Etiopía y Eritrea y también por el virus del HIV/Sida. Algo me enganchó en este país que me planteé volver el siguiente verano.

En 2013 volví a Wukro para continuar con este compromiso, en esta segunda experiencia la ONG vasca, Jangela Solidaria, me pidió que elaborara un proyecto para mejorar la escuela de verano para niñas y niños huérfanos. Pusimos en marcha el proyecto y tuve la oportunidad de visitar la Asociación de Mujeres de Tigray, WAT, en Mekelle, donde conocí al responsable de proyectos de esta Asociación, Kinfe Abraha, y también a Zufan Ababe, directora de la ODWACE del estado regional de Tigray. El mismo día que conocí a Zufan Ababe, me invitó a visitar a una paciente de fístula en el Mekelle Hamlin Fistula Center. Yo había oído hablar sobre este problema de salud pero desconocía este centro especializado en la atención de mujeres con fístula. En el camino, Zufan se refirió a la situación de estas mujeres, de sus dificultades, de la carencia de información, la ignorancia de la ciudadanía en general sobre este tema y de las mujeres en particular con respecto a derechos sexuales y reproductivos, el desconocimiento sobre los derechos de las niñas y niños, de los nuevos casos de fístula que su organización identificaba, la identificación de nuevos casos de prolapso uterino, las estrategias de trabajo de su ONG en zonas rurales, etc. Ese día tomé conciencia sobre la compleja dimensión social que rodeaba a esta problemática. A partir de los contactos posteriores con WAT, ODWACE y Mekelle Hamlin Fistula Center, decidí llevar a cabo una investigación sobre sus causas y consecuencias, centrándome en las vivencias de las mujeres que han sufrido de fístula obstétrica. 


\section{Metodología de la investigación}

En esta investigación he entrevistado a catorce mujeres, trece de ellas tratadas en el Mekelle Hamlin Fistula Center y Addis Ababa Fistula Hospital, y que se encontraban reintegrándose ${ }^{6}$ en la vida comunitaria. En este trabajo, a mi juicio, pongo en valor las historias de vida de estas mujeres, trasladar sus relatos sobre sus vivencias durante los años que han estado sufriendo en soledad como las consecuencias de la fístula, conocer las experiencias que han tenido durante su estancia en el hospital al encontrarse con otras mujeres que las hacían sentirse iguales y su posterior proceso de reintegración en sus aldeas. Considero que el trasladar y compartir en el ámbito académico sus puntos de vista y vivencias es importante por dos razones, porque han sido, y siguen siendo, invisibilizadas y homogenizadas, y porque como feminista mi compromiso es traer sus voces y vivencias al foro de la academia y a los distintos discursos públicos. La fístula no puede tratarse como un problema sólo de mujeres y adscrita a la esfera privada, es un problema de la sociedad, de hombres y mujeres, y de la salud pública, sobre el cual el gobierno de Etiopía es responsable de facilitar recursos humanos cualificados y financiación necesaria para ofrecer atención obstétrica básica e integral de emergencia, del diagnóstico y tratamiento inmediato a las mujeres con fístula, de implementar programas de prevención y reintegración social, etc. Finalmente, en esta investigación me he inclinado por el método etnográfico porque me posibilita analizar diferentes relatos sobre vivencias de la referida fístula obstétrica.

Para realizar la investigación requerida para el Trabajo Fin de Máter (TFM), he permanecido dos meses y medio, marzo-junio de 2014, en Mekelle. La primera dificultad surgió cuando solicité realizar la observación participante en el Mekelle Hamlin Fistula Center. Aunque en la primera reunión con el director de cirugía, Dr. Melaku, me manifestó su interés y total apoyo a mi proyecto, más tarde me informó que era necesario disponer de un permiso del Addis Ababa Fistula Hospital. Dado que la respuesta se demoraba, empecé a trabajar con la ODWACE, visitando zonas rurales y contactando con mujeres que se mostraron interesadas en participar en mi investigación.

El aspecto innovador de la misma es, a partir del conocimiento obtenido en el trabajo de campo, impulsar una ciudadanía responsable, capacitada para ejercitar y hacer respetar sus

\footnotetext{
${ }^{6}$ Considero la reintegración, una vez que estas mujeres han sido dadas de alta en el hospital, y vuelven a su casa o a casa de algún familiar para empezar una nueva etapa con el fin de restaurar sus vidas plenas y productivas. Derivado de sus relatos distingo dos etapas fundamentales en sus vidas, por una parte, la vida antes de la intervención quirúrgica y, por otra, la "nueva" vida que empieza en el hospital. Tomo en cuenta el contexto hospitalario porque es el espacio donde estas mujeres empiezan a hablar con libertad y abiertamente sobre su problema de salud, es el lugar donde empiezan a tomar conciencia de que no están solas, que no son las únicas personas que les ha sucedido lo que les sucede.
} 
derechos fundamentales como personas, a partir de la formación en derechos humanos, sexuales y reproductivos de mujeres y niñas, sensibilizando hacia el cambio y la ruptura de estereotipos de género y prácticas tradicionales dañinas que propician afecciones graves en la salud integral de mujeres y niñas. Las mujeres entrevistadas manifestaron, reiteradamente, la existencia de un vacío en el sistema escolar, al no contemplar el sistema de educación pública la sensibilización y educación de la juventud sobre esta problemática; tampoco hay programas que posibiliten el conocimiento de Derechos Humanos, especialmente derechos fundamentales de las mujeres, ni sobre derechos sexuales y reproductivos. En definitiva, también con este trabajo busco información para el diseño de un programa de educación para ser implementado en escuelas públicas de zonas rurales del estado regional de Tigray, a nivel de bachillerato, para trabajar los citados temas.

En este apartado abordo cuestiones relativas al objetivo central del trabajo, hago referencia a modo de pinceladas sobre algunas características generales de las mujeres entrevistadas y, también me refiero a las preguntas a investigar, a las herramientas de recogida de información, a la ética que ha guiado este trabajo de investigación y a las dificultades y limitaciones que he encontrado a la hora de realizar este trabajo en el estado regional de Tigray y en el campo de la fístula obstétrica.

Al final del documento, en el Anexo I, adjunto las preguntas utilizadas en las entrevistas y, en el Anexo II, los relatos transcritos en inglés. He traducido los diferentes fragmentos de dichas descripciones utilizadas en la cuarta sección, Relatos sobre vivencias de la fístula obstétrica, con el fin de facilitar la comprensión de estos textos.

\subsection{Objetivo y preguntas de la investigación}

El objetivo de este trabajo consiste en conocer las vivencias y experiencias personales de las mujeres afectadas por la fístula obstétrica. Lo que conlleva conocer, desde sus puntos de vista y que voluntariamente desean compartir conmigo, las causas, formas de afrontar este problema, vivencias de vergüenza, miedo y exclusión, experiencias vividas en su ingreso en el hospital, y el proceso de la vuelta a casa y reintegración social. Esto es, busco rescatar sus vivencias, dar voz a estas mujeres y poner en valor sus contribuciones en el ámbito académico y, también, en la esfera pública, ámbitos donde se encuentran invisibilizadas e ignoradas.

Carmen Gregorio (2006), siguiendo a Edwin Ardwener, propone la teoría de los "grupos silenciados". Estos grupos minoritarios por carecer de medios de expresión adecuados a una 
determinada problemática se encuentran obligados a recurrir a las ideologías dominantes para pronunciarse al respecto. En este sentido, Carmen Gregorio señala que "es necesario tomar en consideración la existencia de discursos hegemónicos que dejaban fuera otras formas de interpretar la realidad o la imposibilidad de acceder a estos grupos "subalternos" (Gregorio 2006:26). Es debido a esta realidad que me parece de vital importancia traer a este ámbito académico una parte de estas perspectivas subalternas para visibilizar las historias de vida de mujeres etíopes, concretamente relatos relacionados con la fístula obstétrica y que profundamente me han impresionado a nivel personal.

Una de las preguntas centrales de investigación tiene como finalidad indagar y profundizar en los sentimientos y vivencias que durante años han sentido estas mujeres viviendo con la fístula, el trato recibido por parte de la familia y/o del vecindario, y sentimientos que aún hoy en día despiertan esos recuerdos del pasado.

También tenía interés en indagar sobre la posible relación entre los matrimonios acordados por los padres varones a edades tempranas (menor de dieciocho años), la edad del primer embarazo y un parto prolongado que finaliza ocasionando la fístula. Además de la posible conexión entre el lugar donde dieron a luz con el origen de la fístula.

La primera vez que visité el Mekelle Hamlin Fistula Center, en 2013, tuve la impresión que no sólo era otro hospital más, sino que era un lugar agradable, acogedor y seguro, es por esta razón que consideré de interés conocer sus vivencias y experiencias compartidas durante su permanencia aquí.

Finalmente, tenía mucho interés en conocer los tipos de acogida que tuvieron en su vuelta a casa y qué ayudas, apoyo (económico, psicológicos, formación) y de qué organizaciones encontraron para reiniciar una vida digna y de independencia. También era importante indagar sobre el tipo de ayudas para la reintegración existentes y su opinión al respecto.

\subsection{Cuestiones a tener en cuenta durante la investigación feminista}

Para el feminismo, la objetividad de las investigaciones ha sido, y es, una cuestión que suscita preocupación y debate. Defiende que la objetividad neutral siempre ha estado marcada por el sexismo y el androcentrismo dominante, ocasionando resultados negativos para las mujeres. Por tanto, la manera óptima y real de hacer ciencia requiere empezar desde los márgenes, desde la vida de los márgenes, y analizar la vida cotidiana como el problema central de la investigación. En esta perspectiva se sitúa la teoría del punto de vista (standpoint), que centra su interés en la vida de los márgenes y de las personas o de los 
grupos; y defiende que la objetividad científica no es la objetividad máxima o única, sino que es objetividad producida por la clase dominante y en la que los conocimientos resultantes están socialmente situados por la clase, la raza, género, sexualidad, etc., (Harding, 1993:50 y $54)$.

Dado que considero útil esta aportación, en mi trabajo de investigación el punto de partida es la percepción sobre vivencias y experiencias de vida de las mujeres que han sufrido de fístula. A mi juicio, es interesante tener en cuenta el punto de partida que propone Sandra Harding porque me ayuda a identificar las relaciones de poder que existen en la sociedad etíope y cómo estas relaciones afectan a las mujeres. Obviamente, las cuestiones que se recogen en este trabajo no pueden ser generalizables a todas las mujeres que sufren o han sufrido la fístula obstétrica. La finalidad última de este trabajo es conocer y dar a conocer las vivencias de las mujeres que he entrevistado y, coincidiendo con las aportaciones de Dorothy Smith, sus experiencias de vida son la base del conocimiento feminista. Además, esta perspectiva sería deseable que fuera incorporada por las diferentes disciplinas, lo cual favorecería la creación de un conocimiento que incluye diferentes perspectivas (Harding, 1993:55).

Así, el primer paso para llevar a cabo una investigación, teniendo en cuenta las aportaciones de Donna Haraway (Haraway, 1988), es aclarar desde dónde se empieza a hacer el análisis de la investigación y qué corresponde a la investigadora, dado que los y las lectoras ya disponen de su propia subjetividad y, también, de su propio contexto social. La interpretación de las personas que leen el texto dependerá en sus creencias y valores, y del contexto social donde se sitúan. Por esta razón, es importante dejar claro desde dónde se inicia el análisis. Mi posición privilegiada y de poder en esta investigación comparando con la posición que tienen las mujeres que han sido parte de esta investigación es evidente, he podido viajar a Etiopía para realizar este trabajo de campo y dispongo de una formación académica universitaria realizada en universidades españolas y holandesas. En mi caso, incluir en la investigación y análisis el punto de vista de las mujeres que han vivido la experiencia y las consecuencias de la fístula es como Márgara Millán, licenciada en sociología y doctorada en antropología defiende una aportación que "enriquecerá los resultados y conclusiones, y se logrará una mayor y más profunda comprensión de su realidad social" (Millán 1996:3).

También, Donna Haraway (Haraway, 1988:581) subraya que la objetividad feminista se encuentra situada en sus conocimientos. Esta perspectiva estará fuera de la influencia de los conocimientos dominantes, transmitidos desde la perspectiva de la raza blanca, dominante y 
parcial que garantiza la objetividad que la ciencia no ha mostrado (Haraway, 1988:582-583).

Las observaciones de la sociedad desde la parte inferior o desde los márgenes son complicados de aprehender $\mathrm{y}$, en algunos casos, nos pueden causar problemas. Las perspectivas desde las posiciones de los subyugados no son "inocentes" (Haraway, 1988:584). Estos puntos de vista serán más enriquecedores, puesto que nos posibilitan visibilizar y prestar atención a perspectivas que no hacen parte del conocimiento hegemónico producido desde planteamientos occidentales y androcéntricas, por ello es necesario tenerlos en cuenta para obtener un conocimiento más amplio y más acorde a la realidad objeto de investigación.

Como consecuencia, Donna Haraway busca deslegitimar las doctrinas del conocimiento creadas desde los grupos dominantes occidentales y des-construirlas, tratar de transformar estos sistemas de conocimiento y formas de plasmar la realidad. La utilización de diferentes perspectivas es una manera de garantizar un conocimiento amplio y menos influenciado por la perspectiva dominante, y menos discriminatoria hacia los grupos de los márgenes (Haraway, 1988:585).

Este modo de hacer ciencia ha despertado críticas virulentas hacia grupos de feministas, en tanto que grupos activos y críticos hacia las perspectivas científicas que consideran el "objeto" de investigación o intervención a modo de "objeto" pasivo e inerte (Haraway, 1988:591). En este aspecto, en la teoría de los conocimientos situados cambia radicalmente el tratamiento de "objeto" y, también, la relación que se establece con el "sujeto" (hasta el punto de tratarlo como "sujeto o sujeta de derecho" en la actualidad). Son planteamientos que se alejan de la perspectiva tradicional científica, el "objeto" del conocimiento no será representado como algo pasivo, sino "sujeto" o agente activo de la investigación.

También es importante tener en cuenta que el conocimiento de las personas está socialmente situado, depende de la posición social que cada una ocupa. En mi caso, por ejemplo, mujer europea, blanca y estudiante de máster universitario, lo que supone situarme en una posición de poder comparativamente a las mujeres entrevistadas (de raza negra, clase social baja y con escaso nivel de escolarización). También al hecho que durante mi última estancia en Mekelle estuve viviendo en la casa del presidente del estado regional de Tigray (Abay Weldu), lo que me facilitó contactar con el consejero de Salud Pública (Hagos Godefay) y con el cirujano jefe de Mekelle Hamlin Fistula Center (Dr. Melaku). Mi posición privilegiada me facilitó contactos necesarios para la realización de mi investigación, sin embargo, no me resolvió el problema suscitado a raíz del pensamiento individualista de 
nuestra cultura (me encontraba allí porque necesitaba realizar este trabajo por interés profesional personal) y lo que se esperaba de mí en una cultura colectivista como es la sociedad etíope (estaban de acuerdo en facilitarme información pero su preocupación era cómo mi trabajo ayudaría a mejorar este problema de salud de las mujeres etíopes).

Por último, otra de las perspectivas que he tenido en cuenta en la realización de este trabajo son los estudios postcoloniales y su definición del "otro". Según Robert Young, los estudios postcoloniales hacen visibles algunos países que desde la perspectiva occidental han sido invisibilizados por la colonialización (Young, 2012:23). La crítica principal se centra en las características que se utilizan para crear y definir el "otro", la dicotomía que utilizamos para referirnos al grupo dominante y al grupo minoritario definido como el "otro". En este caso, el occidente considerado como el grupo dominante, dueño del conocimiento dominante, y todo lo demás como ese "otro", donde se incluye lo que no es occidental, otras razas diferentes a la blanca o las minorías que no pertenecen a los estándares establecidos por el Occidente (Young, 2012:36). También Joan Scott (2009) critica la creación del "otro" como una victimización de las mujeres desde el punto de vista del feminismo occidental, imponiendo las ideas, opiniones, reflexiones y análisis a feminismos distintos. He tenido en cuenta ambas aportaciones y me han sido muy útiles para no caer en la tentación de percibir a las mujeres entrevistadas a modo de "víctimas pasivas" y en otras trampas del eurocentrismo.

Una de las críticas frecuentes hacia las feministas del primer mundo se debe a los intentos de universalizar a las mujeres del Tercer Mundo o de países en desarrollo, eludiendo las diferentes realidades de este segundo grupo, visualizándolas como grupo oprimido y victimizándolas (Rajan and Park, 2004:54). En esta línea Soledad Vieitez, siguiendo a Mohanty, plantea con claridad que "las mujeres africanas han sido vistas como víctimas, oprimidas por cultura y religión o por sus maridos y parientes masculinos especialmente" (Vieitez 2012:36-37). Asimismo, de acuerdo con Mikell (1997) y Mohanty (1991, 2002), Soledad Vieitez subraya que hay “una reiteración continua y perversa de imágenes donde las mujeres africanas son representadas como víctimas, atrasadas, excesivamente “tradicionales" y sujetas a todo tipo de prácticas adversas y discriminatorias". Las mujeres etíopes, en este particular caso, opino que sufren múltiples discriminaciones pero no por ello se podrán victimizar, al fin y al cabo las mujeres seguimos discriminadas en diferentes ámbitos de la vida cotidiana (Vieitez 2005:2). Por lo tanto, no podemos cuestionar la agencia de estas mujeres, y como acertadamente señala Carmen Gregorio, no deberíamos etiquetar a estas mujeres como pasivas porque encontrarse en "esa posición de subalternidad", y mucho menos colocarnos en una relación (ma)paternalista", tratándolas como menores de edad 
(Gregorio 2012:579). Las mujeres entrevistadas me han demostrado que han sufrido una tremenda exclusión, tanto familiar como social, pero no por ello han dejado de luchar para que a otras mujeres les ocurra lo mismo. Desde mi experiencia considero que es erróneo etiquetarlas como mujeres vulnerables, tal y como se tiende desde la perspectiva occidental.

En el caso de las mujeres que han sufrido la fístula, he observado que existe esta tendencia a homogeneizarlas en un único grupo en base a características estereotipadas. En mi trabajo de investigación, también, he prestado atención a este desacierto, centrándome, prestando atención y rescatando los relatos sobre las vivencias personales, individualizando y poniendo en valor sus aportaciones personales.

La disciplina feminista de la postcolonialidad va un paso más allá de las actividades culturales y teóricas de las diferentes culturas, trata de interiorizar y explicar aspectos tanto culturales como políticos, y también económicos e históricos para entender mejor la cultura que se quiere analizar (Rajan and Park, 2004:54). En mi investigación he tratado de tener en cuenta los citados factores, por ser cuestiones fundamentales a la hora de analizar en su globalidad la situación que rodea a las mujeres con fístula. Tanto la historia, la cultura como la política vigente en Etiopía son realidades que influyen en ellas, por ejemplo, con respecto a la maternidad, en caso de que una mujer no pueda o no quiera ser madre, no está considerada como "una verdadera mujer", es estigmatizada socialmente y puede ser motivo para que el marido se divorcie por presiones de su familia. En la misma línea, también, las mujeres que sufren de la fístula son apartadas de la comunidad porque se cree que han hecho algo mal o que han tenido un comportamiento no adecuado, razón por la que están siendo castigadas. También, su situación económica, la pobreza, las afecta, puesto que si carecen de medios económicos no pueden acceder a centros de salud o a un hospital para dar a luz.

\subsection{Mujeres con las que he trabajado}

En total he realizado catorce entrevistas, trece de ellas con mujeres que han sido tratadas por su problema de fístula y que la mayoría se encuentran totalmente recuperadas, aunque alguna todavía sufría secuelas físicas y/o psicológicas. La otra entrevista con la directora regional de ODWACE, Zufan Ababe, y trabajadora social en la Asociación de Mujeres de Tigray.

En la selección de las trece mujeres participaron tanto Zufan Ababe como personas responsables de la Fundación Healing Hands of Joy. De todas las mujeres contactadas por ambas organizaciones, sólo entrevisté a aquellas que voluntariamente demostraron interés por el proyecto. 
El trabajo de Zufan Ababe, además de ocuparse de asuntos propios de oficina, consiste en visitar a mujeres en sus hogares en zonas rurales. Por ejemplo, cuando una mujer se pone en contacto con ella por un tema relacionado con la fístula, se acerca a su casa, le ayuda a preparar todo lo que necesita para su ingreso y viajan juntas al Mekelle Hamlin Fistula Center. Normalmente Zufan les lleva ropa limpia y pañales para el viaje. A partir del ingreso hospitalario, va a visitarlas y a charlar un rato con ellas. Cuando son dadas de alta su tarea es hacer un seguimiento sobre el proceso de reintegración.

Las otras trece entrevistas han sido con mujeres que han sido tratadas de la fístula y que residen en zonas rurales, en las mismas pequeñas aldeas (kebeles) a las que se trasladaron cuando contrajeron matrimonio. Sus edades oscilan entre veintitrés, la más joven, y cincuenta, la de mayor edad. El rango de edad de estas mujeres cuando se casaron por primera vez oscila entre los trece y los veinte años, aunque con veinte años sólo contrajo matrimonio una mujer, y las demás se casaron cuando tenían dieciocho años o menos. En todos los casos, excepto en uno, los matrimonios fueron acordados por sus padres varones. El primer embarazo fue a la edad comprendida entre los quince y veinticuatro años.

Considero relevantes estos datos porque se encuentran en clara contradicción con recomendaciones del Comité de la CEDAW (Convención sobre la eliminación de todas las formas de discriminación contra la mujer) (2011:4) al gobierno de Etiopía, en las que se reitera la necesidad de adoptar medidas para garantizar la aplicación efectiva del Código Federal de la Familia (2000), particularmente en lo relativo a la igualdad de derechos de mujeres y hombres a contraer libremente el matrimonio, la igualdad de derechos y responsabilidades de los esposos durante el matrimonio y en los procesos de separación, y en el cumplimiento de la edad mínima para contraer matrimonio a los dieciocho años tanto para las chicas como para los chicos. Esto es, los casamientos sin haber cumplido la mayoría de edad y sin el consentimiento de la propia mujer están prohibidos, van en contra de los derechos sexuales y reproductivos de las mujeres y niñas.

También, los datos publicados en el último censo poblacional y de vivienda 2007 de Etiopía, en referencia a casamientos a edad temprana de niñas en el estado regional de Tigray, ponen en evidencia que no se atienden las recomendaciones de la CEDAW, puesto que del total de niñas de edades comprendidas entre diez y catorce años (298.938), el 6,14\%, 18.375 chicas, se encontraban casadas. La situación de las jóvenes de entre quince y diecinueve años (251.650) no es menos alarmante, debido a que el 25\% de las chicas de estas edades, 62.795 jóvenes, se encontraban casadas (2010:100). Mediante estos datos constato la reiterada 
violación de los derechos y recomendaciones de organismos internacionales, de las propias normas acordadas por el gobierno de Etiopía y el peso, aún hoy, de la tradición en la ciudadanía etíope.

Hay que subrayar también que de todas las mujeres entrevistadas sólo dos fueron a la escuela, las más jóvenes, una tiene veintitrés años y la otra veintiséis. La primera finalizó el grado sexto y la segunda el cuarto ${ }^{7}$.

En relación a sus partos, he identificado tres grupos: la mayoría de ellas, nueve mujeres, han tenido a todas sus hijas e hijos en el propio hogar, como reza la tradición y la religión, con la ayuda de una partera tradicional; solo dos han dado a luz en centros hospitalarios; y las otras dos restantes tuvieron sus primeras hijas o hijos en sus casas y más tarde, por haber sido intervenidas debido a la fístula, en hospitales siguiendo, en estos casos, la recomendación médica: las mujeres que han sido intervenidas de fístula deben ser atendidas en su próximo parto en un centro hospitalario porque el parto debe realizarse por cesárea.

\subsection{Recogida de información}

La metodología que he llevado a cabo en esta investigación es la etnografía antropológica. Previamente a iniciar a desarrollar el trabajo de campo, pensé que sería suficiente con realizar algunas entrevistas en profundidad con las mujeres que habían sido intervenidas de la fístula. Más tarde, reflexionado sobre esta cuestión, me di cuenta de que no era suficiente, que necesitaba ir más allá de las entrevistas para entender la complejidad de las experiencias vividas por las mujeres que habían vivido durante años con la fistula. Por lo tanto, consideré que la observación participante era necesaria para complementar y enriquecer la información recabada mediante las entrevistas. María Espinosa (2010) define que las personas "tienen una existencia propia como resultado de un proceso histórico, cultural y social" (Espinosa 2010:70), por ello, consideré que la observación participante me ayudaría a comprender mejor las complejas realidades que rodeaban a estas mujeres. Debido a que la etnografía nos facilita un mejor entendimiento de las costumbres y tradiciones en las que las personas o grupos se encuentran inmersos y deseamos investigar.

Por tanto, he utilizado la entrevista y la observación participante visitando a las mujeres en sus aldeas y pasando varios días con ellas en sus hogares. Adicionalmente, también, he revisado diversas fuentes secundarias de información con el fin de ampliar y enriquecer la

\footnotetext{
${ }^{7}$ En Etiopía la Enseñanza General Básica es obligatoria y gratuita, y comprende los grados 1-8 (de siete a catorce años).
} 
información sobre la fístula obstétrica en Etiopía en general y en el estado regional de Tigray en particular.

\subsubsection{Entrevistas}

En este trabajo etnográfico he realizado varias entrevistas que considero como una herramienta importante y de largo recorrido para recabar información sobre experiencias y vivencias personales. Esta técnica me ha posibilitado traer los discursos y relatos de las mujeres al ámbito académico, poner en valor sus discursos y dar a conocer este problema de salud que sufren muchas mujeres y niñas que viven en países en vías de desarrollo. La tradición de la investigación mediante entrevistas ha estado muy ligada a la justicia social, es un estrategia útil para traer a la esfera pública experiencias de personas olvidadas, invisibilizadas. Es por esta razón que es considerada una herramienta excelente para las investigaciones feministas (DeVault y Gross, 2006:176) y, en mi caso, para alcanzar el objetivo establecido en mi trabajo de investigación.

Además, de acuerdo con Marjorie DeVault y Glenda Gross (2006), la finalidad de la investigación feminista es entender que el contexto social que rodea a la vida de las personas debe encontrarse históricamente situada y constituida mediante las actividades realizadas por las mismas. Asimismo, subrayan que el proceso de la investigación tiene que integrar estos aspectos para la construcción de conocimiento de la sociedad (DeVault y Gross, 2006:176). En esta línea, he llevado a cabo mi trabajo de investigación en una sociedad particular, la zona rural del estado regional de Tigray, y en un momento histórico determinado. En concreto, el gobierno de Etiopía se encuentra haciendo esfuerzos importantes para facilitar el acceso a recursos materno-infantiles y, recientemente, en el Hospital Público de Mekelle (Ayder Hospital) se atiende a mujeres que sufren de fístula y también de prolapso uterino. Estos cambios en decisiones políticas sobre el sistema de salud pública afectan positivamente a las mujeres.

La investigación feminista defiende que lo personal tiene que ser político para poder mejorar la situación de las mujeres, dando voz a sus experiencias y a sus interpretaciones sobre un tema en particular (Pillow y Mayo, 2006:159). También este punto de vista ha estado presente en este trabajo, sus aportaciones han sido de gran ayuda para identificar puntos débiles y vacíos relacionados con el trabajo en prevención y reintegración que se está llevando a cabo con las mujeres tratadas de la fístula. Por ejemplo, la ausencia de programas de sensibilización y educación de la juventud en derechos humanos, sexuales y reproductivos 
de mujeres y niñas, sensibilizando hacia el cambio y la ruptura de estereotipos de género y prácticas tradicionales dañinas, etc., en centros escolares de bachillerato.

a) Mujeres que han vivido con la fístula

Las feministas académicas han utilizado las entrevistas, de diferentes maneras, para desafiar el conocimiento heredado sobre mujeres, y para elaborar trabajos creativos y críticos (DeVault y Gross, 2006:192). Por ello, he optado por utilizar esta técnica, dado que la finalidad de mi trabajo es recabar información sobre las percepciones que tienen las mujeres de sus vivencias relacionadas con la fístula.

En la casi totalidad de los casos, he realizado las entrevistas en los hogares de las mujeres, aunque, en ocasiones y debido a las largas distancias a recorrer a pié para llegar sus hogares o por la falta de transporte público o carretera para acceder a determinada aldea rural, acordábamos un punto intermedio para nuestros encuentros. En estos casos, las entrevistas las realizaba en un café local o en los paritorios de los centros de salud de los pueblos cercanos. También tres de ellas las llevé a cabo en el centro de Healing Hands of Joy, en Mekelle.

Fueron realizadas en el idioma materno de estas mujeres, en Tigriña, y que la traductora o traductor que me acompañaba traducía al inglés. En la selección de la persona traductora, he tenido en cuenta, principalmente, su experiencia en el campo de la fístula. Una de las traductoras ha sido Zufan Ababe, quien posee una larga experiencia de trabajo con estas mujeres y conocía previamente a todas ellas. Las otras dos personas han sido Goitom, un chico de veintitrés años, antropólogo de formación y que trabaja en la Fundación de Healing Hands of Joy, en Mekelle, también experto en temas relacionados con la fístula, y, la tercera traductora, Senait, trabaja en la citada Fundación, es trabajadora social y directora de proyectos, también tiene una dilatada experiencia y conocimientos en este campo.

El contacto inicial con nueve de las mujeres entrevistadas fue gracias Zufan Ababe, que conocía a todas ellas porque habían participado en el programa de reintegración social mediante micropréstamos concedidos por esta ONG local ODWACE. Con las otras cuatro mujeres contacté a través de la Fundación Healing Hands of Joy.

En cuanto a la relación que establecí con ellas, siendo una persona desconocida para las mujeres que iba a entrevistar, que no hablaba su idioma y les preguntaba sobre temas tabús y escondidos socialmente en este país, han sido aspectos o barreras que dificultaron la relación, sobre todo al inicio. Esto es, el hecho de ser una mujer europea y universitaria, tenía un peso 
importante en Etiopía. Como bien afirma la teoría del punto de vista, las investigadoras tenemos que participar activamente en la investigación pero sin esconder la procedencia, la cultura, la ética y la moral que nos acompaña. Añadiendo a esto que en muchos casos iba a sus casas a entrevistarlas, lo que las podía incomodar, sus casas de una sola habitación eran el retrato de su estatus social humilde, y para mí falta de experiencia en estos avatares. Consciente de esta situación, decidí que lo más adecuado era que la persona traductora fuera conocida para ellas y así garantizar mayor cercanía y naturalidad para hablar de las cuestiones planteadas en las entrevistas. Ambas traductoras y el traductor eran personas conocidas para las mujeres entrevistadas (por haber trabajado con ellas con anterioridad), lo que facilitó mucho el primer contacto, llegando a establecer entre nosotras una relación cercana, sincera y relajada.

\section{b) Directora de la ODWACE}

Esta primera entrevista la realicé en su despacho, en el edificio de la Asociación de Mujeres de Tigray, en Mekelle. Recabé información general sobre el trabajo que realiza esta ONG local en el campo de la reintegración social de las mujeres que han sido tratadas en el Mekelle Hamlin Fístula Center. Las cuestiones planteadas eran las relativas a las características de las mujeres con las que trabajan, el modo que se dan a conocer para que puedan contactar con esta organización, los diferentes tipos de apoyo que ofrecen (apoyo económico, psicológico, de intervención en la aldea, etc.), estrategias para identificar los casos de fístula, cómo intervienen posteriormente, etc.

Esta información fue enriqueciéndose conforme transcurría el tiempo, ya que Zufan me acompañaba en muchas ocasiones a entrevistar a las mujeres y pasábamos juntas muchas horas trabajando y discutiendo. Entre los temas recurrentes estaban los relacionados con las tradiciones y la fuerte influencia de la iglesia católica ortodoxa (a la que la gran mayoría de las personas del estado regional de Tigray pertenece) y de la musulmana, principalmente en las zonas rurales del estado regional de Tigray. El compartir muchos cafés y largas horas de desplazamientos me posibilitaron tomar contacto con una realidad social y cultural de la fístula que desconocía hasta ese momento.

\subsubsection{Observación participante}

Desde mi punto de vista, una de las finalidades de la etnografía feminista es analizar los prejuicios que tienen que ser examinados y desafiados, también percibir las formas de opresión hacia la ciudadanía. El punto de partida de dicha etnografía consiste en cuestionar el 
lugar del poder, la autoridad y la subjetividad de la investigadora, cuestiones algo diferentes a la etnografía tradicional (Pillow y Mayo, 2007: 156, 158 y 162).

Uno de los compromisos imprescindibles para la investigación feminista es la responsabilidad para el cambio o para la acción, principio que comparto plenamente y que incluyo a modo de compromiso implícito en mi trabajo de investigación. Por tanto, una de las claves importantes de la metodología feminista son las prácticas de reflexividad y análisis crítico, explorando la naturaleza del proceso de la investigación (Pillow y Mayo, 2007:163).

A través de la observación participante he podido aprehender el día a día de las mujeres en sus hogares, las dinámicas de relación en la familia (comunicación cercana, comunicación distante y fría, demostración de afectos, soledad, indiferencia), con el vecindario, el tipo de vivienda, los objetos que tienen, la higiene, etc. También he prestado atención a gestos, silencios, pausas, cambio de expresiones, experiencias que les hacían llorar, miradas, etc. Toda esta información ha sido interesante y enriquecedora, aunque el hecho de esperar a recibir la traducción de la información verbal me ha dificultado el trabajo de la observación (la información verbal me llegaba más tarde que la información visual).

También he pasado varios días con estas mujeres. En un principio mi idea era quedarme a dormir en sus casas pero Zufan Ababe no me lo recomendó, porque son casas de una sola habitación, porque ella no podía quedarse conmigo y porque podía alterar la dinámica cotidiana de las familias. Aún así, en algunos casos pude pasar dos o incluso tres días enteros compartiendo con ellas su día a día. Con alguna fui al mercado semanal a hacer la compra, con otra y su familia pasé el fin de semana santa compartiendo su manera tradicional de festejarla. También el viernes santo una de ellas me invitó a acompañarla a la misa de ese día, donde pasaban la noche y el día siguiente rezando.

Además de los citados contenidos de observación, era consciente de que la entrevista a la directora de ODWACE, y las muchas horas compartidas con ella, una vez apagada la grabadora, fueron de gran ayuda para entender mejor el contexto donde me estaba moviendo. También, hice amistad con el consejero de Salud Pública del estado regional de Tigray (Health Bureau), Hagos Godefay. Un hombre que está haciendo su tesis doctoral sobre salud materna y persona clave en facilitarme contactos interesantes en el campo de la fístula. Fuimos en más de una ocasión a cenar y hablábamos sobre la situación de las mujeres rurales, las diferentes tradiciones etíopes, sobre creencias y presión social que mantienen a las mujeres dando a luz en sus hogares, resistencias de los maridos para que sus esposas acudan a dar a luz a centros hospitalarios, etc. 
Según su opinión, la tradición de dar a luz en casa (como la han hecho sus madres, abuelas y bisabuelas) está cambiando poco a poco y, en gran medida, porque se utiliza el "truco" de ofrecer en los hospitales el "porridge" (papilla hecha con diferentes cereales) inmediatamente después de dar luz. La creencia es que esta papilla debe ser ingerida después del parto y a lo largo de una semana. También me explicó que la consejería de Salud trabaja con el apoyo de los Grupos de Mujeres para el Desarrollo que hay en cada aldea, barrio, municipio y distrito. El trabajo directo de estas mujeres es muy importante para sensibilizar a las familiares que las embarazadas realicen las cuatro revisiones ginecológicas recomendadas y utilicen recursos hospitalarios para dar a luz.

\subsubsection{Fuentes secundarias}

Adicionalmente a la literatura teórica utilizada en este trabajo, he revisado otras fuentes secundarias, películas, novelas e informes facilitados tanto por Mekelle Hamlin Fístula Center como recogidos en el Informe Anual sobre Salud Pública en el estado regional de Tigray y publicado por la consejería de Salud (2013).

En la película "A walk to beautiful", de la que Allison Shigo (creadora de la Fundación Healing Hands of Joy, 2009) es co-directora, se relatan historias de mujeres etíopes que sufren de fístula centrándose en la convivencia diaria que establecen estas mujeres cuando llegan al Addis Ababa Fistula Hospital y en cuestiones relacionadas con la reintegración en su entorno una vez reciben el alta médica. Esta película se basa en la novela escrita por el cirujano español José Manuel Devesa (2011). Este profesional trabaja en Madagascar en la reparación quirúrgica de mujeres que sufren de fístula. La protagonista principal de esta obra literaria es una chica joven que vive en Etiopía, que sufre de fístula y relata sus experiencias de vida y las dificultades que encuentra a consecuencia de este problema de salud.

Finalmente, he revisado el informe facilitado por el cirujano jefe, Dr. Melaku, de Mekelle Hamlin Fístula Center, en el que se recoge información enriquecedora sobre características generales y específicas de las mujeres atendidas en este centro (2012).

\section{5. Ética de la investigación}

Según las sociólogas Marjorie DeVault y Glenda Gross (2006), en las entrevistas que pueden ser sensibles porque se pregunta o indaga sobre sentimientos o preocupaciones, se recomienda utilizar pseudónimos a la hora de la redacción, y si es necesario cambiar algunos detalles cuando se escribe de las personas sujetas (DeVault y Gross, 2006:187). Teniendo presente esta recomendación y, también, porque la primera mujer entrevistada me manifestó 
su preocupación en caso de que "la entrevista saliera en la TV o en otro medio de comunicación", garanticé que los nombres u otros detalles de identificación no serían publicados. En las siguientes entrevistas y a cada una de ellas les fui preguntando si querían que se utilizara su nombre real o deseaban uno ficticio. También, les expliqué que la finalidad de mi trabajo era recabar información tanto sobre ellas como sobre sus experiencias en la comunidad, así como explorar las necesidades más apremiantes, según su percepción, existentes en sus comunidades para trabajar en el campo de la prevención de la fístula, en la reintegración y en derechos sexuales y reproductivos.

También fui aconsejada que debía ofrecer un regalo como muestra de mi agradecimiento a su generosidad al acogerme en su casa o por pasar largas horas conmigo hablando sobre temas íntimos. Me habían explicado que en las zonas rurales es muy difícil conseguir café, bien porque no hay tiendas o por su alto precio (100 birr/cuatro euros por kilo). Así que iba a cada una de las entrevistas con un paquete de café, galletas, azúcar y algunas golosinas para sus familiares. La ceremonia del café ${ }^{8}$ en Etiopía es un modo de socialización con las vecinas y amigas, por lo tanto, es un regalo simbólico. Sus reacciones eran de sincero agradecimiento, hasta el punto en que en algunas situaciones me hicieron sentir mal debido a su modo tradicional de manifestar agradecimiento, por ejemplo, cuando las mujeres de mayor edad y de zonas rurales se ponían de rodillas para besarme los pies. Mi reacción fue cogerlas de los brazos, levantarlas y darles un abrazo.

\subsection{Dificultades y limitaciones}

Una de las limitaciones más importantes que he encontrado al realizar el trabajo de campo ha sido debido al problema de idioma, Tigriña, y su traducción al inglés. Aunque las personas encargadas de la traducción tenían un buen dominio del inglés, tengo la certeza de que mi desconocimiento de su lengua supuso perder mucha y valiosa información, expresiones que no se pueden traducir, matices, gestos, etc. Las sociólogas Marjorie DeVault y Glenda Gross (2006:183) afirman que es importante tener en cuenta los silencios, las pausas y las dificultades a la hora de hablar sobre un tema determinado, también, cuando las personas levantan el tono de voz o cuando lo bajan. He podido realizar este tipo de observaciones pero no meticulosamente por el problema antes expuesto. Tengo la certeza de que ha sido una gran

\footnotetext{
${ }^{8}$ El café es uno de los productos más importantes de exportación de Etiopía y, también, parte importante de su historia y leyendas. Además, es la expresión de la hospitalidad y el elemento en torno al que se estrechan los lazos sociales y familiares. La ceremonia del café, lenta y determinada por reglas centenarias, es la ocasión para la charla y compartir, y el modo de acoger y agasajar al visitante.
} 
pérdida tanto para mí como para el enriquecimiento de este trabajo. Grabé las entrevistas con el consentimiento de cada una de ellas en formato electrónico para su posterior transcripción.

Otra de las limitaciones encontradas es que, inicialmente, tenía previsto realizar la mitad de las entrevistas a mujeres que se encontraban ingresadas en el Mekelle Hamlin Fístula Center y la otra mitad una vez habían sido dadas de alta. En el primer caso no fue posible porque el permiso solicitado al Addis Ababa Fistula Hospital no fue respondido a tiempo. Ello me obligó a realizar el trabajo de campo con mujeres que habían sido tratadas y se encontraban de vuelta en sus hogares. Lo cierto es que mirando atrás pienso que ha sido más adecuado lo que me vi obligada a hacer, puesto que, durante su permanencia en el hospital, estas mujeres se encuentran en un estado psicológico delicado, nerviosas por la intervención, apenadas por tener que abandonar a sus nuevas amigas o ansiosas por volver a casa (así me describió su estado de ánimo el Dr. Melaku). Valorando todo ello, lo acertado fue entrevistar a mujeres una vez que ya habían sido dadas de alta y habían vuelto a sus vidas cotidianas.

Finalmente, están las dificultades de arraigo cultural a la hora de hablar abiertamente sobre el problema de la fístula. Aunque la persona traductora que me acompañaba conocía a las mujeres que entrevistaba, en ocasiones algunas de ellas se sentían incómodas al hablar de temas relacionados con la investigación. Es cierto que, en términos generales, abordaban sus experiencias y vivencias con bastante soltura, sin embargo, podía percibir a través de la comunicación no verbal que todo aquello vinculado con la fístula continuaba siendo un tema "tabú" y doloroso. Una de ellas, durante la entrevista se sentía tan nerviosa que no paraba de mirar una y otra vez a la entrada de su casa, tenía la necesidad de asegurarse que nadie venía mientras hablábamos. Incluso, ante determinadas preguntas, su tono de voz disminuía por miedo a que alguien nos pudiera estar escuchando. 


\section{Marco teórico de análisis de la fístula como problema social, más allá de lo}

\section{biomédico}

En la revisión bibliográfica sobre marcos teóricos he encontrado una amplia y rica aportación desde el feminismo. Sin embargo, teniendo en cuenta que mi trabajo de investigación se centra en el análisis de las vivencias y experiencias de las mujeres que han sufrido la fístula obstétrica, he seleccionado determinadas aportaciones por considerar que son más útiles a la hora de explicar las cuestiones personales y sociales relacionadas con esta problemática. Estos marcos teóricos son: derechos sexuales y reproductivos, antropología médica o de la salud, repugnancia hacia los cuerpos de las mujeres, salud, enfermedad y religión, y la interseccionalidad.

\subsection{Derechos sexuales y reproductivos}

"En gran parte del mundo, las mujeres no tienen el apoyo para las funciones fundamentales de una vida humana. Están peor alimentadas que los hombres, están menos sanas y son más vulnerables a la violencia física y al abuso sexual. En comparación con los hombres es mucho menos probable que estén alfabetizadas y existen muchas menos probabilidades de que tengan una educación preparatoria o técnica" (Nussbaum, 2002:89).

Los Derechos Humanos han sido criticados, especialmente desde el Movimiento Internacional de Mujeres, al problematizar la visión androcéntrica que impregna sus contenidos. Las críticas fundamentales, según Rebeca Cook, se centran en tres diferentes ejes: porque han sido establecidos y desarrollados por hombres, y como consecuencia se encuentran impregnados de la orientación masculina; porque no han sido interpretados para responder a las experiencias de injusticia que viven las mujeres; $\mathrm{y}$, finalmente, porque los derechos humanos, especialmente los relativos a las mujeres, requieren que sean incorporados en la agenda central cuando se trabaja en estas temáticas y no marginalizarlos (Rodríguez, 1988:3).

Asimismo, el Movimiento Internacional de Salud de las Mujeres centra sus críticas específicamente en contenidos incluidos en los derechos sexuales y reproductivos de las mujeres. El debate, según Lilia Rodríguez, se concentra en los siguientes puntos (Rodríguez 1998:5): 
- Los derechos sexuales y reproductivos se sitúan tanto en la esfera privada como también en la pública. Las cuestiones sexuales y reproductivas aunque se ubican en la esfera privada para su pleno ejercicio se tienen que garantizar cuestiones relativas a la esfera pública como el acceso a la información adecuada, servicios de salud de calidad, métodos anticonceptivos, etc., que los gobiernos y los estados son responsables y deben hacerse cargo.

- La reproducción hace parte de la vida sexual, por lo tanto, se debe de garantizar el uso de la sexualidad tanto con fines reproductivos como con fines de búsqueda de placer.

- Las decisiones sobre sexualidad y reproducción "no siempre son explícitas, no involucran necesariamente a la pareja y, también, puede ocurrir que no sean consensuales... en éstas operan significaciones culturales profundas sobre la maternidad, el ser mujer u hombre, y relaciones concretas de poder entre hombre y mujer" (Gysling, citada en Rodríguez 1998:5-6).

- El lenguaje universal de los Derechos Humanos necesita ser revisado para que recoja las diversidades de las sociedades, puesto que los derechos sexuales y reproductivos tienen diferentes significados o prioridades dependiendo en las diferentes culturas o contextos sociales (Correa y Petchesky, citada en Rodríguez 1998:6).

- Finalmente, el principio de igualdad implica que tanto hombres como mujeres tienen el derecho a decidir sobre la sexualidad y la reproducción. Incluso así se tiene que reconocer y tener en cuenta que las mujeres se encuentran en una situación de desigualdad social, económica y política en relación a los hombres. Las mujeres no tienen iguales posibilidades de decisión debido a las relaciones de poder que permean la vida de pareja (Rodríguez 1998:6).

No obstante, los derechos sexuales y reproductivos se encuentran protegidos por la legislación internacional de derechos humanos y por documentos de las Naciones Unidas, y representan avances importantes y un ideal común que todos los pueblos y naciones deben garantizar su cumplimiento. Entre los principales instrumentos internacionales en los que se fundamentan los derechos sexuales y reproductivos se encuentran la Declaración Universal de los Derechos Humanos (1948); el Pacto Internacional de Derechos Civiles y Políticos (1976); el Pacto de Derechos Económicos y Sociales (1976); la Convención Internacional para la Eliminación de Todas las Formas de Discriminación contra la Mujer (1981); la 
Convención sobre los Derechos del Niño (1990), la Declaración y Programa de Acción de la Conferencia Internacional de Derechos Humanos, Viena (1993); el Programa de Acción de la Conferencia Internacional de Población y Desarrollo, El Cairo (1994); y el Programa de Acción de la Conferencia Mundial de la Mujer, Beijing (1995).

Teniendo en cuenta los acuerdos logrados en la Conferencia sobre Población y Desarrollo (E1 Cairo, 1994) y en la Cuarta Conferencia Mundial sobre la Mujer (Beijing, 1995), los citados derechos implican el derecho a la vida, a la integridad física, psíquica y social, libertad en el ejercicio de la sexualidad, respeto a las decisiones personales respecto a la preferencia sexual, respeto a la opción de la reproducción, elección del estado civil, libertad de fundar una familia, libertad de decidir sobre el número de hijas e hijos y a la elección de métodos anticonceptivos, derecho a la igualdad de sexo y de género, derecho a tomar decisiones respecto a la sexualidad, libertad para elegir compañero(a), para elegir si se tienen o no relaciones sexuales, derecho a recibir información acerca de la sexualidad, derecho a disponer de servicios de salud, derecho a recibir protección ante la amenaza o la violación de los derechos fundamentales, sexuales y reproductivos, entre otros. Y uno de los puntos claves a tomar en cuenta a la hora de hablar sobre la fístula obstétrica son los derechos sexuales y reproductivos de las mujeres.

Estos derechos y acuerdos internacionales y nacionales están directamente relacionados con la problemática de la fístula y, a mi juicio, no son respetados en Etiopía, puesto que las mujeres etíopes no eligen, en la mayoría de los casos de las entrevistadas, con quién desean casarse, a qué edad, tampoco si quieren o no tener descendencia o el número de hijas e hijos, dónde quieren dar a luz y asistidas por qué personas, etc.

A su vez, el demógrafo Samuel Kibret (2011) sostiene que la falta de garantías de los derechos sexuales y reproductivos hace parte de una violencia contra las mujeres y niñas o es un tipo de violencia sexista igual que la violencia física, sexual, psicológica, abuso sexual, la violación marital, mutilación genital y abortos forzados entre otras. Para este autor una de las desventajas que afrontan las mujeres es el relativo a la salud y, en Etiopía, esta violencia contra los derechos de las mujeres y niñas es un crimen tolerado por la sociedad y resultado de la cultura tradicional y creencias religiosas. Además añade que esta violencia contra las mujeres es universal, aunque los patrones y las causas varíen de una sociedad a otra y de una época a otra. En esta línea Samuel Kibret defiende que "cada sociedad dispone de mecanismos para que la violencia sea legitimada, negada y perpetúa la actitud personal sobre las relaciones entre hombres y mujeres y los tabúes sociales que impiden comentar 
asuntos privados en público. Esto hace que la violencia sea un medio aceptable para afirmar el poder y la resolución de conflictos" (Kibret, 2011:2).

Este es el claro ejemplo de la realidad de las mujeres que tienen la fístula. La cultura etíope prohíbe hablar sobre sexualidad en la familia y con amistades, dificultando así que las mujeres con esta problemática pidan ayuda en la familia o en el exterior. La solución que adoptan es ubicar la enfermedad en el ámbito privado y "esconder el problema" para no perjudicar la imagen de la familia.

Este autor concluye remarcando que los derechos sexuales y reproductivos son derechos universales de las mujeres y niñas, lo que implica que las mujeres tienen el derecho a decidir sobre su matrimonio, la persona con la que desean compartir su vida en pareja, si desean o no tener descendencia, el número de hijas e hijos que desean tener y cuándo tenerlos (Kibret, 2011:9).

En Etiopía, los matrimonios concertados a edad temprana siguen siendo acuerdos entre los padres de cada familia (en pocas ocasiones participa la madre). Son los varones cabeza de familia quienes deciden la edad del casamiento de sus hijas y las personas que serán sus futuros maridos. Esta violencia o privación de libertad de las mujeres afecta directamente a su movilidad e independencia. También afecta a la libertad de reírse, de participar en actividades de ocio y en asuntos políticos de la comunidad (Nussbaum, 2005:173).

En este país, los casamientos sin la aprobación de la mujer o de la niña responden a la tradición etíope que sostiene como único destino de las mujeres el casarse porque es una exigencia previa para ser "alguien" y parte de la vida social. Es por ello que una parte importante del trabajo de padres y madres es ahorrar para hacer frente a la larga ceremonia que conlleva el casamiento de las hijas. El siguiente paso, como resultado de la presión social, es que inmediatamente a la boda las mujeres se queden embarazadas y tengan descendencia.

La Constitución Etíope (1995), en el artículo 34, regula que "el casamiento se celebrará solamente con el consentimiento de las hijas" (Kibret, 2011:13). Incluso así, el incumplimiento de la Constitución así como de Convenciones y acuerdos internacionales en materia de derechos de las mujeres y niñas continúa siendo una asignatura pendiente en este país; en contadas ocasiones se tiene en cuenta los intereses de las hijas a la hora de concertar una boda (Kibret, 2011:14). 
Estos matrimonios son una realidad extendida en Etiopía, principalmente en zonas rurales donde vive el $83 \%$ de la población. Teniendo en cuenta los datos del Censo de Etiopía (2007), 18.375 niñas del estado regional de Tigray, de entre 10 y 14 años, son casamientos concertados por sus padres (las madres no son tenidas en cuenta o consultadas) violando así derechos fundamentales de niñas y niños. Además, esta situación es muchísimo más alarmante en áreas rurales donde 62.835 niñas de entre 15 y 19 años se encontraban en esta misma situación. En ambos casos, Etiopía y el estado regional de Tigray tiene un grave problema en garantizar los derechos de las chicas a la elección del estado civil y el compañero con quien compartir su vida (se dice compañero por que los casamientos homosexuales están prohibidos por ley).

Esta realidad todavía persiste en Etiopía, aunque en el año 2000 se revisó la Ley de Familia de 1960, debido a que dicha Ley contemplaba artículos que contravenían lo establecido en la Convención sobre los derechos de niños y niñas como la edad legal de matrimonio. La revisada Ley de Familia 213/2000 establece que un matrimonio será válido cuando la esposa dé libremente su consentimiento y que la edad legal para contraer matrimonio de chicas y chicos es los dieciocho años (artículo 6 y 7), lo que modifica la edad legal anterior (quince años para las chicas y dieciocho para los chicos). Los matrimonios acordados, sin embargo, son comunes y esta situación se agrava por el hecho de que raramente se registran oficialmente las fechas de nacimiento de niñas y niños y la edad que declara el padre es la aceptada. La realidad es que las tasas de estos matrimonios continúan siendo altas, puesto que entre el año 2000 y 2005, la incidencia de chicas de edades entre quince y diecinueve años que estaban casadas, divorciadas o viudas sólo decreció en tres puntos, de un 30\% a un 27\% (censo de Etiopía 2007). En Etiopía, la maternidad a edad prematura es considerada como una de las principales causas de los niveles altos de mortalidad materna y de otros problemas físicos, psicológicos y sociales.

Según la tradición etíope, una vez que las chicas han menstruado por primera vez están preparadas para el casamiento. Sin embargo, los chicos deben esperar hasta lograr su independencia económica para mantener a una esposa y a la futura prole. Este tipo de tradiciones son mecanismos que refuerzan y perpetúan la dominación masculina sobre las mujeres en la sociedad etíope. También, según Samuel Kibret (2011:15-16), los matrimonios a edad temprana se defienden porque es una manera de evitar que la familia sufra la vergüenza de que sus hijas tengan hijos o hijas fuera del matrimonio; por la propia seguridad de las mujeres (es deseable que las mujeres se casen mientras que los padres y madres sean jóvenes); para encontrar el mejor marido posible; para evitar la atribución de connotaciones o 
estigmas negativos por no estar casadas a determinada edad; para asegurarse que las chicas lleguen vírgenes al matrimonio; o para establecer relaciones de amistad con la otra familia (frecuente en las clases sociales altas). Entre las consecuencias derivadas de los matrimonios a edad temprana se encuentran la pérdida de la posibilidad de adquirir una educación adecuada, puesto que una vez que han sido casadas deben responder a roles "esposa-madre", incompatibles con la continuidad en la escuela; también afecta negativamente a la salud sexual y reproductiva porque la sociedad etíope ejerce una fuerte presión para que las mujeres, una vez casadas, queden embarazadas y tengan descendencia lo antes posible (si una mujer no puede tener descendencia la familia del marido le plantea al hijo que se divorcie). Los embarazos a edad temprana son una de las causas de la mortalidad materna en los partos y también de los episodios de fístulas, debido a que estas chicas todavía no tienen el cuerpo suficientemente desarrollado "el cuerpo es inmaturo a esas edades y la pelvis no esta suficientemente desarrollado, provocando asi un parto prolongado y debido a esto la muerte fetal y la fistula" (Kibret, 2011:17).

Finalmente, una de las mayores causas para esta privación de los cuerpos de las mujeres en Etiopía son las tradiciones y las creencias religiosas, ya que refuerzan la idea de la superioridad masculina, concretamente las interpretaciones que se hacen de la Biblia, describe que el cuerpo de la mujer no pertenece sólo a ella sino que también a su marido (Kibret, 2011:28). Las religiones Cristiana Ortodoxa y la Islámica afirman que la mujer debe sumisión al hombre y tolerar actitudes violentas del marido. Las normas tradicionales también aceptan y refuerzan esta inferioridad, tanto física como mental, que es trasmitida a través de la educación que reciben.

Según la filósofa estadounidense Martha Nussbaum, la violencia y el miedo a la violencia hacia los cuerpos de las mujeres y niñas dificulta el acceso a la educación y a la libertad de expresión. Esta amenaza contra "los cuerpos de las mujeres ha sido silenciada durante mucho tiempo". En opinión de esta filósofa, "ninguna mujer en el mundo está segura ante la violencia" (...). Sostiene que existen distintas formas de violencia contra las mujeres, unas son obvias o visibles y otras son sutiles y más difíciles de identificar. Sin embargo, ambas formas de violencia contribuyen a que las mujeres vivan con la sensación de miedo. En este sentido, esta autora menciona, a modo de ejemplos, el miedo al acoso sexual, el miedo a la privación de libertad de los cuerpos y el miedo a la desnutrición de las niñas. La Declaración de la Eliminación de la Violencia contra las Mujeres de las Naciones Unidas (1994) tipifica como violencia contra las mujeres "cualquier acción física, sexual o psicológica que va en su contra" (Nussbaum, 2005:167 y 172). 
Para Martha Nussbaum, la vulnerabilidad de las mujeres ante la violencia dependerá en gran medida de factores como la nacionalidad, religión, cultura, clase social, edad, profesión, etc.; pero una característica común a la mayoría de ellas es que experimentan el miedo a la violencia (tanto las que han sufrido violencia como las que no). Por lo tanto, el miedo hace parte de "una violencia psicológica en la vida de las mujeres que afecta a la seguridad humana y que esta vivencia se extiende desde el nacimiento hasta los últimos años de vida" (Nussbaum, 2005:168).

Las mujeres que entrevisté compartieron conmigo que durante los años que habían estado afectadas por la fístula sentían miedo, miedo a que en sus casa, en sus familias y en el vecindario se conociera su problema; en ocasiones, miedo a que el marido les abandonara o miedo a lo que el vecindario pudiera comentar. Por estas razones, algunas veces, familiares cercanos o las propias mujeres se escondían en casa, aislándose de toda actividad social y religiosa.

\subsection{Antropología médica o de la salud}

El problema de salud de la fístula obstétrica no sólo implica un problema médico o biológico, sino que va más allá implica tener en cuenta aspectos culturales, tradiciones e incluso creencias religiosas. Por esta razón, a mi juicio, la perspectiva que ofrece la antropología médica o de la salud aporta bases teóricas muy útiles para el desarrollo de mi trabajo de investigación. En términos generales, la antropología médica se interesa en entender características de la enfermedad, cómo los y las enfermas la experimentan, cómo personas cercanas la viven y cómo las creencias y prácticas sobre la salud están arraigadas por la sociedad, la cultura y el contexto que rodean a las personas enfermas (Singer y Baer, 2007:11). En definitiva, busca explicar los origines sociales de la enfermedad y la construcción cultural de los síntomas.

Según Merrill Singer y Hans Baer (2007), el punto de partida de la antropología médica es que los problemas relacionados con la salud, incluyendo la enfermedad y el tratamiento, sobrepasan los factores biológicos. Esto es así porque las razones de cómo nos enfermamos, por qué enfermamos y qué significa la enfermedad para una persona están determinadas no solo biológicamente sino también por factores sociales y culturales. Por ejemplo, se cuestiona el problema de salud del VIH/Sida, donde tan importante como saber cómo afecta esta enfermedad a las células del cuerpo humano o cómo destruye el sistema inmune, es conocer cómo se siente el o la paciente en cuanto a esta enfermedad: cómo le afecta en sus comportamientos, si está aceptado o no socialmente este problema de salud, cómo se siente 
ante esto él o ella, etc. Por lo tanto, más allá de la biología, de la atención médica y del tratamiento del VIH/Sida, las cuestiones culturales y sociales son factores a tener en cuenta (Singer y Baer, 2007:2).

Otro de los ejemplos utilizados desde la Antropología Médica es el de la enfermedad del Dengue. Muchos y muchas antropólogas médicas utilizan una vía alternativa a la medicalización, la prevención y la sensibilización de la enfermedad. Así, partiendo del estudio y utilizando las creencias locales sobre la salud, se implementan campañas educacionales para concienciar a la población (Singer y Baer, 2007:5). En otra investigación llevada a cabo por las mismas autoras y utilizando la misma estrategia comunitaria, grupos de trabajo y de discusión, lograron sensibilizar sobre el Dengue para prevenir la enfermedad y para conocer las actuaciones a realizar cuando tuvieran que enfrentarse a esta enfermedad infecciosa de causa viral (Singer y Baer, 2007:6).

Según esta y este autor, las enfermedades involucran un complejo proceso bio-social en el cual se deben tener en cuenta, además de factores biológicos, los del sistema de creencias, las estructuras de las relaciones sociales y condiciones ambientales (Singer y Baer, 2007:10). En definitiva, se necesitan aproximaciones biológicas pero complementadas y enriquecidas con aspectos relacionados con la cultura y la sociedad, tanto para conocer el origen de la enfermedad como para trabajar en prevención y tratamiento (Singer y Baer, 2007:11). En ese sentido, he percibido que factores culturales y creencias tradicionales, en el caso de las mujeres entrevistadas para esta investigación están condicionando la percepción sobre la fístula, Por poner un ejemplo, la tradición etíope trasmite que las mujeres tienen que dar a luz en sus hogares, serán castigadas en caso de optar por un centro hospitalario.

En opinión de Mari Luz Esteban, las reflexiones clásicas sobre la salud y la enfermedad se han ido superando, tomando en cuenta factores sociales y culturales de los procesos de la enfermedad y de la muerte. Esto se refiere al planteamiento bio-psico-social (Esteban, 2007:8). Hay diferentes formas de definir y explicar los procesos de salud/enfermedad en función de diferentes sociedades y teniendo en cuenta cada cultura. La antropología de la salud también utiliza diferentes técnicas cualitativas como la observación participante, entrevistas en profundidad o historias de vida con el fin de elaborar etnografías. Estas técnicas permiten profundizar en aspectos de la vida cotidiana de las personas y recoger distintas voces y experiencias, adquiriendo de este modo un conocimiento cualitativo sobre el tema (Esteban, 2007:73).

Puesto que "articular debidamente lo biológico, psicológico, social y cultural implica que 
estos niveles, que hemos definido en nuestra cultura como constitutivos de la realidad, son fenómenos abiertos, complejos y en continua interacción entre sí con el entorno. Esta posición nos lleva a buscar e implementar diferentes visiones y conceptualizaciones de la salud y de la enfermedad más allá de las definiciones médico-científicas, sin ver estas como "La” verdad universal" (Esteban, 2007:80).

Para Mari Luz Esteban "es preocupante la ideología cultural acerca de lo femenino como vulnerable que ha contribuido a reforzar una forma muy concreta de mirar y considerar el cuerpo, la salud y los ciclos vitales femeninos, considerándolas como las otras" (Esteban, 2007:83). En opinión de esta autora el origen de este pensamiento discriminatorio hacia las mujeres proviene del discurso médico-científico donde la diferenciación corporal y sexual se encuentra arraigada.

Por lo tanto, el punto de vista defendido por la antropología médica se encuentra directamente relacionado con mi tema de investigación. Puesto que no solamente he trabajado el tema de la fístula obstétrica de mujeres de áreas rurales del estado regional de Tigray como una cuestión sanitaria, teniendo en cuenta las consecuencias derivadas de los factores culturales y sociales tanto en sus orígenes como en sus frutos; son también estos factores por los que estas mujeres son discriminadas y excluidas, escondiéndolas del vecindario para que nadie sepa que están siendo castigadas por el poder divino por su mala conducta.

\subsection{Repugnancia hacia los cuerpos de las mujeres}

El cuerpo de las mujeres con fístula está considerado como repugnante, asqueroso, por el olor que desprende debido a que no pueden controlar la orina y, en ocasiones tampoco las heces. Estos desechos expulsados por el cuerpo se consideran repugnantes y, por lo tanto, la exclusión de los cuerpos de las mujeres de la esfera pública, a mi juicio, conecta directamente con lo que la filósofa estadounidense Martha Nussbaum (2006) denomina como repugnante.

Según el sociólogo Carlos Figari (2009), la repugnancia y la indignación son dos factores claves de la exclusión o la violencia, tanto material como simbólica de los cuerpos (Figari, 2009:131). A su vez, para Martha Nussbaum, la repugnancia es la contaminación del ser humano y nos recuerda o tendemos a asociarlo con la muerte o con una condición animal que son contaminantes para el ser humano (Nussbaum 2006:120). Además, Martha Nussbaum remarca que "el asco representa el sentimiento que califica la separación de las fronteras entre el hombre y el mundo, entre sujeto y objeto, entre interior y exterior. Todo lo que debe 
ser evitado, separado y hasta eliminado; lo peligroso, inmoral y obsceno entra en la demarcación de lo hediondo y asqueroso", por lo tanto, el asco será la reacción humana de lo abyecto (Nussbaum, 2006, citada en Figari, 2009: 133). Las mujeres que sufren de fístula representan esta separación a la que se refiere Martha Nussbaum y, por lo tanto, una de las razones para el rechazo y exclusión social tanto por parte de la familia como del vecindario. El hecho de no controlar la orina o las heces las convierte en algo asqueroso o repugnante y por tanto rechazable.

Puesto que la repugnancia de los cuerpos está asociada con la parte animal de las personas, obviamente con connotaciones negativas como "horrible, mal oliente, asqueroso" hace referencia a la parte no humana, a la parte animal de los seres humanos, que no sólo produce repugnancia sino que también nos aterra por lo que tiene que ser excluida socialmente, apartada de la civilización, porque este estado conllevaría a su fin. En opinión del sociólogo Carlos Figari (2009), este extremo de la animalidad en los humanos lleva a la agresión y a la violencia, hasta el punto del exterminio por no considerar a estas personas seres humanos. Además de esta exclusión de los cuerpos, se crea con fuerza el miedo a la contaminación (Figari, 2009:135-136). Un ejemplo interesante sobre "grupo de personas repugnantes" utilizado por Martha Nussbaum está relacionado con los judíos. Este grupo de por sí no es que sea repugnante, sino que los discursos dominantes los estigmatizaron para poder separarlos del grupo dominante (Nussbaum, 2006:133).

La materia que se expulsa del cuerpo, como la orina, las heces, el sudor, la menstruación, etc., es considerada materia marginal, contaminante y peligrosa. Al igual que sucede en las sociedades, cruzar determinadas líneas de comportamiento significa convertirse en impuro y peligroso para el buen funcionamiento del sistema. La línea de separación entre la impureza y pureza se establece en la repugnancia y el miedo al contagio. Por estas razones, en el caso de Etiopía, las mujeres afectadas de fístula suelen ser excluidas de las viviendas familiares y aisladas en un recinto separado, como les ha pasado a algunas de las mujeres que he entrevistado.

En algunas culturas, las mujeres cuando tienen la menstruación no pueden mantener relaciones sexuales y para volver a mantenerlas necesitan realizar rituales de purificación para que los maridos puedan estar otra vez con ellas (Figari, 2009:136). La mayoría de las sociedades trasmiten a la ciudadanía que se debe huir de ciertos grupos de personas que físicamente son repugnantes y contaminadoras, ello se debe a que las relaciones sociales están estructuradas para rechazar lo que se denomina repugnante. La repugnancia corporiza 
un rechazo a la contaminación, considerando a estas personas o grupos de personas como animales (Nussbaum, 2006:90 y 93).

Los desechos de los cuerpos, como previamente se ha expuesto, están considerados como contaminantes "lo muerto que sale de los cuerpos". Las mujeres están expuestas a más fluidos corporales, por ello, sus cuerpos serán más repugnantes que de los hombres. Haciendo referencia a Mary Douglas, esta autora denomina que "lo sucio o susceptible de polución será materia fuera de lugar" (Douglas: citado en Figari, 2009:136-137). Según el análisis de Martha Nussbaum, los flujos propios del cuerpo, menstruación, las heces, orina, vómitos, etc., mientras se encuentran dentro del cuerpo no van a ser denominados como repugnantes; este concepto sí que cambiará cuando el cuerpo los expulsa. Asimismo, desde el punto de vista de Mary Douglas, la repugnancia se encuentra socialmente contextualizada; en una situación determinada, un objeto puede ser denominado puro pero en otro diferente todo lo contrario. Además, la repugnancia más que ser percibida como algo peligroso, tendrá orígenes mágicos o tradicionales (Nussbaum, 2006: 108, 112 y 124).

La denominada repugnancia misógina para esta autora tiene una explicación sencilla. Las mujeres son las que dan a luz, por lo tanto, estarán vinculadas con la naturaleza, con la vida animal. Además, dado que las mujeres son las que reciben el semen (tan repugnante para muchos hombres), una vez que está fuera es muy probable que vean a las mujeres contaminadas por esta sustancia, mientras que ellos quedan intactos y no contaminados. En esta relación de fluidos, el cuerpo de las mujeres se percibirá como pegajoso, blando, sucio y contaminante. Esta repugnancia hacia los cuerpos de las mujeres y sus desechos, ayuda a mantener jerarquías sociales. Este rechazo también se producirá por los tabúes que se crean alrededor del sexo, menstruación, nacimiento, etc., (Nussbaum, 2006:134, 141 y 136).

Resumiendo, los desechos de los cuerpos son percibidos y valorados a modo de fluidos contaminantes y repugnantes, tratándolos como enfermedad. Es por esta razón que son socialmente excluidos y clasificados como lo "otro", por ser una materia contaminante y peligrosa definida desde el pensamiento hegemónico dominante.

En definitiva, la repugnancia es un arma que justifica la exclusión social. A lo largo de la historia se ha excluido a toda aquella persona que no se ajustaba y no cumplía los parámetros estandarizados normativos. En esta línea argumental, Martha Nussbaum afirma que la repugnancia está ligada directamente con experiencias vulnerables y de la vergüenza, en este caso con la mortalidad, ya que a toda costa lo tenemos que ocultar o trascender (Nussbaum, 2006:132). Al igual que en la repugnancia, la vergüenza también funciona de modo similar, 
las sociedades seleccionan algunos grupos de personas o personas individuales que no cumplen los parámetros normativos como medio para establecer quiénes son las personas "anormales", lo cual hace que las personas que han sido etiquetadas de "anormales" se sientan avergonzadas por no "ser" como el grupo dominante. Las personas enfermas, con algún tipo de deformidad, con diversidad funcional, o en este mismo caso la fístula, son discriminadas, avergonzadas y motivo de mofa en ocasiones por el discurso dominante. " $L a$ conducta social les dice todos los días que deberían sonrojarse al aparecer en presencia de los “normales" (Nussbaum 2006:206). Como bien afirma Martha Nussbaum, "avergonzar a quienes son diferentes es un aspecto pernicioso de las costumbres sociales dominantes" (Nussbaum, 2006:207).

En la línea de las aportaciones de Martha Nussbaum (2006), las mujeres que he entrevistado comparten conmigo que sienten vergüenza por el qué dirán de ellas en el caso de que el vecindario supiera lo que les sucede. Estas mujeres, al no entrar en los parámetros de "normalidad" vigentes en el medio que les rodea, son excluidas y avergonzadas, y además cargan con la culpa por "haber hecho algo mal" en su pasado, razón ésta por la que se interpreta que están siendo castigadas.

\subsection{Salud, enfermedad y religión}

Algunas sociedades establecen estrechas relaciones entre salud/enfermedad y religión. Continúa existiendo una fuerte conexión entre recuperar la salud si se abraza una religión. La capacidad de sanar dolencias o enfermedades es un éxito para el poder de Dios y una forma efectiva de legitimar la fuerza de la iglesia cristiana (Vallverdú, 2010:237-238). Este tipo de creencias, aunque no relacionadas con la iglesia sino con la medicina, pude constatar en mi trabajo de campo cuando una de las mujeres que entrevisté me comentó que en el vecindario se afirmaba que en Mekelle existía un Dios, un Dios que era capaz de curar a las mujeres que sufrían de fístula. Más tarde me di cuenta de que se estaba refiriendo al director de cirugía, Dr. Melaku, del Mekelle Hamlin Fistula Center.

Las creencias religiosas en Etiopía, por ejemplo, implican a que la sociedad piense que cuando una persona contrae una enfermedad, específicamente en el caso de la fístula, se debe a que "esa mujer" no ha sido buena religiosa, ha sido envidiosa, no se ha portado bien con otras personas o porque no ha sido buena esposa o madre. Por todo ello, "esa mujer" ha sido castigada con todo merecimiento. Asimismo, las enfermedades pueden considerarse a modo de posesiones demoníacas, como una "prueba" enviada por Dios a modo de castigo por la desobediencia a los mandatos de debido cumplimiento. Esta posesión maligna requerirá 
entonces de prácticas exorcistas especializadas para lograr liberarse de la afección, y se presenta como opuesta a la posesión carismática y privilegiada por parte del Espíritu Santo (Vallverdú 2010:240). Según Antonio Lasala, el historiador Erwin Ackerknecth (1985) explicó que cuando una persona enfermaba, la primera preocupación en la aldea era indagar e identificar qué ley social del grupo no había cumplido. De esta forma, la enfermedad se encontraba asociada con el incumplimiento de una determinada ley social vigente (Lasala, 2010:259).

Estas creencias son los referentes para establecer las diferencias entre el bien y el mal, los actos y pensamientos buenos, inspirados por Dios (la salvación eterna) y recompensados otorgando una buena salud, y los malos, inducidos por el diablo (perdición) y castigados con la enfermedad. Dualismo por lo tanto entre la victoria de Dios y la derrota del diablo. Según Antonio Lasala, todas las culturas discriminan entre lo bueno y lo malo y la persona curandera será considerada como el "hombre santo", el que ha devuelto la vida, tener salud nuevamente (Lasala, 2010: 241, 245 y 263).

En mi trabajo de campo he constatado que las creencias que explican dicotomías como enfermedad-salud, buenos actos-malos actos, premio-castigo, etc., son frecuentemente mencionados por muchas de las mujeres que he entrevistado. Según ellas, enfermaron porque no se portaban bien o pensaban que algo malo habían hecho y Dios o los espíritus malignos les estaban castigando.

\subsection{Interseccionalidad}

La discriminación por motivos de sexo, origen racial, sexualidad, clase, creencias religiosas, edad y así sucesivamente, se ha entendido y tratado como temas separados, en lugar de comprenderlos conjuntamente. Sin embargo, se constata que una situación particular que implica discriminación o algún otro tipo de inconveniente puede ser resultado de una discriminación donde entran en juego al mismo tiempo múltiples motivos o factores. Por ejemplo, una persona perteneciente a un grupo minoritario puede ser una mujer, una mujer puede ser lesbiana, la mujer lesbiana puede ser una persona con discapacidad y, también, puede ser una mujer de edad avanzada. En cualquier persona pueden encontrarse todas estas características al mismo tiempo y a la vez experimentar formas muy complejas de discriminación, porque las personas y las mujeres en particular no pertenecemos a un grupo homogénico social. 
Teniendo en cuenta lo anterior, la teoría de la interseccionalidad me aporta una visión más amplia sobre la discriminación que sufren estas mujeres por la fístula, esto es, al ser mujeres en las sociedades patriarcales, en este caso Etiopía, tienen mayores desventajas. Pero si a esto le añadimos que pertenecen a una clase social baja, que tienen un escaso nivel escolar y que debido a su problema de salud no pueden realizar tareas domésticas ni tampoco cuidar de los animales y que económicamente dependen de sus maridos, si a los ejes del sexo, clase social, educación y otros factores añadimos una "enfermedad", el resultado del análisis de la discriminación es muy complejo. No obstante, el resultado más evidente que he constado es que se da una actuación contra sus vidas, colocándolas en el margen de la sociedad y excluyéndolas de la vida cotidiana.

El análisis de la interseccionalidad se elabora en 1989, a modo de crítica desde el feminismo negro de los Estados Unidos de América que cuestiona la tendencia de tratar la raza y el género como dos categorías de experiencias y análisis mutuamente excluyentes. La interseccionalidad consiste en la comprensión de experiencias y análisis donde "en todos los tipos de discriminación pueden interactuar entre sí y producir experiencias concretas de discriminación" (Makkonen, 2002:9).

Kimberlé Crenshaw defiende que la "intersección de los factores como el racismo y sexismo en la vida de las mujeres negras, no se pueden percibir en su totalidad si se separan por ejemplo en este caso la raza o el género" (Crenshaw, 1991:1243). Por lo tanto, primero es necesario observar las intersecciones que se producen en torno a una persona y a continuación analizarlos en su total complejidad para entender mejor el problema. Refiriéndose a la interseccionalidad de la raza y género, Crenshaw (2000), en la misma línea que plantea Makkonen, subraya que "ni los aspectos de género de la discriminación racial ni los aspectos raciales de la discriminación de género se recogen en torno a los discursos sobre los derechos humanos" (Makkonen, 2002:1).

Siguiendo esta idea de Kimberlé Crenshaw, Makkonen sostiene que la conjunción de dos o más motivos hace a una persona vulnerable a la discriminación, como resultado se puede producir el "efecto de activación (trigger effect)". En general, una persona puede no ser discriminada por ser mujer o inmigrante, sin embargo la combinación de ambos factores pueden desencadenar un comportamiento discriminatorio. Este autor también describe la discriminación intersectorial de la siguiente manera (Makkonen, 2002:14):

"Discriminación interseccional, en el sentido más estricto, se debe utilizar para referirse a una situación en la que hay un tipo específico de discriminación, en el que 
hay varios motivos de discriminación que interactúan simultáneamente. Por ejemplo, las mujeres de las minorías pueden estar sujetas a tipos particulares de prejuicios y estereotipos; pueden enfrentar modos diferentes y especificos de discriminación racial, que los hombres pertenecientes a su mismo grupo racial no experimentan”.

Rey Martínez (2009) refiriéndose al punto de vista defendido por Kimberlé Crenshaw expone la tesis principal de esta autora, subrayando que las mujeres negras pueden ser discriminadas de la misma manera que las mujeres blancas y los hombres negros. Pueden sufrir una doble discriminación por motivos de los efectos combinados sobre la base del sexo y la raza, o pueden ser objeto de discriminación específica por ser mujeres negras (no por la suma de estos dos factores: género y raza) (Martínez, 2009:5-6).

En el caso de las mujeres afectadas por la fístula, interactúan diferentes niveles de discriminación: por ser una problemática de salud propia de la maternidad, porque afecta a las mujeres de la clase social más baja y por ser mujeres que apenas han ido a la escuela. La combinación de estos diferentes factores implica una situación de mayor vulnerabilidad y mayores niveles de discriminación. Según Kimberlé Crenshaw, la interseccionalidad significa "la tendencia de tratar la raza y el género como categorías mutuamente influyentes en las experiencias y en el análisis" (Crenshaw, 1988:139).

Kimberlé Crenshaw describe y analiza la discriminación sufrida por las mujeres negras con las siguientes palabras (Crenshaw, 1989:140):

"Con las mujeres negras como punto de partida, se hace más evidente cómo las concepciones dominantes de la discriminación condicionan que pensemos en la subordinación como desventaja que ocurre a lo largo de un solo eje categórico. En otras palabras, en los casos de discriminación racial, la discriminación tiende a ser vista en términos de sexo o de clase privilegiada los negros; por otra parte, en los casos de discriminación sexual, la atención se centra en la raza y en la clase de las mujeres privilegiadas.

La contribución de esta autora es útil para realizar el análisis de diferentes grupos no dominantes. Según ella, la interseccionalidad tiene que incluir un análisis completo de todas las formas discriminatorias, de lo contrario, no se tratará de un análisis exhaustivo (Crenshaw, 1989:140). 


\section{Vivencias en torno a la fístula: partos obstruidos, rechazo, castigo y reintegración}

En esta sección recojo determinadas aportaciones realizadas por las mujeres que he entrevistado por considerar que hacen referencia a cuestiones centrales e importantes relacionadas con sus experiencias y vivencias personales. Estos relatos se refieren a la experiencia de partos prolongados, la exclusión por parte de la comunidad, el miedo al abandono por parte del marido, la explicación de la fístula obstétrica a modo de castigo divino, experiencias en el contexto hospitalario y cuestiones vinculadas con el retorno al hogar después de la intervención quirúrgica hospitalaria y la reintegración en el contexto de origen.

Asimismo, una vez más quiero subrayar que la información que expongo aquí, recogida mediante entrevistas en profundidad a trece mujeres que residen en zonas rurales del estado regional de Tigray, Etiopía, e intervenidas en un centro hospitalario por su problema de fístula, no es más que una pequeña muestra de sus realidades, si tenemos en cuenta que la OMS estima que en el mundo hay aproximadamente dos millones de mujeres que sufren de este problema de salud. Con ello no estoy infravalorando la experiencia tan importante de haber conocido a estas mujeres, de cómo me acogieron en sus hogares, de conocer a sus familias y el contexto donde viven, y de su gran generosidad al dedicarme el tiempo requerido para realizar las entrevistas. No obstante, reconozco que debido al tamaño de la muestra, la información recabada no puede ser generalizada ni tampoco homogenizada.

Una de las principales causas de la fístula obstétrica es la indefensión por la falta de garantías de las mujeres en el ejercicio de sus derechos sexuales y reproductivos, principalmente, en el derecho a decidir sobre la maternidad. Aunque el quinto Objetivo de Desarrollo del Milenio 2015 consiste en garantizar y mejorar la salud materna, Etiopía tiene una de las mayores tasas de mortalidad materna y se estima que cada año 500.000 mujeres y chicas padecen algún tipo de problema por partos complicados y prolongados (Muleta; Hamlin; Fantahun y Tafesse, 2007:45).

La malnutrición de las niñas y mujeres, la prohibición de ingerir determinados alimentos básicos durante el embarazo y los embarazos a edades tempranas o en la adolescencia son factores que inciden negativamente y son causas principales de los partos prolongados. Algunas autoras y autores subrayan la relación directa entre partos prolongados y fístula. Añaden a este factor las barreras de acceso desde zonas rurales a servicios de emergencia obstétrica (Muleta; Fantahun; Tafasse; Hamlin y Kennedy, 2007:44). 
La mayoría de las muertes materno-infantiles se producen en las primeras veinticuatro horas del parto. No obstante, hay casos que por razón de un parto prolongado (entre tres y cinco días), el o la bebé muere provocando en la madre una lesión entre la vejiga y la vagina o el recto. Esto se denomina fístula (Health Bureau, 2013:2).

La prevención de la fístula requiere garantizar a las mujeres embarazadas el derecho al acceso a personal sanitario cualificado y a la atención en centros de salud u hospitales, como una forma de prevenir muchas de las muertes y también problemas obstétricos en las mujeres. Por personal sanitario cualificado entiendo médicas y médicos, parteras y enfermeros y enfermeras con preparación adecuada con el fin de diagnosticar y solucionar cualquier tipo de complicación que se presenta en un parto. Según datos publicados por la Consejería de Salud del estado regional de Tigray se estima que el 50\% de las mujeres han dado a luz con algún profesional sanitario; sin embargo, un porcentaje alto y preocupante, el 43,3\%, da a luz en su casa y sin la ayuda de profesionales sanitarios, y el 6,6\% restante son atendidas por promotoras de salud, que pueden o no haber recibido formación específica en este campo (Health Bureau, 2013:32).

Todas las mujeres que he entrevistado me informaron que antes de tomar conciencia de su incontinencia urinaria tuvieron partos complicados. La mayoría de ellas estuvieron entre dos y cuatro días de parto y, en algunos casos, sus embarazos fueron a edades muy tempranas, antes de cumplir la mayoría de edad.

Cuando les pregunté a Letekiros, Tesfai y Aregawit ${ }^{9}$ a qué edad tuvieron el primer bebé, el lugar donde dieron a luz y quién les asistió en el parto, relataron lo siguiente:

\section{Letekiros:}

"Tuve mi primer bebé a los diecisiete años, di a luz en casa, es normal dar a luz en casa en Etiopía. He tenido ocho embarazos pero dos de los bebés murieron. En el último embarazo, el bebé murió en el parto y esto fue la causa que me provocó la fistula (...). Una partera tradicional, mi madre, mi hermana y una vecina estuvieron durante el parto".

A Letekiros, de cuarenta años, su padre le obligó a casarse cuando tenía dieciséis años, de ocho embarazos viven dos hijas y cuatro hijos. Es una mujer honesta y alegre, me miraba directamente a los ojos cuando contestaba a mis preguntas, incluso hacia pequeñas bromas

\footnotetext{
${ }^{9}$ Los nombres que aparecen en los relatos son ficticios debido a que algunas de ellas me transmitieron su preocupación ante la posible utilización de sus nombres reales. Los he sustituido por nombres típicos etíopes.
} 
durante la entrevista y me miraba, yo le respondía con una pequeña sonrisa porque hasta que me traducían no sabía lo que había comentado. Vive en una casa de piedra muy sencilla, de una sola habitación donde vive toda la familia; a las afueras de la aldea tiene una parcela para el cultivo y dos bueyes para arar la tierra. Su día empieza a las cinco de la mañana, realiza las tareas del hogar y sus hijos e hijas se van a la escuela, mientras que ella sigue limpiando, cocinando, trabajando en el campo, etc. Su marido murió hace un año, tenía muchos problemas con la bebida, incluso Zufan me comentó que le solía pegar. Es una mujer muy fuerte, vital y habla sin ningún problema, sin ninguna vergüenza sobre la fístula. Estuvo sufriendo las consecuencias de la fístula durante tres años sin salir de su casa y sin que nadie le visitara durante ese tiempo.

Tesfai:

"Mi primer embarazo fue a los quince años y es cuando se me produjo la fístula. El parto fue en casa, con una partera tradicional. Tuve un parto complicado, el bebé murió deshidratado a causa del parto prolongado y me provocó la fístula. Estuve cuatro dias de parto".

Tesfai, de treinta y tres años, tiene tres hijos y una hija de dos hombres diferentes. Su padre concertó la boda cuando ella solamente tenía diez años y fue casada a los trece. Me contó que en esos momentos no entendía nada de lo que estaba pasando a su alrededor. A los dos años de la boda, se quedó embarazada y desarrolló la fístula en su primer parto. Esta mujer ha conseguido abrir un pequeño café en su aldea con micropréstamos concedidos por diferentes microfinancieras. Vive en una casita humilde hecha de piedra y con techo de paja; en una habitación vive la familia y en la otra se encuentra el pequeño café familiar donde acuden la mayoría de los hombres de la aldea para tomar un café, té o cervezas. En Etiopía no está bien visto que las mujeres acudan a bares y menos de noche. Tesfai está muy contenta con la decisión de abrir este negocio, porque en su aldea no había un espació así y muchas personas van a dicho local.

Y Aregawit:

“Mi primer embarazo fue a los dieciséis años (...). El parto fue en casa, pasé el último mes de embarazo con fuertes dolores y también durante el parto. Fueron tres días de parto. Sufrí mucho, estaba en shock, no me acuerdo absolutamente de nada. Más tarde mi madre tuvo que explicarme todo lo que había sucedido durante los días que duró mi parto". 
Aregawit, de treinta y cinco años, es una mujer alta, con cuerpo atlético. Una mujer fuerte, aunque todavía sufre algunas consecuencias psicológicas que le llevan a comentar que no se encuentra del todo curada. Detrás de sus relatos pude notar que había mucho dolor, muchas heridas sin cicatrizar. Cada vez que se mencionaba la palabra fístula, se le humedecían los ojos. Su padre la casó cuando tenía quince años, ella admitió que su padre compró el que sería su marido por ocho vacas. Tiene dos hijas y su marido murió hace quince años. Me comentó que para ella ahora mismo lo más importante es que sus hijas terminen el colegio, no quiere que les pase lo mismo que a ella y, tampoco, se le pasa por la cabeza casarlas, ellas mismas decidirán con quién y cuándo casarse. Una tarde cuando estaba con Aregawit, le pedí que me contara cómo había sido su boda, al principió dudó un poco pero enseguida empezó con el relato que tantos recuerdos le traía. Su padre acordó el matrimonio con el padre del novio cuando ella sólo tenía trece años. No supo nada sobre su futuro marido hasta que cumplió quince años (su ex marido tenía veintiocho). El día de la boda fue cuando se encontró por primera vez con su futuro marido. Se reunieron la familia y amistades y aquí fue cuando su padre entregó ocho vacas al marido como dote. Me contó también que la luna de miel depende en la economía de la familia, puede durar desde una semana hasta tres meses. En su caso duró un mes entero y lo pasó en su casa. Durante el mes de luna de miel no podía salir a la calle durante el día, solamente a partir de la puesta del sol y para seguir celebrando su casamiento con comida, bebida y bailes.

Letekiros, Tesfai y Aregawit, como tantas otras mujeres en el estado regional de Tigray, en Etiopía y en otros países en vías de desarrollo, tuvieron partos a edades tempranas, con quince y dieciséis años, cuando todavía eran niñas, cuando sus cuerpos no estaban desarrollados para poder tener un bebé, en un país donde los preceptos de derechos sexuales y reproductivos no se respetan... El resultado de estas realidades es la fístula, que algunas de ellas lo callan durante años y años para que nadie se entere, porque sienten una profunda vergüenza. En el caso de estas tres mujeres, la experiencia de un parto prolongado y en sus propias casas hizo que tuvieran un bebé muerto, habiéndoles provocado previamente la fístula.

Desde mi punto de vista, el compromiso firme de la comunidad con los derechos sexuales y reproductivos es una de las vías más importantes para terminar con las lesiones producidas por partos de esta naturaleza (Wegner; Rumijo; Sinclair; Presso y Mehta, 2007:108). Sin embargo, es el marido el que toma las decisiones, es él quien decide si a su esposa la atenderá una profesional con formación en partos, qué personas la acompañarán durante el parto, dónde dará a luz o si se requiere o no transporte para una posible emergencia hospitalaria. El 
marido, en la mayoría de los casos, desconoce lo que puede suceder durante un parto, qué tipo de complicaciones pueden presentarse, qué síntomas son indicadores de un parto prolongado y sus consecuencias tanto para la madre como para la o el bebé. Todo ello dificulta que, ante un parto difícil, el marido reaccione a tiempo y tome la decisión de trasladar a su esposa a un centro hospitalario (Wegner; Rumijo; Sinclair; Presso y Mehta, 2007:109).

Tanto el marido como su madre se encargan de los preparativos del parto y, también, de la planificación financiera. Ambos son los que deciden si, ante un parto con complicaciones, hay dinero o no para trasladar a la mujer a un centro hospitalario (Wegner; Rumijo; Sinclair; Presso y Mehta, 2007:109). Puesto que las decisiones se toman de esta manera, y para asegurar que esto poco a poco vaya cambiando, los Grupos de Mujeres para el Desarrollo orientan y sensibilizan a las mujeres embarazadas, a sus maridos y a las madres de los maridos de la conveniencia de acudir durante el embarazo a las cuatro revisiones ginecológicas establecidas, así como la atención del parto en un centro hospitalario.

También es importante que la comunidad disponga, fundamentalmente en zonas rurales, de parteras formadas para la asistencia en el parto y para el diagnóstico de partos obstruidos con alto riesgo de producir una fístula, porque en caso contrario las parturientas estarán en peligro de sufrir consecuencias o secuelas negativas, en algunos casos y, en otros, irreversibles (Wegner; Rumijo; Sinclair; Presso y Mehta, 2007:109).

Es evidente que la realidad de las mujeres durante sus embarazos y partos (ausencia de libertad para decidir si desea o no tener hijos o hijas, cuándo y cuántos desea tener, dónde dar a luz, qué personas tener a su lado, etc.) es una violación contra sus derechos sexuales y reproductivos. Así, el demógrafo etíope Samuel Kibret (2011:17) considera que esta falta de garantías de los derechos de las mujeres es violencia contra ellas y, además, demuestra las desventajas que tienen las mujeres en el acceso a la sanidad pública. Por esta razón, tanto la Asociación de Mujeres de Tigray y la Consejería de Salud están trabajando en estrecha colaboración con los Grupos de Mujeres para el Desarrollo con el fin de sensibilizar sobre estos temas tanto a las mujeres como a sus familias.

Incluso así, en el caso de Abba Maharon, cuando le pregunté dónde dio a luz me contó que su marido le asesoró que era mejor acudir a un centro de salud por si ocurría algún problema durante el parto: 
"Tuve todos los partos en hospitales. Mi marido pensaba que era mejor así, aunque por mi parte los hubiera tenido en casa, al final me convenció".

Abba Maharon es una mujer muy cariñosa y sonriente, no sabía exactamente a qué hora llegaríamos a su casa, así que se sentó en una roca al lado de la carretera a esperarnos durante un buen rato. Se puso muy contenta cuando nos vio y directamente fue a abrazar a su gran amiga Zufan. Inmediatamente nos hizo pasar dentro de su casa donde ya tenía hirviendo el café y nos sacó el pan recién horneado. En las casas etíopes, cuando llega una visita es costumbre ofrecer café y un trozo de pan y, aunque no se tenga hambre, las invitadas comen un trozo pequeño para agradecer la hostilidad. Su marido ese día no trabajaba, optó por estar presente durante toda la entrevista, escuchando y observándonos en silencio, hasta que decidí que él también participara en la entrevista, tenía curiosidad por conocer su opinión. Según él, la fístula no es un castigo, sino un problema de la salud no sólo de mujeres sino también de sus maridos. Debido a que, al fin y al cabo, son ambos los que deciden tener hijos o hijas. También insistía en que había que trabajar mucho más en la prevención y facilitar recursos obstétricos para todas. Traer aquí la opinión del marido de Abba Maharon.

Viven en una casa muy modesta con un hijo con problemas de crecimiento y una hija con parálisis cerebral. Fuera de su casa hay un buey, gallos y gallinas que andan a sus anchas dentro y fuera de la casa. Hubo momentos que no podía escuchar nada de lo que se decía por el continuo "cacareo" de las gallinas. Abba Maharon tuvo siete partos, cinco murieron bien durante el parto o pocas horas después. Ella afirma que su casamiento con su actual marido fue por amor, que nadie la obligó.

Aunque son los maridos quienes ostentan el poder de decisión ante cuestiones que conciernen directamente a sus esposas, sin embargo, en esta ocasión la orientación del marido de Abba Maharon era la adecuada tanto para garantizar su salud como la del hijo o hija que iba a nacer.

En ese sentido, los partos prolongados que tuvieron las mujeres que entrevisté fueron la principal causa de la fístula que les llevó a experimentar la exclusión por parte de la comunidad. El tiempo o los años que las mujeres entrevistadas han convivido con la fístula es muy variado. Algunas de ellas, después del parto al darse cuenta que perdían orina, acudieron de inmediato al hospital para el diagnóstico. En estos casos, tras contactar con el Hospital Hamlin en Addis Ababa o en Mekelle, tuvieron que esperar tres meses para ser intervenidas. Sin embargo, otras mujeres han vivido durante años y años, alguna de ellas hasta quince 
años. La razón fundamental era el miedo a que sus maridos, familia y vecindario les dieran la espalda.

Como bien afirman algunas autoras y autores, la exclusión o el aislamiento social dificulta poder contactar con mujeres que sufren del problema de la fístula e informarles que hay muchas otras mujeres que la sufren, dónde y cómo se puede tratar, etc. (Wegner; Rumijo; Sinclair; Presso y Mehta, 2007:109). La "solución" al problema de la fístula mediante el aislamiento fue un tema que también me relataron algunas de las mujeres entrevistadas. El hecho de pensar que eran las únicas mujeres en el mundo que no controlaban la orina y que olían mal, el miedo a que sus maridos y personas vecinas se dieran cuenta de lo que les sucedía, les llevó a encerrase en casa. Reconocen que estos fueron los motivos principales para no pedir ayuda hasta pasar muchos años. También es cierto que la cultura etíope no admite compartir cuestiones relativas a la sexualidad con otras personas, incluso para algunas de las mujeres entrevistadas, al principio, era un poco violento hablar abiertamente sobre estas experiencias.

Letekiros me relató su experiencia de exclusión y aislamiento, y también sus miedos con estas palabras:

"Estuve tres años viviendo con la fistula. Sentí que todo el mundo me discriminaba por esto. Nadie venía a visitarme... Me sentí muy rechazada durante esos años. No podía dejar la casa porque tenía miedo, no pude hacer nada por la comunidad, sufrí mucho. Tenía miedo a salir de casa, de ir al mercado, a la iglesia, a las ceremonias del café. Sabía que olía mal y que todo el mundo hablaba de mí, incluso algún vecino me dijo que era mejor que me muriese porque nadie podía curarme ese problema”.

Y continúa: “después de la operación, sin embargo, todo el mundo estaba muy contento cuando me vieron otra vez bien. Antes del tratamiento, nadie venía a visitarme a casa o nadie me invitaba a sus casas, pero ahora otra vez quieren que esté con ellos y ellas".

El vecindario y la comunidad, por la falta de información sobre este problema de salud, creen que lo que les sucede a estas mujeres no tiene solución y que sufrirán sus consecuencias durante toda su vida. Incluso, como en el caso de Letekiros, un vecino le llegó a desear la muerte como solución.

El octavo parto prolongado le provocó a Tesfay la fístula. Ella también me relató vivencias de exclusión y soledad a raíz de este problema de salud de la siguiente manera: 
"Fue un gran problema el tener la fístula. Fui excluida de la comunidad y sentí que estaba totalmente sola ante este problema. Había algunos vecinos y vecinas que venían a visitarme, pero la mayoría me odiaba y no querían saber nada de mi".

Tesfay es una mujer de cuarenta y dos años, muy seria pero amable y cariñosa. Relata que cuando tenía dieciséis años su padre la obligó a casarse con un hombre mayor que ella. En el momento de entrevistarla estaba realizando los cursos ofrecidos por la Fundación Healing Hands of Joy, en Mekelle. Me admitió, después de apagar la grabadora, que físicamente se encuentra bien pero que todavía estaba en proceso de curación psicológica y que le estaba viniendo muy bien estar en esta Fundación durante un mes. Cuando finalice el curso de formación quiere trabajar con el Grupo de Mujeres para el Desarrollo de su aldea para mejorar la vida de otras mujeres de su comunidad. La percibí muy ilusionada con este proyecto, no quiere que otras mujeres sufran lo que ella ha sufrido durante años. Habla con mucho resquemor hacia algunas personas de su vecindario y comenta muy seria que nunca les podrá perdonar cómo la trataron cuando se enteraron que sufría de fístula.

Las mujeres entrevistadas deciden no salir de casa porque piensan que si salen el vecindario hablará de ellas. Por ejemplo, en el caso de Hatsed, su hermana cuidó de ella durante los tres meses que estuvo con la fístula y con una grave infección en ambas piernas. Hatsed fue recluida en una habitación. Me contó esta experiencia así:

“En una habitación estaba viviendo toda mi familia y en otra apartada me encontraba yo sola. Nadie entraba en la habitación, nadie venía a visitarme por el mal olor que desprendía, solamente mi hermana. Ella me lavaba todos los días. Estuve sin salir de la habitación tres meses. Y continúa: "un día una vecina vino a mi casa y grito iqué mal huele aqui! Aunque mi hermana limpiaba mi habitación todos los días y utilizaba perfume e incienso para que no oliese mal’.

Hatsed es una chica de veintitrés años, tímida pero muy reflexiva sobre temas relacionados con la fístula. Admite que ha sido muy duro pasar por todo esto siendo tan joven. Lo cierto es que ha sacado fuerzas para alcanzar sus sueños, mudarse a Mekelle y empezar a trabajar. Es una de las pocas entrevistadas que fue escolarizada. Su familia la casó cuando tenía dieciséis años con un hombre once años mayor que ella. Todavía hablaba con mucho resquemor sobre su ex marido. Me comentó que ella no quería casarse con el hombre que eligió su padre, no le gustaba cómo la trataba, pero que no podía hacer nada. Se quedó embarazada al poco tiempo de casarse y estuvo de parto durante tres días. Dio a luz un bebé muerto que le había producido la fístula. 
Cuando le pregunté a Ascual cuál fue su reacción ante la fístula y si se lo contó a alguien o no, me respondió así:

“Tenía mucho miedo y vergüenza de contárselo a nadie, tenía que guardármelo para mí. Llevaba siempre pantalones debajo de las faldas y también algunas veces compresas. Todo el tiempo solía pasar limpiando mis ropas para que no oliesen mal. Pasaba el día entero llorando cuando nadie me veía...".

Estas mujeres, por la escasez de agua a la que tienen acceso, especialmente en las zonas rurales, utilizan el humo que desprende un pequeño hornillo para cocinar y el incienso de las ceremonias del café para neutralizar el olor de la orina. Ascual describe esta situación tan cruel así:

"Las víctimas de la fístula escondemos nuestros cuerpos porque tenemos miedo a la discriminación, empapamos nuestras ropas con humo e incienso para no tener un olor tan malo a orina y heces. Hacemos esto porque tenemos miedo de la comunidad, estamos traumatizadas... Tenemos que cambiar esta forma de pensar de la comunidad".

La teoría de la interseccionalidad también se puede adecuar muy bien a estos discursos, esto es, Kimberlé Crenshaw defiende que si se separan los factores como la raza o el sexo de la vida de las mujeres la discriminación no se percibirá en su totalidad (Crenshaw, 1991:1243). Pero si analizamos la discriminación como una intercesión entre ser mujeres, normalmente de clase social baja, con bajo nivel escolar y, además, "enfermas" de la fístula, estos diferentes factores nos llevan a entender su exclusión de forma más compleja y real.

Estos testimonios ponen de manifiesto que las consecuencias derivadas de la fístula no sólo son físicas y sociales, sino también psicológicas, y que algunas de las mujeres entrevistadas padecían aún después de la intervención quirúrgica. Según las autoras Ahmed y Holtz, en un estudio realizado en Nigeria con mujeres que habían sufrido el problema de la fístula, afirman que muchas de ellas padecen depresiones, cambios repentinos de humor (enfados) y sensación continuada de estar decepcionadas con la vida (Ahmed y Holtz, 2007:S12). Datos muy similares he encontrado en informes facilitados por el Hospital Hamlin Fistula de Mekelle, en los que se constata que el 32\% de las mujeres ingresadas en este hospital, en el año 2012, sufría de problemas psicológicos como depresión, ansiedad, psicosis y desórdenes post traumáticos. Estas autoras, Ahmed y Holtz, constatan también que en la mayoría de las mujeres que sufren de fístula sienten vergüenza en la vida social o se sienten muy enfermas y 
con dificultades a la hora de mantener relaciones sexuales. Muchas de ellas afirman que no pueden hacer una vida social como antes, por ejemplo, ir a la iglesia, a misa o a visitar a sus amigas (Ahmed y Holtz, 2007:S13).

Otra consecuencia es la soledad, sentirse solas y "únicas" ante su problema. Dado que hablar sobre todo lo relacionado con la sexualidad es tabú, a ninguna mujer se le ocurre compartir su problema en casa, con otras mujeres o con otras personas de la comunidad. Sin embargo, en la mayoría de los casos, cuando ingresan en el hospital y se encuentran con otras mujeres que sufren el mismo problema de salud, empatizan y comparten sus experiencias, y comienzan a elaborar un pensamiento más real: "lo que me ha sucedido a mí, también les ha sucedido a otras mujeres". Este nuevo posicionamiento ante la fístula les ayuda a desechar la idea de que han sido castigadas por ser "malas mujeres, esposas y madres".

Para Cook, Dickens y Syed se convierten en personas socialmente invisibles y olvidadas tanto para el marido, las familias y la comunidad (Cook; Dickens y Syed, 2004:74). La discriminación que sufren es una actitud que va en contra de los derechos humanos y de sus derechos sexuales y reproductivos, impidiendo la igualdad real y efectiva. Las mujeres que viven durante muchos años con la incontinencia urinaria y, algunas veces, también de las heces, creándoles infecciones graves, reciben una respuesta personal y social que es de exclusión de la vida cotidiana (por miedo a la familia y a la comunidad) (Cook; Dickens y Syed, 2004:74).

Las experiencias de exclusión y aislamiento social fueron vivencias duras para todas las entrevistadas y que marcaron sus vidas. Percibí mucho dolor detrás de sus palabras, pero también mucho entusiasmo por cambiar sus vidas y disposición para ayudar a cambiar la vida de otras mujeres que sufren del mismo problema; esto último, el ayudar a otras mujeres para aliviar su exclusión y aislamiento social, implica un deseo por transformar en positivo su dolorosa experiencia.

Finalmente, considero una aportación a subrayar la que me hizo el marido de Abba Maharon, no sólo porque su participación fuera casual sino por la visión social que tenía sobre la fístula:

"La fístula no es un castigo hacia las mujeres y no es un problema que sólo afecte a ellas, es nuestro problema, de mujeres y de hombres. Ellas son las que sufren la fistula porque son quienes dan a luz, porque ambos queremos tener hijos e hijas, por lo tanto, este problema nos afecta a los dos". 
De algunos relatos, como recogen las palabras del marido de Abba Maharon, se desprende que ven necesario socializar el problema de la fístula, traspasando los límites de lo privadoindividual, asumiéndolo como un asunto de salud pública de la propia sociedad en general y del gobierno de Etiopía en particular. En caso de lograr este cambio de actitud, el afrontamiento de la fístula no sería tratado como "algo" que atañe exclusivamente a las mujeres, sino un problema que conlleva garantizar plenamente los derechos sexuales y reproductivos de las mujeres y la no discriminación.

Otra de las cuestiones importantes, según Ahmed y Holtz, es el miedo a que sus maridos se divorcien o las abandonen, lo que, frecuentemente, les lleva a recurrir a la mendicidad como una forma de sobrevivencia (Ahmed y Holtz, 2007:S10). En relación a los problemas económicos derivados del divorcio, en un estudio llevado a cabo en Addis Ababa sobre mujeres divorciadas se evidenció que en el 39\% de los casos, las mujeres dependían de sus familiares más cercanos para poder comer y el 22\% mendigaba o vivía de donaciones (Ahmed y Holtz, 2007:S12). Las normas sociales y una infraestructura judicial limitada, especialmente en zonas rurales, son barreras para que muchas mujeres no busquen reparación legal ante situaciones que contravienen sus derechos, y también a que desconocen la regulación vigente que las ampara en caso de divorcio. En 2003, el gobierno de Etiopía inició un proceso de registro de tierras comunitarias que condujo a la certificación conjunta de las mismas. Esta última medida tenía como fin fortalecer los derechos sobre las tierras y el ganado complementando de esta forma la revisada Ley de Familia de 2000 que garantizaba la igualdad de derechos para las mujeres y los hombres en términos de matrimonio, herencia y propiedad de las tierras (Hallward-Driemeier y Gajigo, 2011). La revisada Ley de Familia, por ejemplo, sostiene que los casos de divorcio deben tratarse y ser resueltos en el Tribunal de Justicia, dado que es la instancia que puede garantizar un trato igualitario en estos casos.

Es debido a este miedo que las mujeres afectadas por este problema de salud ocultan su situación durante años a sus maridos y a otras personas de su entorno; es el temor a quedarse solas con sus hijas e hijos y sin recursos económicos. De este modo me relató Takien su miedo al posible abandono por parte de su marido y sus consecuencias:

“Tuve que guardármelo todo para mí durante cinco años, era una situación muy, muy mala lo que me estaba pasando. Si le hubiera dicho a alguien sobre mi problema, mi marido me habría abandonado y también mis amigas y todos empezarian a hablar de mí. Me hubieran dejado sola, todos huirían de mi”. En este punto del relato Takien empieza a llorar. 
Takien, de treinta y tres años, sin decir nada a nadie y mintiendo a su marido viajó a Mekelle para ser intervenida de fístula. La excusa que utilizó para justificar este viaje fue que la cesárea realizada en el último parto le estaba causando problemas, una nueva intervención era la recomendación de su médico de Wukro.

Takien es una mujer muy tímida pero atenta, amable y cariñosa al mismo tiempo. Cada vez que iba a su casa me acogía con una sonrisa de oreja a oreja y siempre me hacía café sin preguntar si quería o no. Takien se mostraba muy sensible, todavía a día de hoy, cuando hablábamos de la fístula, en más de una ocasión empezó a llorar recordando su pasado, todos los años que vivió escondida, sin contarle a su marido lo que le estaba pasando. Vive en Wukro, el pueblo al que iba a pasar los fines de semana durante mi estancia en Mekelle porque disfrutaba visitando a las amistades que, desde hace dos años, tengo allí. El fin de semana de Semana Santa coincidió que me encontraba en Wukro y fui a visitar a Takien. Me invitaron a quedarme y a compartir con la familia el ritual del sábado de Pascua, en el que su marido mató una gallina para celebrar el domingo de Pascua. Cuando una familia mata una gallina significa que su clase social es baja, una familia rica, al contrario, mata un cordero. Tanto las hijas como ella se ocuparon de desplumar la gallina y cocinarla y de a hacer el pan durante toda la noche. Pasé el día entero en su casa, bebiendo, comiendo y celebrando ese día festivo.

Vivencias de miedo al abandono y también de vergüenza parecían en los relatos que Ascual compartió conmigo:

"Nunca conté nada a nadie hasta que fui a una clínica y me dieron las infusiones como tratamiento de la fistula. No les dije nada a mis hijos e hijas ni a mi marido. Me daba mucha vergüenza... Hasta que un día encontré a la presidenta de mi pueblo, Berhane, y contacté con ODWACE. Les expliqué mi problema. Nunca conté a mi marido sobre lo que me pasaba, tenía miedo de que se divorciara de mí. Se hubiera divorciado de mí y se hubiera marchado con otra mujer".

Ascual, de cuarenta años, es una mujer vital, muy alegre, comprometida para que otras mujeres no pasen por lo mismo, expresa abiertamente lo que piensa. Me admitió que en la sociedad etíope hay tabúes acerca de la sexualidad femenina. Me contó que su madre nunca le habló sobre la menstruación, incluso cuando le bajó la regla por primera vez no le quiso explicar lo que le estaba sucediendo y qué hacer. Sin embargo, Ascual me reconoció que ella nunca hará lo mismo con su hija; aunque todavía es una niña ya le hablaba con naturalidad sobre estos temas. Mientras me contaba esto, la hija volvió del colegio, se sentó en el suelo y 
discretamente se reía escuchando a su madre. Compartió conmigo que este cambio en la educación de su hija se había producido después de la intervención.

En referencia a su infancia, me contó que su familia la obligó a casarse con un hombre diez años mayor y que tuvo tres hijos y una hija. Un jueves, día de mercado, la acompañamos a hacer las compras. Ascual nos explicó que el mercado era una parte importante de su vida social, el lugar donde se encontraba con muchas de sus vecinas y vecinos, disfrutaba charlando un rato y enterándose de lo que sucedía en el pueblo. Me comentó que durante los quince años que vivió con la fístula iba al mercado pero deprisa y corriendo, evitaba así que sospecharan de su problema porque era consciente que desprendía mal olor. Las vivencias de Ascual son un claro ejemplo sobre los condicionantes derivados de la fístula. Estas mujeres no pueden disfrutar de sus relaciones sociales en los espacios públicos ni tampoco en los privados, en sus propias casas. Además, el miedo que sienten ante la posibilidad de ser descubiertas dificulta el poder hablar entre ellas sobre la fístula. Todas las mujeres sienten este miedo hasta que llegan al Hospital, lugar o espacio que por primera vez siente como seguro, espacio donde pueden discutir libremente y compartir sus experiencias, y darse cuenta que no son las únicas con esta problemática. Por esta razón, cuando hablaba con estas mujeres sobre su permanencia en el Hospital, ello les evocaba tan buenos recuerdos que no podían evitar empezar a llorar..., después de tantos años escondidas por la fístula, era el primer espacio donde se sentían seguras.

Ambas, Ascual y Takien, también compartieron conmigo cómo sintieron miedo a que otras personas detectasen que perdían orina. Takien nunca contó la verdad a su marido sobre la fístula y todavía hoy, después de un año de haber sido operada, sigue hablando de este tema con miedo. No quiere que nadie sepa lo que le sucedió, incluso durante la entrevista, como nos encontrábamos a unos quince metros de la entrada de su casa, hablaba bajito y, de vez en cuando, miraba nerviosa hacia su casa, buscaba asegurarse de que nadie viniese de sorpresa y escuchara la conversación que teníamos. A su vez, Ascual relata que el día que se marchó al hospital, a Mekelle, para que el doctor que trabaja en el Hospital Hamlin Fístula le hiciera la revisión ginecológica, fue la primera vez que habló de su problema, nunca antes le contó a su marido. El mismo día que volvió de Mekelle, con la fecha de la operación concertada, le contó a su marido lo que le pasaba. No obstante, tanto Takien como Ascual manifestaron el miedo a que sus maridos al enterarse de su problema de salud decidieran abandonarlas.

Contrariamente a lo defendido por algunas autoras y autores, los maridos de las mujeres entrevistadas no las han abandonado a causa de la fístula, excepto en dos casos, Gidey y 
Hatsed. Sin embargo, teniendo en cuenta las aportaciones tanto Carlos Figari como de Martha Nussbaum, podemos entender el miedo a ser abandonadas por sus maridos o el miedo y vergüenza en caso de ser "descubiertas" por el vecindario y que tantas veces ha sido mencionado por la mayoría de las entrevistadas. Sus contribuciones, a mi juicio, explican con acierto las vivencias personales explicitadas por algunas de ellas en base al concepto de la repugnancia hacia los cuerpos. Esto es, la repugnancia a los cuerpos de las mujeres por su incontinencia urinaria y de heces. Según la filósofa Martha Nussbaum, los flujos o los desechos de los cuerpos se convierten en materia repugnante y asquerosa, denominada como peligrosa o contaminante para las personas que estén en contacto (Nussbaum, 2006: 108, 112 y 124). Por esta razón, como explica Carlos Figari (2009), la repugnancia de los cuerpos está asociada con la parte animal de las personas y con connotaciones negativas de oler mal. Como resultado, los cuerpos que huelen a orina y heces deberán ser marginados o excluidos de la vida social.

Gidey me relató que ambos padres varones concertaron su boda cuando ella tenía sólo trece años, su marido era quince años mayor. Al poco tiempo de casarse quedó embarazada. Relata el abandono por parte de su marido en los términos siguientes:

"El casamiento fue acordado por las dos familias, yo era muy joven para entender lo que estaba pasando. El primer embarazo me produjo la fístula, el bebé murió porque tuve un parto prolongado. Inmediatamente, cuando mi primer marido supo lo que me sucedía, se divorció de mi”".

Gidey es una mujer de veintiocho años, un poco tímida pero muy cariñosa. La casaron cuando sólo tenía trece años con un hombre bastante mayor que ella quien se marchó de su lado cuando se enteró de su problema de salud. Algunos años más tarde volvió a casarse y tuvo dos hijos. Nuevamente se separó y retomó la relación con su primer marido. Percibí que estaba muy satisfecha y contenta de sus decisiones.

La historia de Hatsed es algo diferente. Esta joven de veintitrés años reiteradamente me insistía que fue ella quien tomó la decisión de divorciarse de su primer marido. En este caso, al igual que en el caso de las otras once mujeres entrevistadas, el primer matrimonio fue concertado entre los varones de ambas familias cuando tenía dieciséis años con un hombre once años mayor que ella. En todas las situaciones que Hatsed se refería a su primer marido aparecían expresiones de sentimientos de rencor. También ella pasó por la experiencia de un parto prolongado de tres días cuando tenía diecisiete años. Este parto fue el origen de su fístula. Ella me relató que su decisión de divorciarse fue debido a la fístula: 
"Cuando volví del hospital me fui a casa de mi hermana. El médico me dijo que no podía mantener relaciones sexuales en seis meses y que después de ese tiempo debía empezar a utilizar métodos anticonceptivos durante dos años porque era peligroso para mi salud quedarme nuevamente embarazada. Estaba muy preocupada por mi marido, ¿cómo no puede mi marido tener relaciones sexuales en seis meses y ningún hijo o hija en dos años? La solución era divorciarme de él'".

El caso de Hatsed pone en evidencia los roles culturales en Etiopía, a través de ellos se trasmite y se subraya hasta la saciedad que si una mujer no puede tener hijas o hijos no es una mujer de verdad, no es una mujer completa. El futuro de la gran mayoría de las mujeres es ser esposa y madre. Por tanto, aunque Hatsed está convencida que la decisión de divorciarse de su marido fue suya, sin embargo, refleja también el peso que tuvo en su decisión el hecho de no poder responder a las obligaciones como esposa ni como madre durante dos años. En el relato de Hatsed el papel de la cultura etíope queda nítidamente reflejado en la pregunta que se hace así misma: ¿cómo no podía tener relaciones sexuales mi marido durante seis meses y ningún hijo o hija durante dos años?

Y es debido a estos mandatos de la cultura etíope que Hatsed tomó la decisión de separarse, no podía tener relaciones sexuales, quedarse embarazada y darle un o una descendiente a su marido durante un determinado tiempo.

Otro aspecto importante y extendido a tener en cuenta en la sociedad rural de Etiopía, del cual se derivan consecuencias nefastas para las mujeres que sufren de fístula, es la creencia de que la fístula es el resultado de un comportamiento no adecuado por parte de las mujeres, esto es, porque han sido infieles a sus maridos, por sus actitudes y comportamientos poco respetuosos con las personas mayores, por haber sentido envidia, etc., o, en caso de no poder tener hijas o hijos, se debe a que Dios las está castigando, o por algún maleficio o mal de ojo. Además, en algunas comunidades rurales se percibe la fístula como un indicador de "mujer blanda", débil, que no ha cumplido con su deber de esposa-madre debidamente y por lo tanto será castigada, en vez de ver como una lesión provocada por un parto prolongado.

He encontrado con frecuencia este tipo de valoraciones en las entrevistas realizadas. Es un discurso que está arraigado entre personas de mayor edad. Generalmente, las mujeres más jóvenes, aunque carezcan de información, asocian la fístula con el parto prolongado y por no haber acudido a un centro hospitalario para dar a luz. Sin embargo, las de mayor edad continúan relacionándola con un castigo de Dios (Donnay y Ramsey, 2006:257). 
Ejemplo de esta creencia es el caso de Letekiros, de cuarenta años, que asoció con total certeza su fístula a un castigo divino:

"Inmediatamente cuando me di cuenta de lo que me pasaba, pensé que era un castigo de Dios. Una vecina me explicó que no era así, que lo que me sucedía era porque el bebé había muerto en mi vientre causándome la fístula. Aún así, en ese momento no la creí, seguí pensando que era un castigo".

Letekiros creyó durante mucho tiempo que su problema de salud era una "señal" por su mal comportamiento, las explicaciones de la vecina no eran creíbles. Para Letekiros, este mal comportamiento estaba relacionado con la pérdida del bebe durante el parto prolongado. A la hora de la entrevista, ya operada y formada en cuestiones relativas a la fístula, ya tenía claro que no se debía a un castigo divino, sino consecuencia de un parto prolongado.

Pero también la familia de Hailu estaba convencida de que el perder el bebé en el parto respondía a un castigo. Hailu relató esta vivencia en los términos siguientes:

"Mi familia se puso muy triste cuando se enteró. Toda la familia pensaba que era un castigo y no podían creer que la fístula tuviese tratamiento. Pensaron que era un castigo porque yo era responsable de la pérdida del bebe".

Hailu es una chica de veintiséis años, muy inteligente y alegre, siempre me recibía sonriente y cariñosamente me abrazaba. Me contó que su padre y su madre antes de casarse le preguntaron si le parecía adecuado el hombre que habían elegido para ella. Su primer embarazo fue cuando tenía veinte años y fue el segundo parto el que le produjo la fístula. El primer día que conocí a Hailu, era Jueves Santo, estaba muy contenta ese día porque en la cultura etíope Viernes Santo es un día muy señalado. Pasan el día y la noche rezando, horas y horas arrodillándose y levantándose, es la manera de pedir perdón y de demostrar arrepentimiento por todos los actos sancionados por su religión. Incluso al día siguiente un tema de conversación es sobre el número de genuflexiones y cuánto han durado. Hailu nos invitó a que la acompañáramos a la misa de Viernes Santo. Estuvimos casi dos horas en misa, lo que más me llamó la atención fue que casi todas las personas iban vestidas con sus trajes tradicionales blancos impolutos, con sus mejores joyas (en la cabeza, pendientes, anillos y llamativas pulseras) y perfumadas. Apenas había nadie ni circulación en la calle principal, todo el mundo se encontraba dentro de la iglesia rezando o fuera conversando. La iglesia era sencilla y amplia por dentro y en su exterior, a un lado de la entrada principal, se encontraba un cementerio antiguo, donde me dio la impresión de que las tumbas de cemento estaban 
muy descuidadas, los cactus se habían adueñado de ese espacio. No encontré a nadie que me explicara por qué varias tumbas se encontraban tapadas con mantas de rayas ajadas por el sol y la lluvia...

Al igual que Letekiros y Hailu, la familia de Gidey pensó también que su fístula era debido a un castigo o a un mal de ojo, incluso ella misma estaba de acuerdo con estas creencias. Cuando su padre empezó a preguntar en la vecindad si había alguna mujer que tenía ese problema, es cuando la familia de Gidey, y la propia Gidey, se dieron cuenta que no se debía a un castigo divino o a un mal de ojo:

“Al principio estaba muy confundida, pensé al igual que mi familia que estaba maldita, hasta que mi padre averiguó que era un problema físico y que se podía tratar".

Resulta interesante comprobar la relación que establecen, o está presente en algunos de los relatos de estas mujeres, entre la recuperación de la salud y las creencias religiosas. Por ejemplo, la familia de Letekiros y personas cercanas del vecindario se referían al ginecólogo del Hospital Hamlin de Mekelle como "Dios". Este profesional era considerado como una persona con poderes divinos que podía devolver a Letekiros a la vida "normal". Letekiros me lo explicó en los siguientes términos:

“Después de la operación me encontraba bien otra vez, era capaz de andar y estar de vuelta con la familia, otra vez gracias al gobierno (de Etiopía) y a Dios. Mis vecinos y vecinas decían que en Mekelle existía un Dios que curaba a las mujeres, el Dr. Melaku (ginecólogo de Mekelle Hamlin Fistula Center)".

Abundando en esta misma línea de pensamiento, la tradición local defiende que las mujeres (las madres, las abuelas, las bisabuelas) siempre han dado a luz en su casa y se subraya la importancia de dar a luz en casa porque así se garantiza, como se ha indicado más arriba, que después del parto la madre podrá ingerir el "porridge" (especie de papilla elaborada con diferentes tipos de cereales). Esta papilla evita que el diablo le eche el mal de ojo a la madre y al recién nacido. Es por esta razón que el Grupo de Mujeres para el Desarrollo ha puesto en marcha la iniciativa de distribuir cereales, harina y dinero en los centros de salud con el fin de garantizar el "porridge" a las mujeres inmediatamente después de dar a luz.

Otra tradición extendida y perjudicial para la salud de las mujeres embarazadas es la prohibición de la ingesta de determinados alimentos durante el embarazo. Entre los productos prohibidos, ordenados de mayor a menor prohibición, son: leche y productos lácteos, verduras, carne y pescados, fruta, huevos y miel (EGELDAM, 2011:40). Estas restricciones 
se defienden en base a que es mejor para su salud (EGELDAM, 2008:138). La malnutrición de las mujeres embarazadas afecta directamente en posteriores fístulas, puesto que conlleva a que su peso esté por debajo de la media, se encuentran debilitadas y el riesgo de padecer un parto prolongado es mayor (Ahmed y Holtz, 2007:S11).

En cuanto a la permanencia en el Mekelle Hamlin Fistula Center, la estancia mínima es de tres semanas a un mes y medio para el pre-operatorio y post-operatorio, aunque la duración del ingreso va a depender de la gravedad de la fístula. En cuanto las mujeres llegan al hospital se les facilitan ropas nuevas y queman las que traen consigo, a modo de acto simbólico de "dejar atrás el pasado". El hospital también ofrece un programa de prevención y reintegración para las mujeres intervenidas quirúrgicamente.

Cuando las mujeres entrevistadas relataban su estancia en el hospital (personas que conocieron, experiencias vividas, historias compartidas, atención recibida, etc.), a más de una le saltaban las lágrimas y se quedaban un largo tiempo en silencio, pensando. Para todas ellas las experiencias en el hospital fueron vivencias inolvidables. Contaban maravillas sobre el hospital: la limpieza, espacios acogedores, la disponibilidad de duchas y baños, etc. También del tratamiento recibido por parte de las enfermeras y médicos. A raíz del ingreso en el hospital, descubrieron vivencias personales vitales: sentir que no eran las únicas que no podían contener la orina, que su problema era similar al de otras mujeres, sentirse comprendidas por "mujeres desconocidas" pero que eran iguales, compartir temas que nunca antes habían podido hablar con nadie...

Takien, de treinta y tres años, cuando le pregunté acerca de su estancia en el hospital, las experiencias vividas allí, describió con mucho cariño y nostálgica:

“Cuando estaba en casa con este problema, pasaba las veinticuatro horas llorando, preguntándome, ¿por qué me pasaba a mí esto? ¿Qué podía hacer? Pero cuando llegué al hospital empecé a reírme y a divertirme otra vez porque vi que no era solo un problema mío, sino que muchas mujeres estaban en la misma situación en la que yo me encontraba!"

También Berhane compartió conmigo comentarios similares a los de Takien:

"Hasta llegar al hospital pensaba que era la única que tenía este problema, pero una vez alli vi tantas mujeres como yo o con problemas peores, pude entender que no era la única". 
Berhane es una mujer de cincuenta años, aunque aparenta ser mucho mayor por la cantidad de arrugas que tiene en la cara y en las manos, y porque camina un poco encorvada. Es una mujer de clase social humilde, muy tímida y entrevistarla no fue fácil, le costaba mucho hablar sobre temas personales y cada vez que recordaba su pasado empezaba a llorar... Es una de las mujeres que cuando le ofrecí el kilo de café en agradecimiento quiso besarme los pies como es costumbre entre la gente mayor en Etiopía. Rápidamente, cuando me di cuenta de lo que iba a hacer, la levanté agarrándole de los brazos, nos dimos un abrazo y tres besos en las mejillas. Berhane vive a unos veinte kilómetros de Mekelle, pero no hay carretera para llegar a su aldea. Vive con sus dos hijas y un hijo, el cuarto hijo está casado.

La casaron con el que hoy es su ex marido cuando tenía diecisiete años y admitió que hasta el día de su boda no sabía con quién se iba a casar. Vive en una casa muy humilde, como casi todas las familias. Dispone de una habitación para hacer la vida familiar: dormir, cocinar, comer o para las ceremonias del café. El suelo del cuarto es de tierra, tiene pocos utensilios de cocina, y los pocos muebles que hay son sencillos y básicos. Me contó que en la aldea donde vive no disponen de ningún pozo de agua; el pozo más cercano se encuentra a unos cuarenta y cinco minutos andando. Cuando le pregunté si no sería mejor tener un pozo en la misma aldea, para mi sorpresa me contestó que no, que para ella era mejor así, porque en esa hora y media podía caminar con sus amigas y charlar tranquilamente sobre sus cosas. Me dijo que le encantaba poder hacerlo, que era una excusa para ponerse al día de las cosas que pasaban. La verdad es que nunca me hubiera esperado esta contestación, puesto que desde mi punto de vista el hecho de tener que ir a por agua cada dos días a tan larga distancia supone un suplicio. Sin embargo, para Berhane era una actividad socializadora y que disfruta muchísimo.

Y Letekiros me resumió sus vivencias en el hospital con las siguientes palabras:

"Pudimos compartir muchas cosas entre nosotras, hablábamos de todo. De nuestros maridos también (empezó a reírse), algunos maridos sí eran buenos, pero otros no tanto... Algunas comentaban que también sus maridos se habían divorciado de ellas a raíz de la fistula".

La estancia en el hospital fue un episodio muy importante en las vidas de estas mujeres, no sólo porque se produce una "reparación física", sino porque establecen relaciones muy especiales con otras mujeres, comparten vivencias íntimas, hablan abiertamente sobre los problemas que han tenido, de sus maridos, de sus relaciones sexuales, de sus vidas en las aldeas, etc. Se apoyan y crean un ambiente seguro, de empatía y de sincera amistad. 
Una vez intervenidas quirúrgicamente y dadas de alta en el hospital, la reintegración social representa otra fase no exenta de problemas, debido a que entre sus objetivos está la búsqueda de la independencia económica o el empoderamiento económico. En el estado regional de Tigray, existen diferentes organizaciones que trabajan en la reintegración social. Por una parte, la ONG local ODWACE apoya económicamente para el transporte y también facilita el acceso a micropréstamos para emprender pequeños negocios o actividades agropecuarias. También existe una fundación extranjera, Healing Hands of Joy, que facilita formación de formadoras para que las mujeres que han sido intervenidas de la fístula sean agentes de cambio mediante la prevención y sensibilización de la ciudadanía en cuestiones relativas a este problema de salud y para que las mujeres embarazadas acudan a un centro hospitalario para dar a luz. Asimismo, desde esta fundación se posibilita el acceso a micropréstamos. Es de resaltar que muchas de ellas manifestaban motivación e interés por volver a la escuela o emprender pequeños negocios a su regreso a sus hogares (Ahmed y Holtz 2007:S14).

Casi todas las entrevistadas han recibido tanto de la ONG local ODWACE como de la Fundación Healing Hands of Joy micropréstamos para empezar una nueva vida, lo que es valorado positivamente desde su punto de vista. Estos micropréstamos les posibilitan poner en marcha un pequeña tienda, comprar semillas para cultivar la tierra o comprar animales (cabras, gallinas, ovejas principalmente) para su engorde y posterior venta.

En Etiopía, el Plan de Crecimiento y Transformación (2010/11-2014/15) y el Programa de Desarrollo Económico Local se conectan a través de pequeñas empresas a micro escala, cooperativas y otras asociaciones. El Programa de Desarrollo Económico Local pretende impulsar un funcionamiento eficiente de las economías locales. Por ello, los micropréstamos de ambas organizaciones se alinean directamente con los esfuerzos del citado Plan de Crecimiento y Transformación que plantea la provisión de micropréstamos a modo de estrategia para el desarrollo local, la sostenibilidad de los pequeños negocios, con el fin de contribuir a la reducción de las tasas de pobreza. Del mismo modo Asemelash (2003) sostiene que los micropréstamos facilitados por las microfinancieras, además de incrementar los ingresos de las personas pobres, les ayuda a poder enviar a sus hijas e hijos a mejores escuelas, en caso de enfermedad a poder llevarlos a centros médicos, a hacer mejoras en la vivienda y a aumentar el consumo de estas familias.

No obstante, algunas manifestaron la necesidad de más ayudas económicas y mayores posibilidades para la educación y la formación. También en esta línea las autoras Ahmed y 
Holtz defienden que no es suficiente con proporcionarles recursos económicos sino también se requiere trabajar con ellas para que conozcan cuestiones relativas a derechos humanos y justicia social. Y subrayan: "hay que mejorar la vida social y económica de las mujeres con fistula, no solamente desde programas de salud pública y perspectivas humanitarias en el nombre de la justicia social, también con los derechos reproductivos" (Ahmed y Holtz 2007:S15).

En términos generales, el estado regional de Tigray ha realizado importantes esfuerzos durante los últimos años gracias a compromisos políticos y, sobre todo, al papel tan relevante que desempeñan los Grupos de Mujeres para el Desarrollo en las zonas rurales. Sus pilares fundamentales de trabajo son: mejorar la salud materna y reducir la mortalidad materna a través de la planificación familiar, atención prenatal, partos en centros hospitalarios y cuidados post natales.

Finalmente, desde el punto de vista de las mujeres entrevistadas, es importante terminar con la exclusión social derivada de la percepción errónea sobre la fístula por parte de la ciudadanía en general y de las mujeres en particular. Lo cual requiere impulsar programas de prevención y sensibilización sobre los efectos negativos y dañinos de los matrimonios a edades tempranas y la concienciación de las mujeres y de la comunidad para que los partos sean atendidos por profesionales formados y en centros hospitalarios.

En opinión de Ascual, cuando le pregunto sobre programas de prevención que existen en su aldea me cuenta que:

“Ahora tenemos programas de prevención en las comunidades, especialmente gracias al trabajo del Grupo de Mujeres para el Desarrollo. Más o menos cada dos semanas nos juntamos y hablamos sobre los problemas que nos afectan a las mujeres y sobre la fistula”.

“Tenemos que educar a la comunidad, porque la fístula no es un castigo de Dios, es un problema de salud y por esta razón no podemos ser rechazadas por la comunidad y por la familia. A cualquier mujer le puede suceder y, por lo tanto, hay que ayudar a estas mujeres y que no sean rechazadas".

Según su opinión, existe la necesidad de informar y sensibilizar a la juventud sobre el problema de la fístula, derechos humanos, derechos fundamentales de las mujeres, etc., con el fin de cambiar, paulatinamente, la mentalidad de las personas. Esta se encuentra fuertemente influenciada por tradiciones y creencias religiosas las cuales tienen efectos negativos en el 
abordaje de las causas y consecuencias de la fístula obstétrica.

A modo de resumen, considero importante remarcar que todas las mujeres que he entrevistado tuvieron partos complicados a la edad de quince y dieciséis años, cuando todavía eran niñas y sus cuerpos no estaban desarrollados para poder tener un bebé. En opinión de algunas de estas mujeres, entre los motivos que les impidió buscar ayuda fueron el pensar que sólo ellas no controlaban la orina y olían mal, y consecuentemente lo mejor era quedarse encerradas en casa por el miedo a que sus maridos y vecindario se dieran cuenta de su problema. Contrariamente a lo defendido por algunas autoras y autores, los maridos de las mujeres entrevistadas no les han abandonado a causa de la fístula, aunque la exclusión social tuvo connotaciones devastadoras porque se convierten en personas socialmente invisibles y olvidadas (Cook; Dickens y Syed, 2004:74). El miedo a ser abandonadas por sus maridos y a que el vecindario hablase mal de ellas era tan fuerte que algunas mujeres optaron por no contar a nadie lo que les sucedía durante años. La repugnancia hacia los cuerpos de las mujeres por su incontinencia urinaria y de heces, por ser desechos de los cuerpos se convierten en materia repugnante, peligrosa o contaminante (Nussbaum, 2006: 108, 112 y 124). La fístula, en opinión de las mujeres de mayor edad, se explica a modo de castigo divino, debido a algún maleficio o mal de ojo por no ser "buenas mujeres", sin embargo, las mujeres más jóvenes, aunque carezcan de información, asocian la fístula con el parto prolongado. La curación, desde el punto de vista de algunas mujeres, también es obra del médico que es considerado como un Dios. Para todas ellas la permanencia en el hospital fue una experiencia inolvidable y se les saltaban las lágrimas al recordarlo. Allí tuvieron, vivencias personales vitales significativas y positivas como sentirse que no eran las únicas que no podían contener la orina, que su problema era similar al de otras mujeres, sentirse comprendidas por "mujeres desconocidas", etc. Casi todas las mujeres entrevistadas han accedido a micropréstamos para poner en marcha un pequeña tienda, comprar semillas para cultivar la tierra o comprar de animales (cabras, gallinas, ovejas principalmente) para su engorde y posterior venta, todas ellas valoraban positivamente esta iniciativa. No obstante, algunas relataron que todavía sufren consecuencias psicológicas derivadas de la fístula; problemas psicológicos como depresión, ansiedad, psicosis y desórdenes post traumáticos son realidades recogidas en un informe publicado por el Mekelle Hamlin Fistula Center (2012).

Estas mujeres están trabajando en la prevención de la fístula en sus comunidades, también proponen que sería una buena idea poder trabajar en las escuelas, ya que la educación pública debería tratar estos temas sociales. 


\section{Conclusiones}

En el trabajo titulado "Etiopía, historias de vida de mujeres tigriñas: causas y consecuencias de la fistula obstétrica" he intentado rescatar las vivencias de las mujeres que han sufrido la problemática de la fístula para poder compartir y visibilizar en el ámbito académico y en otros espacios públicos sus experiencias. Por esta razón he llevado a cabo un trabajo de campo etnográfico, con entrevistas y observación participante, con el fin de indagar sobre sus diferentes realidades así como sobre sus vidas en torno a la fístula. En total he realizado catorce entrevistas, una de ellas con la directora regional de la organización sin ánimo de lucro ODWACE y trece entrevistas a mujeres de zonas rurales que han sido tratadas en el Addis Ababa Fistula Hospital o en el de Mekelle.

Las entrevistadas viven en las zonas rurales del estado regional de Tigray, en pequeñas aldeas (kebeles) a las que se trasladaron cuando contrajeron matrimonio. Sus edades oscilan entre veintitrés, la más joven, y cincuenta años, la de mayor edad. La edad de casamiento de estas mujeres varía entre trece y veinte años. No obstante, a la edad de trece años sólo contrajo matrimonio una de ellas, mientras que el resto de las mujeres fueron casadas siendo todavía menores de dieciocho. En todos los casos, excepto en uno, los matrimonios fueron acordados por los padres varones de las hijas. A su vez, la edad del primer embarazo varía entre los quince y veinticuatro años.

En términos generales, la fístula se considera solamente como un problema médico y en pocas ocasiones se presta atención y se exploran otras cuestiones que van más allá de la perspectiva de la medicina. Afortunadamente, desde la perspectiva antropológica médica, como argumentan Merrill Singer y Hans Baer (2007), este problema es el resultado de determinadas condiciones sociales que perjudican la salud de las mujeres. Como he expuesto a lo largo del trabajo, estas condiciones sociales están relacionadas con decisiones ante situaciones como el derecho a decidir dónde parir, quién asiste en el parto, cuándo casarse, con quién casarse, etc.

En este trabajo he revisado alguna de las leyes y acuerdos nacionales e internacionales firmados por el gobierno de Etiopía sobre los derechos de las mujeres y que están vigentes; sin embargo, su aplicación es lenta, así como el cambio de mentalidad de la ciudadanía. Es de destacar que el gobierno está haciendo esfuerzos importantes, aunque todavía tiene problemas para llegar a cumplir plenamente los acuerdos firmados. También encuentra obstáculos para alcanzar los ocho Objetivos del Milenio para el 2015, lo que es un tema de gran preocupación para el gobierno etíope. 
Una de las causas directas de la fístula son los matrimonios a edades tempranas que implican que estas mujeres tengan embarazos a edades tempranas que hoy en día se siguen permitiendo y responden normalmente a acuerdos entre los padres varones de ambas familias. Estas realidades son actos de violencia o una privación de la libertad de las mujeres y niñas etíopes. Casi todas las mujeres entrevistadas tuvieron que casarse antes de los dieciocho años para cumplir así su rol de mujeres, esposa-madre, lo que trajo consigo que estas jóvenes abandonasen sus estudios. En estos casos no se han respetado derechos universales de las mujeres y niñas, no han podido ejercer el derecho a decidir sobre el matrimonio, si desean o no tener hijas e hijos, el número de hijas e hijos que desean tener, cuándo tenerlos, etc.

El cuerpo de las mujeres y de las niñas está expuesto a muchos tipos de violencia y esto dificulta el acceso a la educación y a la libertad de expresión según la filósofa estadounidense Martha Nussbaum (2006). Según se observa, hay distintas formas de violencia, algunas de ellas son visibles y otras no. Por ejemplo, las mujeres que sufren la fístula están sometidas a una violencia contra sus cuerpos y a consecuencia de ella son excluidas y escondidas de la sociedad. Es una violencia emocional y social continuada hacia ellas, que las priva de la libertad de tener una vida "normal".

La gran aportación desde la antropología médica es ir más allá de explicaciones biologicistas de la fístula. La antropóloga Mari Luz Esteban (2007), defiende que la enfermedad no está exclusivamente determinada biológicamente, sino que tenemos que superar este discurso y tomar en cuenta factores sociales, culturales, ambientales, creencias y tradiciones así como las estructuras de las relaciones sociales de cada cultura o sociedad. En los discursos de las mujeres entrevistadas he podido constatar que las creencias, religión, tradiciones culturales y las relaciones de poder son factores que han jugado un papel relevante en sus experiencias de vida. Por poner un ejemplo, las mujeres con mayor edad pensaban que la fístula había sido un castigo de Dios, que habían hecho algo mal y que por eso estaban siendo castigadas. Entre las más jóvenes, este discurso no tiene tanta fuerza, ya que son conscientes de que la fístula es consecuencia de un parto prolongado.

Según Carlos Figari (2009), la repugnancia o el asco hacia los cuerpos de las mujeres es un factor clave para ejercer violencia y excluir los cuerpos de las mujeres que sufren de fístula. Las personas cercanas experimentan cierto miedo porque piensan que pueden ser contaminadas si se ponen en contacto directo con ellas. Estos tipos de rechazo, de asco y de repugnancia, se encuentran asociados con lo que consideramos asqueroso. Puesto que todo 
aquello que huele mal y nos aterra tendemos a excluirlo del plano social a modo de mecanismo para la "no contaminación". A su vez, Martha Nussbaum (2006) plantea que la materia que expulsa el cuerpo de las personas (orina, heces, sudor, mensuración, etc.) es materia marginal, contaminante y peligrosa. Este planteamiento teórico explicaría el miedo, rechazo y exclusión social de las mujeres que sufren de fístula. La incontinencia urinaria y en algunas ocasiones de heces implica no tener control de estas materias por sus cuerpos, por ello estas mujeres son castigadas socialmente, excluyéndolas de sus vidas cotidianas para que no contaminen a personas cercanas. En definitiva, esta repugnancia a los cuerpos de las mujeres afectadas podríamos considerarla como un arma de exclusión social hacia las personas que no se ajustan y no cumplen los parámetros estandarizados y normativos de las sociedades como es el caso de las mujeres que sufren de fístula.

El discurso dominante basado en la tradición y religión también apoya y refuerza esta exclusión trasmitiendo que la fístula es un castigo por no haber cumplido adecuadamente el rol establecido de esposa y madre. Esta opinión está extendida entre las mujeres de mayor edad que he entrevistado. Muchas veces se culpan a ellas mismas de su problemática de salud diciendo que están siendo castigadas por Dios porque han hecho mal algunas cosas.

Dado que una de las finalidades de esta investigación era identificar puntos débiles en los procesos de reintegración de las mujeres que han sido tratadas de fístula, he observado que la preocupación central de las mujeres entrevistadas es la falta de educación de la ciudadanía sobre este problema de salud. Manifiestan reiteradamente este vacío de información y sensibilización tanto en los centros escolares como a nivel de comunidad.

Después de haberlas escuchado y de haber reflexionado sobre sus inquietudes, y también con las profesionales de la Asociación de Mujeres de Tigray, creo que sería interesante diseñar un proyecto de intervención (talleres de formación y sensibilización) dirigido al alumnado de bachillerato en torno a derechos de las mujeres y especialmente sobre derechos sexuales y reproductivos, incluyendo también cuestiones relativas a la no discriminación de las mujeres que sufren de fístula obstétrica y prolapso uterino, y facilitando información sobre recursos de atención.

A través de esta sensibilización y formación en el ámbito escolar se conseguiría que la juventud fuera más responsable ante problemas médico-sociales de esta índole. A partir del conocimiento de sus derechos en general y también de sus derechos sexuales y reproductivos, las mujeres podrían ejercitarlos y exigir que los mismos sean respetados por el resto de la sociedad. 


\section{Bibliografía}

Ahmed, Sarah y Holtz, S.A (2007). Social and economic consequences of obstetric fístula: life changed forever? International Journal of Gynecology and Obstetrics 99(1) p. S10S15.

Biadgilign, Sibhatu, Lakew, Yihunie, Reda, Ayalu y Deribe, Kebede (2013). A population based survey in Ethiopia using questionnaire as proxy to estimate obstetric fístula prevalence: results from demographic and health survey. Reproductive Health, Addis Ababa, Ethiopia.

CEDAW (2011). Observaciones finales del Comité para la Eliminación de la Discriminación contra la Mujer. Naciones Unidas. En: http://www.un.org/womenwatch/daw/cedaw/cedaw36/cc/chile/0647950S.pdf

Central Statistical Agency (2010). Population and Housing Census Report- Tigray Region 2007. Addis Ababa, Ethiopia.

Cook, Rebbeca; Dickens, Bernard y Syed, S. (2004). Obstetric fistula: the challenge to human rights. International Journal of Gynecology and Obstetrics 87, p. 72-77.

Crenshaw, Kimberlé (1991). Mapping the margins: Intersectionality, Identity Politics, and Violence against women of colour, Stanford Law Review, Vol. 43, p.1241-1299.

Crenshaw, Kimberlé. (2005). Intersectionality and identity politics: learning from violence against women of color. In W. Kolmar \& F. Bartkowski (Eds), Feminist theory. New York: McGraw-Hill, p. 533-542.

Crenshaw, Kimberlé (1989). Demarginalizing the Intersection of Race and Sex: A Black Feminist Critique of Antidiscrimination Doctrine, Feminist Theory and Antiracist Politics. The Univeristy of Chicago Legal Forum, p.139-167.

Donnay, France y Ramsey, K. (2006). Eliminating obstetric fístula: Progress in partnerships. International Journal of Gynecology and Obstetrics, 94(3), UNFPA, Islamabad, Pakistan and UNFPA, New York, USA, p. 254-261.

EGELDAM (2011). Survey on Harmful Traditional Practices in Ethiopia. Addis Ababa, Ethiopia, EGELDAM.

EGELDAM (2008). Follow up National Survey on the Harmful Traditional Practices in Ethiopia. Addis Ababa, Ethiopia, EGELDAM

Espinosa Spínola, María (2010). Mi banda, mi hogar. Resignificando la infancia a partir de los niños y niñas de la calle de la Ciudad de México. Tesis doctoral, Universidad de Granada.

Esteban, Mari Luz (2007). Antropología, sistema médico-científico y desigualdades de género en la salud. En Esteban, Mari Luz (ed.), Introducción a la Antropología de la 
Salud. Aplicaciones teóricas y prácticas. OSALDE (Asociación por el derecho a la salud). Bilbao.

Federal Democratic Republic of Ethiopia (2000). The Revised Family Code. Federal Negarit Gazetta of the Federal Democratic of Ethiopia, Addis Ababa, Ethiopia No 213/200.

Figari, Carlos (2009). Las emociones de lo abyecto: repugnancia e indignación. En Figari, Carlos y Scribano, Adrián “Cuerpo(s), Subjetividad(es) y Conflicto(s), hacia una sociología de los cuerpos y las emociones desde Latinoamérica, Buenos Aires, Argentina, Ediciones CICCUS, p. 131-139.

Gregorio Gil, Carmen (2012) Tensiones conceptuales en la relación entre género y migraciones. Reflexiones desde la etnografía y la crítica feminista. Revista de sociología $97(3)$, p. 569-590

- (2006) Contribuciones feministas a problemas epistemológicos de la disciplina antropológica: Representación y relaciones de poder. Revista de Antropología Iberoamericana, 1(1) p. 22-39.

Haraway, Donna (1988). Situated Knowledges: The Science Question In Feminism and the Privilege of Partial Perspective. Feminist Studies 14(3), p. 575-599.

Harding, Sandra (1993). Rethinking Standpoint Epistemology: What is "Strong Objectivity". En L. Alcoff \& E.Potter (Eds.), Feminist Epistemologies. Routledge, p. 49-82.

Kibret, Samuel (2011). Violence against Reproductive Rights of Women in Rift Valley Region of Ethiopia. VDM Verlag Dr. Muller GmbH \& Co. U.K.

Lasala, Antonio (2010). Enfermedad y Pecado. En Martorell, María Antonia; Comelles, Josep M. y Bernal, Mariola (ed.), Antropología y enfermería. Campos de encuentro. Publicaciones de la Universitat Rovira i Virgilli. Tarragona, p. 259-276.

Makkonen, Timmo, (2002), Multiple, Compound and intersectional discrimination: bringing the experiences of the most marginalized to the fore, Helsinki: Institute for Human Rights, Abo Akademi University. En: http://cilvektiesibas.org.lv/site/attachments/01/02/2012/timo.pdf

Marjorie L. DeVault y Glenda Gross (2006). Feminist Interviewing. Experience, Talk and Knowledge. En Nagy Hesse-Biber, Sharlene (Ed.), Handbook of Feminist Research, Theory and Praxis. Boston College. SAGE Publications.

Millán, Margara (1996). En otras palabras, otros mundos: la modernidad occidental puesta en cuestión. Reflexiones a partir de Los hombres verdaderos. Voces y testimonios tojolabales, de Carlos Lenkersdorf. Editorial Siglo XXI. En: http://www.ciesas.edu.mx/proyectos/pagina/t/margarapublicaciones1.pdf.

Muleta, Mulu; Hamlin, Catherine; Fantahun, Mesganaw; Tafesse, Biruk (2007) "Health and Social Problems Encountered by Treated and Untreated Obstetric Fistula Patients in 
Rural Ethiopia. Women's Health. 30(1), p 44-50.

Muleta, Mulu; Hamlin, Catherine; Fantahun, Mesganaw; Tafesse, Biruk y Kennedy, Ruth (2007) Obstetric Fistula in Rural Ethiopia. East African Medical Journal 84(11), p. 526-534).

Nussbaum, Martha (2005) Women's Bodies: Violence, Security, Capabilities. Journal of Human Development. 6(2), p. 167-183.

Nussbaum, Martha (2006). El ocultamiento de lo humano, repugnancia, vergüenza y ley. Princeton Univeristy Press, Princeton (NJ).

Nussbaum, Martha (2002) Las capacidades de las mujeres y la justicia social. En Molyneux, Maxine y Razavi, Sarah (ed.) Gender justice, development and Rights. Oxford Univeristy Press.

PENUD (2013). Informe sobre Desarrollo Humano 2013. Nueva York, USA.

Pillow, Wanda S. y Mayo, Cris (2007). Towards understandings of Feminist Ethnography”. En Nagy Hesse-Biber, Sharlene (Ed.), Handbook of Feminist Research, Theory and Praxis. Boston College. SAGE Publications.

Rajeswari Sunder Rajan and You-me Park (2004). Postcolonial Feminism/Postcolonialism and Feminism. En Henry Schwarz and Sangeeta Ray (eds.) A companion to Postcolonial Studies. Wiley-Blackwell, p 53-71.

Rey Martínez, Fernando (2009), La discriminación múltiple, una realidad antigua, un concepto nuevo, Valladolid: Universidad de Valladolid (Spain). From http://www.oberaxe.es/files/datos/.../discriminacionmultiple/.

Rodríguez, Lilia (1998). Derechos sexuales y reproductivos en el marco de los derechos Humanos. Fondo de Población de Naciones Unidas. En: http://www.decidiresunderecho.org/index.php?option=com_content\&id=103:derechos-

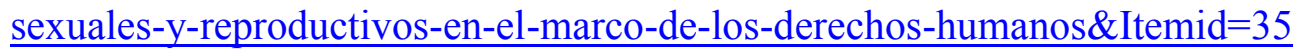

Scott, Joan (2009). Sexularism. European University Institute, Robert Schuman Centre for Advanced Studies. Florence, Italy.

Sen, Gita y Batliwala, Srilatha (2000). Empowering Women for Reproductive Rights. En Presser, Harriet y Sen Gita (Ed), Women's Empowerment and Demographic Processes: Moving Beyond Cairo. Oxford University Press, p.15-35.

Singer, Merrill y Baer, Hans (2007). Introducing Medical Anthropology. Altamira Press, Plymouth, United Kingdom.

Vallverdú, Jaime (2010) "Religión y salud (o curarse y convertirse). En Martorell, María Antonia; Comelles, Josep M. y Bernal, Mariola (ed.), Antropología y enfermería. Campos de encuentro. Publicaciones de la Universitat Rovira i Virgilli. Tarragona, p. 
237-258.

Vieitez Cerdeño, Soledad (2012). “Géneros, feminismos y culturas africanas: repensando los estudios africanos desde la universidad”. En Fundación Habitáfrica (2012). Repensando África. Perspectivas desde un enfoque multidisciplinar. p 19-57. Andalucía, España.

- (2005) “Antropología y género: Miradas desde África Critica, Año 55, Nº23 p. 3235 .

Wall, Lewis (2006). Obstetric Vesicovaginal Fistula as an International Public-Health Problem. The Lancet, p. 1201-1209.

Wegner, M.N; Rumijo, J.; Sinclair, E.; Presso, L. Y Mehta, M. (2007). Improving community knowledge of obstetric fístula prevention and treatment. International Jounrnal of Gynecology and Obstetrics 99, S108-S111- EngenderHealth, New York, NY, USA.

WHO (2010). Facts on Obstetric Fistula. En World Health Organization: En: http://www.who.int/reproductivehealth/topics/maternal_perinatal/fístula-study/en/.

Young, Robert JC (2012). Postcolonial remains. New Literary History 43(1), p 19-43. The Johns Hopkins University Press.

Zacharin, Robert, F. (1988). Obstetric fistula. Springer-Verlag Wien. New York, USA. 
ANEXOS 


\section{Anexo I: Guion de entrevistas}

\section{Interview to women with obstetric fistula}

\section{a) General information:}

- How old are you?

- Until what age did you go to school and what grade did you finish?

- In which place have you been living for the last 5 years?

- How old were you when you got married?

- How many years older or younger is your husband?

- Was your own choice to marry your husband or did someone else tell you to marry him?

- How many sons or daughters do you have?

- Ask for the family members: who else is living in your house?

- Does your husband work or has worked before?

- Did you work or have you been working outside of the house? If yes, ask where and what was she doing.

- At home, can you describe me all the things you are in charge in your everyday life?

- Valid indicators to establish the economic level: Ask if the home is owned or rented, if they have animals or not (number and type of animals), if they own land for cultivation (approximate size of the field), if the land is rented or bought it, type of crop they produce, if they have manual irrigation or not, if they have running water close to the house or not, electricity, radio at home).

\section{b) History of motherhood:}

- How old were you when you had your first child? (This will be hard to know because there is no birthday culture in Ethiopia and usually do not know how old they are)

- Where have you given birth? At home, in a health centre, a hospital...

- If you gave birth at home, who was attending the birth?

- Did you have any complications during the delivery? If the answer is yes ask: what kind of problem? And what did you do?

- How far (approximate time) is your house from the nearest health centre or hospital? And how can you get there?

c) Early symptoms of fistula and social support or rejection:

- From your point of view, what are the consequences of the fistula? 
- When did you realize that you were losing urine?

- What was your first reaction?

- Did you tell someone or did you keep it for yourself?

- If the answer is negative: how did you feel keeping this problem for yourself?

- What was the reaction of your family?

- What was the reaction of the other family members and neighbours?

- Did they help you finding a solution to the problem?

- Did your husband help you? And your sons and daughters?

- How long have you been losing urine?

- Who told you about the Hamlin Fistula Hospital in Mekelle?

- Did your husband and family support you taking this decision?

\section{d) Personal experiences in the hospital:}

- How long have you been in Hamlin Hospital?

- Were you pregnant when you came here?

- What do you value the most about your stay in the hospital?

- Were you able to share personal experiences with other women who were there?

- If yes: In which experiences have you felt understood and supported by other women who were there?

- When you will leave hospital, what are you going to miss the most?

- How do you think is going to be your going back "home"?

- Would you like to keep in contact with some of the women you have met here?

\section{e) Personal valuation about social and family in the returning back:}

- How did your family, friends, neighbours receive you when you returned from the hospital?

- Did you return with your husband and children, to a friend's house, to any relative's house, or did you decide to live alone?

- What are the most positive changes towards you, you have since perceived after your return from the hospital? (From the family, friends, neighbours...)

- What attitudes towards you have not changed and by whom?

- What are the most important changes you have notice in yourself since you came back from the hospital? (Higher self-esteem, self-image, personal goals, dreams, personal desires...)

\section{f) Working together to find solutions:}

- How do you think that fistula can be prevented? 
- And what can be done to avoid social rejection caused by the fistula?

- What educational or strategies aimed at changing the mentality you think would be useful and are not being used?

- In the area where you live, is there a prevention program?

- If there is, when you realized that you had a health problem and you were suffering its social consequences, did you ask for help?

- Who was or were the persons more support offered you and how have they helped you?

- What kind of support (economic, personal, and educational) you have missed and you think it is basic?

- What have been the most significant personal things you have given away because of fistula?

- Is there anything you miss from your experience in the Hamlin Hospital?

\section{Interview to the director of ODWACE (Organization for the Development of Women} and Children in Ethiopia)

\section{a) General information about ODWACE:}

- When was created this NGO in Ethiopia, which was it purpose and who were the promoters of this initiative?

- Was there a social demand to create it and who were them?

- How does this NGO work? Could you explain its functioning staff, training politic of staff, financial resources, social acceptance, support of public administration ...

- Socially in Mekelle, in regional state of Tigray is it very known?

- To whom is your work address?

- How many workers do you have?

- How do people get to know your NGO and how can women of rural areas of the region of Tigray contact you?

- What are the major difficulties that exist on your work? (Low income, lack of trained staff in gender issues, dispersed rural area with limited access, resistance by traditional believes, etc.).

- And the FGM it is very common in Tigray?

- Yes, is not as much as in other regions but it is very known, so we have to work to finish with it, our mains objectives are zero tolerance for the FGM. 
- Reason of OVULA cutting, why?

- During the time NGO has been working, what changes have occurred?

- What are the main challenges to achieve to reduce the rate of fistula?

\section{b) Work strategies:}

- Could you explain which are your NGO's strategies and intervention area?

Our NGO as I explain we are working in all Tigray,

- Do you work in schools with students? Should schools increase awareness among their students sensible about fistula?

- When women suffer of fistula, what is your action protocol? So then, who contact with you?

- What aspects of your intervention program could be improved? You were telling me about transport...something else?

- Describe the situation surrounding women with fistula (economy/family/ educational/social, etc.)?

- From your point of view, what is the most devastating issues (personal, familiar and social) arising from fistula?

- Relating to fistula, are there differences between rural and urban areas between women suffering from fistula? And comparing with other regions of Ethiopia?

\section{c) Return to everyday life:}

- Once these women leave the hospital, does your NGO facilitate any financial support, or are there organizations/institutions that provide some form of financial aid in case they have to start with a "new" life?

- Do you do follow-up these women after hospital discharge?

- Does this NGO offer some type of training to these women to be agents of change and for helping other women who are going through the same situation? 


\section{Anexo II: Transcripción de entrevistas}

\section{Takien Shan, 33 years old \\ Date: 28.03.2014 \\ Place: Wukro \\ Translator: Senait}

\section{a) General information:}

Q: How old are you?

A: I am 33 years old.

Q: Until what age did you go to school and what grade did you finish?

A: I never went to school.

Q: In which place have you been living for the last 5 years?

A: Last 5 years I have been living in Wukro, but before that I was living in Eritrea. I was born in Wukro but then for 20 years I was working in Eritrea, after that I came back to Wukro.

Q: How old were you when you got married?

A: I was 18 years old when I got married.

Q: How many years older or younger is your husband?

My husband is 50 years old right now, so he is 17 years older than me.

Q: Was your own choice to marry your husband or did someone else tell you to marry him?

A: I did not know who I was going to marry until my wedding day. My family, my father decided this marriage when I was only 15 years old.

Q: How were you feeling about that?

A: I was forced to married him, I just wanted to work but my family did not allowed me to work, they just wanted me to get married and have children.

Q: How many sons or daughters do you have?
A: I have 2 girls and 3 boys. $12^{\circ}$ grade, $10^{\circ}$ grade, $9^{\circ}$ grade, grade 3 and the youngest one he does not start school yet.

Q: Ask for the family members: who else is living in your house?

A: In our house we just live my husband, 5 children and me.

Q: Does your husband work or has worked before?

A: He does not have a regular job, he works daily, if he works today, he will be paid for today and when he does not work, they do not pay him, so it depends on the day.

Q: Did you work or have you been working outside of the house? If yes, ask where and what was she doing.

A: Yes I use to work outside of the house for some years in Eritrea, washing clothes and cleaning the houses. But after the marriage I stop working. I really want to find a job now that my children are growing.

Q: At home, can you describe me all the things you are in charge in your everyday life?

A: I take care of everything in the house, cleaning, shopping, and making enjera, washing clothes, feeding the sheep and so on. My children are in the school so I have to do everything in the house.

Q: Valid indicators to establish the economic level: Ask if the home is owned or rented, if they have animals or not (number and type of animals), if they own land for cultivation (approximate size of the field), if the land is rented or bought it, type of crop they produce, if they have manual irrigation or not, if they 
have running water close to the house or not, electricity, radio at home).

A: Our house is rented; we have 6 sheep's, 5 big ones and 2 small one. We do not have any land for cultivation. Yes, we have water in the house, and electricity. We do not have radio but we have television.

\section{b) History of motherhood:}

Q: How old were you when you had your first child? (This will be hard to know because there is no birthday culture in Ethiopia and usually do not know how old they are).

A: Immediately after the marriage I got pregnant, I did not rich to one year since the marriage.

Q: Where have you given birth? At home, in a health centre, a hospital...

A: The first two children at home. In Eritrea the hospital was very, very far from my house. The other three in the hospital here in Wukro. Two of them by caesarean because I had complicated labour so they took me to the hospital...

Q: If you gave birth at home, who was attending the birth?

A: Traditional birth attendance was attending the birth.

Q: Did you have any complications during the delivery? If the answer is yes ask: what kind of problem? And what did you do?

A: I was late during the pregnancy so that's why I had an operation with two of them.

Q: How far (approximate time) is your house from the nearest health centre or hospital? And how can you get there?

A: In Wukro is very close (walking 20 minutes) but in Eritrea (where she had the first two babies it was very far) I was living in a village very far from the nearest hospital but here in Wukro is very close.

\section{c) Early symptoms of fistula and social support or rejection:}

Q: When did you realize that you were losing urine?

A: It started with the last children, 5 years ago.

Q: What was your first reaction?

A: My first reaction was that I could not control the urine after the last children. I went to see a doctor in Wukro Hospital and he told me that I had a fistula and to go to Mekelle where there is a Hospital for the treatment.

Q: Did you tell someone or did you keep it for yourself?

A: I kept it for myself.

Q: If the answer is negative: how did you feel keeping this problem for yourself?

A: I had to keep it for myself because it is a very, very bad thing. If I had told someone, everybody would start speaking about me. I feel shy about it. And I feel like I could not do anything.

Q: You did not even tell to the husband?

A: No, I did not tell to anyone.

Q: What was the reaction of your family?

A: I keep it for myself. There was not any reaction because I did not tell to anyone about my problem. I keep it for myself everything so anyone in my family does not know anything about it.

Q: But to if you went to Mekelle someone had to know it right?

A: Just the doctor in Wukro and he told me to go to see Dr. Melaku in Mekelle. He gave me all the information about the hospital.

Q: And to your husband?

A: I did not tell anything. I tell to my husband that because of the surgery she has to go to recover to Mekelle in that hospital. I prepare my things and I go to the hospital for myself. (Starts crying) 
Q: Did they help you finding a solution to the problem?

A: The one who helped me was the doctor from Wukro. My family did not know anything. My father and my mother are died. I told a little lie to my husband, I told him that because of the caesarean intervention, I had an infection so to cure it I had to go to Mekelle

Q: How long have you been losing urine?

A: 5 years in total, it started after the delivery of the last baby.

Q: Who told you about the Hamlin Fistula Hospital in Mekelle?

A: The doctor of Wukro told me about it.

\section{d) Personal experiences in the hospital:}

* She started crying and feeling nostalgic answering these questions.

Q: How long have you been in Hamlin Hospital?

A: I was in the hospital more or less one month and 2 weeks.

Q: Were you pregnant when you came here?

A: No I was not, I already had the last baby five years ago and I was with the fistula since then.

Q: What do you value the most about your stay in the hospital?

A: It was a very good experience to be in the Hospital. Because you know, that the last 5 years I had this problem and I did not know what it was, so I was very happy when I arrive to the Hospital and when I realize that I was not the only one with this problem. The hospital helped me to be good again.

Q: Were you able to share personal experiences with other women who were there?

A: At first I was very ashamed when I arrive there. But immediately I met Mulu, my best friend there. After that I start speaking with other women in the hospital and I realize that I was not the only one that had this problem, so I felt very happy and I share a lot of things with other women that were there.

Mulu for example got there when she was pregnant because she had some problems, she had an operation, but still she continue having some problems and had another operation and after that she was better. I met a lot of people from different places, from Adua, Agula, Addis... When I was at home with this problem I was crying 24 hours, asking to myself how can I have this problem? Why is me? How can I go out with it? Why Am I punished by God? But then when I came to this hospital I start laughing and having a lot of fun because I realize that I was not the only one with this problem, that there were lot of women with it! And we share a lot of things together! I was very, very happy; I totally forgot that I was sick! But still, if someone doesn't know about this hospital or what can of problem you have, it is very hard. If you do not do anything, you can die at home with it.

Q: When you will leave hospital, what are you going to miss the most?

A: I miss a lot the hospital, I miss everything from the hospital, it is a very clean, beautiful place, good food... if I was sick again, I would like to be there again (laughing).

She starts crying again because she remembers every good moment that she had over there.

Q: How do you think is going to be your going back "home"?

A: When I get back home I was happy because I missed my children but at the same time I feel very sad of having to leave the hospital and the friends that I made there. After I left the hospital I go two times to visit my friends there.

Q: Would you like to keep in contact with some of the women you have met here?

A: It is difficult to see the friends that I made there because each one we are from different 
villages of Ethiopia, so after the discharge and the two visits I did not have the opportunity to see any of them again.

\section{e) Personal valuation about social and family in the returning back:}

Q: How did your family, friends, neighbours receive you when you returned from the hospital?

A: I did not tell to anyone that I had fistula, the family, my neighbours and friends were visiting me in the hospital but they did not know the real problem that I had. I was saying that I had an infection due to the caesarean intervention with my last baby, and that it was because of that I had to have another intervention in Mekelle.

Q: Did you return with your husband and children, to a friend's house, to any relative's house, or did you decide to live alone?

A: I came to live back with my husband and my children to the same house.

Q: What are the most positive changes towards you, you have since perceived after your return from the hospital? (From the family, friends, neighbours...)

A: Anything, anybody know what happened to me.

Q: What attitudes towards you have not changed and by whom?

A: Nothing, I did not tell to anyone my problem, so everything was like before.

Q: Why you did not tell to anyone?

A: Because if I said to someone about it, they were going to leave me alone, they were going to be far from me and they are not going to help me, just they are going to gossip about me and run away from me. Also I was afraid of my husband, if he knew what happened to me, he was going to leave me alone with all the children, I was very afraid.

I did not know that was a common problem, I thought that I was the only person in the world who had this problem, so I was very afraid and I prefer not to speak about it.

Q: What are the most important changes you have notice in yourself since you came back from the hospital? (Higher self-esteem, selfimage, personal goals, dreams, personal desires...)

A: I do not feel any changes, even for my dreams or anything, everything still being the same...just I feel that when I had the problem I was sad but now I'm fine and everything around me still the same, so it is good and I feel happy about it.

\section{f) Working together to find solutions:}

Q: How do you think that fistula can be prevented?

A: Just to take care of it and giving information. Also, we have to give birth in the hospitals, is very important.

Q: And what can be done to avoid social rejection caused by the fistula?

A: We can teach about it but not in Wukro, here cannot in another place yes. But, wait, I think it can be very helpful also I could try to teach!

Q: In the area where you live, is there a prevention program?

A: Here in Wukro there is nothing, in Mekelle yes but here no. Just the doctor told me about it.

Q: Do you think that it can be necessary?

A: In Wukro there isn't any so I think it is a good idea to have.

Q: If there is, when you realized that you had a health problem and you were suffering its social consequences, did you ask for help?

A: No I did not, just the doctor from Wukro give her the contact from the hospital.

Q: Who was or were the persons more support offered you and how have they helped you? 
A: Sister Almaz was very good with me she was every day with me.

Q: What kind of support (economic, personal, and educational) you have missed and you think it is basic?

A: Sister Almaz did not help me economically just personally, when she was giving me the medication also she was teaching me a lot of things, how we have to wash etc. For economic we receive the money for the transportation. After that, to buy the sheep's they give me 400 birr but after one year I had to return back this money, microcredits.

Q: Do you think that this support is enough?

A: If I had more it could be better, for food and for clothes, it is not enough, and we should have higher credits

Q: What have been the most significant personal things you have given away because of fistula?
A: I got a work after the fistula problem, yes I was sick for lot of years but after all I can work again now.

Q: Is there anything you miss from your experience in the Hamlin Hospital

A: I miss the hospital; I miss all my friends, generally my period there.

Q: Something else that you want to tell us?

A: One my side, everything is fine, I feel very happy because I have health after I have been treated. But still I am the only one in Wukro who have this.

Translator: no you are not the only one in Wukro who have a fistula, I know a girl, very young girl who live near my house and she had the same problem. Now she is in Arab and she is fine, but she was sick for lot of years. 


\section{Ascual, 40 years old \\ Date: 04.04.2014 \\ Place: Eshegoda \\ Translator: Zufan Ababe}

\section{a) General information:}

Q: How old are you?

A: I am 40 years old

Q: Until what age did you go to school and what grade did you finish?

A: I did not go to school but I know how to read and write, I learn it by myself

Q: In which place have you been living for the last 5 years?

A: I have living here the last 5 years, I was born here but for 9 years I was living in Mekelle.

Q: How old were you when you got married?

A: I got married late, when I was 18 years old

Q: How many years older or younger is your husband?

A: My husband is 50 so he is 10 years older than me.

Q: Was your own choice to marry your husband or did someone else tell you to marry him?

A: It was not my choice but I was not a small children, I was 18 years old. Actually, it was not my choice to marry him and nobody forced me but my parents choose for me.

Q: How many sons or daughters do you have?

I have three boys and one girl

Q: Ask for the family members: who else is living in your house?

A: No, we only live, me my husband and my 4 children.
Q: Does your husband work or has worked before?

A: He works in construction; he builds the houses, local construction.

Q: Did you work or have you been working outside of the house? If yes, ask where and what was she doing.

A: Right now I do not work. I work in cultivation but it is not paid job.

Q: At home, can you describe me all the things you are in charge in your everyday life?

A: I do not do anything at home. I made enjera, I clean the house, I wash clothes, I prepare the food for my family, and I prepare the coffee. It is not paid work so I do not consider work. I do everything at home, and also work on cultivation. Apart from carrying the water, because I am not able because of the fistula I do all the other things.

Q: Valid indicators to establish the economic level: Ask if the home is owned or rented, if they have animals or not (number and type of animals), if they own land for cultivation (approximate size of the field), if the land is rented or bought it, type of crop they produce, if they have manual irrigation or not, if they have running water close to the house or not, electricity, radio at home).

A: It is our own home; we also have our own cultivation land. We have 5 sheep's, 2 big and 3 small but both big are pregnant and 12 hens. But I cannot count them. We have a manual irrigation and at home we have a radio but right now are broken. Yes, also we have electricity. To take water I have to go down to the village, 15 mins walking.

\section{b) History of motherhood:}


Q: How old were you when you had your first child?

A: I had my first children late, I got married with 18 years old and I wait 5 years, it was with 24 years old.

Q: Where have you given birth? At home, in a health centre, a hospital...

A: I have a very difficult labour I gave birth in hospital. If you gave birth at home, I do not have trained helpers to help me. The first baby I had it at home, the rest of them in the hospital. Only I had one at home because it was an easy labour (18 to 24 hours) that's easy for us. With the others I was late so I went to give birth to the hospital.

Q: If you gave birth at home, who was attending the birth?

A: When I gave birth at home, traditional birth attendance was helping me.

Q: How far (approximate time) is your house from the nearest health centre or hospital? And how can you get there?

A: We do not have close to our village a health centre, the closest one is in Mekelle, so walking are $10 \mathrm{~km}$.

\section{c) Early symptoms of fistula and social support or rejection}

Q: From your point of view, what are the consequences of the fistula?

A: I was not able to walk, I could not work, especially heavy work, I could not be with other people, I could not have any social live since I realize that I was losing urine. I could not go to the church. My father died and all the people were speaking about me, asking why I did not go to the church. All the family and friends where in the church and I was not. I was very afraid because of the smell that I have, so I could not go to the church and also to the market.
Q: When did you realize that you were losing urine?

A: I was losing urine for 15 years. I develop the fistula when my second son was born and now he is in grade 8 so in total I have been with the fistula 15 years. I suffered the fistula with 3 children and the second son has damage in his head that is the cause of my fistula.

Q: What was your first reaction?

A: I was shock and very afraid because I realize that there was a hole between my annus and vagina. Even the gases I could not control them and I was very afraid that someone could listen it. So I was asking to myself what was going on with me, I was very afraid and very shy and shock. Immediately I went to the hospital and they gave me an infusion. Not all the hospitals can treat the fistula, other illness yes but not this one. After they treated me with the infusions I came back to my house and I continue suffering from fistula for 15 years.

Q: Did you tell someone or did you keep it for yourself?

A: I develop the fistula with my second son and I continue having children but I never tell to anyone my problem. After I gave birth to the third children I went to the hospital to ask and they gave me the infusion. But I did not tell to anyone about it, even for my children I did not tell anything. I was too shy. Finally I was able to speak with my chairwoman from the town (Berhane) and she contacted with ODWACE telling about the problem that I had. I did not even tell to my husband, anything. I had two different problems, internal and external, they treat me one and with the other one, when I went to ask, they told me that there was not any problem. And If I told to my husband he was going to divorce from me, I was very afraid of it. In our culture, the sound of gas is forbidden, is somebody listen to it they laugh at me, so how could I tell to my husband? He would divorce me and go with another woman. 
Q: If the answer is negative: how did you feel keeping this problem for yourself?

A: I was very afraid and I had to keep it for myself. I was wearing trousers under the dresses and also dippers. I was cleaning my clothes all the time to try not to smell bad. I was all the time crying, all the time that I was alone I was crying because I could not tell to anyone what was happening to me.

When I arrived to the hospital and when I saw young and old women with the same problem that mine I start to think that I was not alone with this problem that more women had the same problem than me and psychologically I felt much better with myself. I felt understood with other women. But before that, my neighbours were health, nobody could explain me about this problem, so the best thing that I could do was to keep it for myself. If I could found someone before with the same problem I could ask her but nobody speaks about it and now I know that there are a lot of women. Also in our culture is forbidden to speak about our genitals, sexuality and more to share experiences about it, we do not talk about sexuality because if we do we will be punished. After fistula operation, I speak about sexuality and my fistula problems with other persons even with my children but before never. Sometimes my daughter laughs because I speak about the organs and genitals. Even to speak about menstruation is forbidden!! Mother's do not teach their daughters about it. This is the reason that fistula is a hidden issue in our society and that's why I was crying all the time that I was alone. I was being punished from God because I was not a good person.

Q: And what she said when you left to Mekelle?

A: I told that I had a uterus prolapse, I went to see Berhane (chair-person) and explain what was happening to me and she helped me to go to Mekelle. I told to my family that maybe I had a uterus prolapse and that I had to go to be treated. I was taking water when this happen and Berhane told me to be fast to go to
Mekelle. Zufan was taking another woman to drive to the hospital and she took me on the road, I through the water and I went immediately inside of the car. I told everything to Berhane, I show her the trousers that I was and I told her that I had a hole between my vagina and my annus and that I was losing urine so I decide to go with Zufan to Mekelle to see a doctor.

I send a message for my husband and my children telling that I had to go to the hospital in Mekelle. I went to the hospital, they check me and I came back the same day. I arrange everything for the operation. I told to my husband about the fistula after the treatment not before because I was scare about it. Actually he did not know about fistula, but he knew that something was wrong with me but he never spoke with me about it. But he had to realize about the hole that I had when we were having sex, he had to notice about it. I think that my husband as well he was very afraid of asking me what was happening with me. Always the light was switched off when we were having sex so he could not see the hole but yes realize. Even for changing the clothes we cannot see each other naked, only with the hands. After treatment, I told him everything, I changed a lot after the treatment.

Q: How long have you been losing urine?

A: 15 years in total

Q: Who told you about the Hamlin Fistula Hospital in Mekelle?

A: Berhane told me about the hospital, the chairwoman of my village. Then Zufan took me to the hospital.

Q: Did your husband and family support you taking this decision?

A: They did not know anything about my problem. I told him that I needed to go to the hospital because I had a problem.

Berhane: Ascual's husband came running to me the day that she left with Zufan to go to 
Mekelle asking: where is my wife? Where did she go?

Ascual: It was maybe my last chance to go Mekelle that day so I went running.

Berhane: her husband was shocked, asking me: where is she? Does she have a problem? She was supposed that she was going to take water and she did not come back! (All of them laughing)

\section{d) Personal experiences in the hospital:}

Q: How long have you been in Hamlin Hospital?

A: The day that I left running with Zufan to Mekelle, the same day I came back home because I live very close from Mekelle. Until the day of my operation I could stay at my home. Once that I had the surgery I stayed at the hospital 10 days in the hospital (the second children enter in the house, the one who develop the fistula with, and she show me his head, where you can see the birthmark which produced the fistula). Most of the other women in the hospital they have more problems than the fistula and some of them arrive weak to the hospital, so first they need to recover and be strong for the treatment they need time to recover but I did not have any problem, just the fistula, so for me it was fast.

Q: Were you pregnant when you came here?

A: No I was not pregnant, I develop the fistula with my second children and I had two more I had.

Q: What do you value the most about your stay in the hospital?

A: Everything in the hospital was good, the food, clean, nurses and nuns, the doctor and the people. They treated me all of them the nurses, doctors, the cook's all of them very well. I was eating enjera and spaghettis. Everything was very good. Also I had education to prevent the fistula, it was very good. Our government is doing a very good job educating on prevention of fistula.
Q: Were you able to share personal experiences with other women who were there?

A: Yes I share a lot of things. Even we speak about things that it is supposed that we were able to speak. Like about our husbands or brothers, we were discussing everything in the hospital openly! (They laugh). But everything!!

Q: If yes: In which experiences have you felt understood and supported by other women who were there?

A: My friend Tage, she was speaking all the time about everything! I call her "sun" because for me she is like sun, she had the same problem than me and we were discussing everything.

Q: When you will leave hospital, what are you going to miss the most?

A: I miss the life there because I share with these women all my problems and they understand me and I cannot find friends like them here, in my town. I am really willing to find women who are suffering from fistula to help them. If my government do this I am really willing to help my government in its work. I was loved in the hospital, I am very happy with this experience.

Q: How do you think is going to be your going back "home"?

A: My husband came to pick me up in the hospital, we went by taxi to the bus station and the in the bus back home. My husband and my oldest children helped me to come back home.

Q: Would you like to keep in contact with some of the women you have met here?

A: Until now we contact each other by telephone (laughing). I made a little agenda with some telephones and I speak with them sometimes. 


\section{e) Personal valuation about social and family in the returning back:}

Q: How did your family, friends, neighbours receive you when you returned from the hospital?

A: I call to my family telling that I was coming back the $27^{\text {th }}$ and in our culture the $27^{\text {th }}$ is a holiday. It was a special day so my family and neighbours prepare a big party for that day in our house with local beer, everybody was in our hose and happy to see me back. I came back and they saw me with a very good looking so everybody was celebrating it.

Q: Did you return with your husband and children, to a friend's house, to any relative's house, or did you decide to live alone?

A: I came back to the same house, with my husband and children.

Q: What are the most positive changes towards you, you have since perceived after your return from the hospital? (From the family, friends, neighbours...)

A: Some people bring food for present like milk that is good for my health, meat, all of them were very happy to see me and they were discussing with me for one or two hours about how I was feeling. It was like a new birth for me, I was born again.

Q: What attitudes towards you have not changed and by whom?

A: Before the treatment, I was never out of my house; I was all the time inside of my home, washing my clothes and my underwear. Nobody knew that I had fistula, I told them that I had an infection and that was the reason of not going out of my house. Now I am fine and everybody is happy to see me healthy, but before the treatment I was very afraid of going out and now I feel able to discuss with anyone about it. Before I was not able to speak about it, even to have coffee ceremony or to go somewhere, I was hiding from everybody.
Q: What are the most important changes you have notice in yourself since you came back from the hospital? (Higher self-esteem, selfimage, personal goals, dreams, personal desires...)

A: I realize that it was a very good to be back home. I am very healthy again. Now I would like to open a shop to help my parents with money. The organization helps me buying the sheep's and the hens but it was not enough money to open a shop. Now when I finish paying back the money that the organization lends me to buy the animals, I will be very happy because in that moment they will be mine!

\section{f) Working together to find solutions:}

Q: How do you think that fistula can be prevented?

A: We have to treat it on time. We have to go to the hospital early for the delivery. Also we have to avoid the early marriages. Pregnant women have to go for cheeking their pregnancy before and after the delivery.

Q: And what can be done to avoid social rejection caused by the fistula?

A: After I discussed openly with a woman who suffered from uterus prolapse, she saw me her uterus but in our culture it is forbidden to speak about this things and more to show them!!! (laughing). We openly speak about it even if in our culture it is forbidden.

The fistula victims hide themselves because they are afraid of the discrimination; we put our clothes in the fire not to have a bad smell, with the smoke. We do it because we are afraid of the community, we are traumatized, and we have to change the way of the thinking of the community.

Q: What educational or strategies aimed at changing the mentality you think would be useful and are not being used?

A: It is a trauma; young, old and even the priest's wife can develop the fistula. It is good to teach in the schools about it, nowadays we 
are teaching a lot of things but before we just teach only about HIV and not to discriminate them because they are our brothers and sisters. Now we start also teaching about fistula victims and not to discriminate them and if there is a fistula victim, in the school we teach to let us known because she can be treated because it happens with young, old, poor or rich but before we were not teaching.

Q: In the area where you live, is there a prevention program?

A: Yes, we have a program, the women for development groups, once every two weeks organize meetings and we discus about woman's problems and fistula. They constantly repeat that if there is a fistula victim, please to contact us.

Q: If there is, when you realized that you had a health problem and you were suffering its social consequences, did you ask for help?

A: Yes I did but after 15 years of being suffering.

Q: Who was or were the persons more support offered you and how have they helped you?

A: Berhane, my chair person, she helped me to go to Mekelle with Zufan, she tell me not to be afraid and also Zufan, she helped me a lot with my problem.

Q: What kind of support (economic, personal, and educational) you have missed and you think it is basic?
A: I got the microcredit, 4000 birr. I am very happy because without this help I could not buy the animals that I have now. But the food for the sheep and hens is a problem, I have to pay it from my money and it is very expensive. This is a credit so when I finish returning the money back, then I will be very happy because then they will be mine!

Q: What have been the most significant personal things you have given away because of fistula?

A: Now I am OK, but when I was before the treatment I always wanted to go for coffee ceremonies but how can I go with my problem. But now I am happy because I am healthy again and I can do whatever I want.

Q: Is there anything you miss from your experience in the Hamlin Hospital?

A: I miss the people from the hospital and the things that I share with them. I cannot get the same food as in the hospital anymore (laughing), they had a very good food and here I cannot get it (laughing). I miss the valance of nutritional food in the Hospital

Q: Something else that you want to say or add?

A: I have to thank all the people who helped me to be healthy and back home again, thanks for the Hamlin Fistula and for my chair person and also for all the supporters of the Hospital and the reintegration. Thanks for God for being good with me, and also for the Government. 


\section{Berhane, 50 years old}

Date: 07.04.2014

Place: Faleka Salam

Translator: Goitom

\section{a) General information:}

Q: How old are you?

A: I am 50 years old.

Q: Until what age did you go to school and what grade did you finish?

A: I did not go to school.

Q: In which place have you been living for the last 5 years?

A: I have been living for the last 5 years in Faleka Salam

Q: How old were you when you got married?

A: I was 18 years old when I got married

Q: How many years older or younger is your husband?

A: I never knew my husband age

Q: Was your own choice to marry your husband or did someone else tell you to marry him?

A: I was married because my relatives choose it for me. Most of the time is the most common thing here, to get married without knowing each other.

Q: How many sons or daughters do you have?

A: I have four children, two boys and two girls

Q: who else is living in your house?

A: I live with my three children; the oldest one is married so she doesn't live with me.

Q: Does your husband work or has worked before?

A: I am divorced woman.

Q: Did you work or have you been working outside of the house? If yes, ask where and what was she doing.
A: No I do not work, before some years I was a hairdresser but now I do not work.

Q: At home, can you describe me all the things you are in charge in your everyday life?

A: I do the all the household activities, I make enjera, clean the house, bring the water, wash clothes and so on.

\section{b) History of motherhood:}

Q: How old were you when you had your first child?

A: I had my first children when I was 20 years old.

Q: Where have you given birth? At home, in a health centre, a hospital...

A: I gave birth at home; all of my children because the nearest health centre was very far.

Q: If you gave birth at home, who was attending the birth?

A: A traditional birth attendance woman was helping me during the delivery.

Q: Did you have any complications during the delivery? If the answer is yes ask: what kind of problem? And what did you do?

A: No I did not have any problem during the delivery.

Q: How far (approximate time) is your house from the nearest health centre or hospital? And how can you get there?

A: The closest hospital is Quija hospital and it is and the closes health centre is this one, 40 minutes walking from my house. Now for example, a pregnant woman if she has labour pain, she can come to this health post centre. The health extension worker call to the health centre and the ambulance can come directly here if the house of the woman do not have access to a car way and then if the health centre and if the health centre see that she has 
to go to the hospital she goes or to Quija hospital or to Mekelle. For example, form Berhane's house the woman can come by foot the post health centre and if she has a labour pain, people carry her here, around 20 minutes walking. This centre was opened 10 years ago. Now in all the villages are health post centres. Most of women come by walking to this health post, but if they have problems or pain and if the car can go, we go to their house. But most of the time they come walking of people carry them, but there is a belief in our culture that when a person is carried by the people, never will be cured from the illness.

\section{c) Early symptoms of fistula and social support or rejection:}

Q: From your point of view, what are the consequences of the fistula?

A: In my case, the fistula was a very big problem, I could not go out of my house, I was all the time washing my clothes, so that's why I did not go out. But thanks to the government I got repair of my fistula and I am able again to do different things and I can go out to the market, or to coffee ceremonies in friend's houses etc.

Q: When did you realize that you were losing urine?

A: I realize that I was losing urine after 3 days of the delivery but at that time I did not speak with anyone about my problem. I was crying all the time until I told to one head extension worker, she came to my house and I was crying and I explained her my problem. And then this extension worker told me that I do not have to worry about that, that there was a treatment for it, this extension worker is Tadele (the woman that is in the interview) and after that we become very good friends and I came lots of time to visit her in the work.

Q: What was your first reaction?

A: My first reaction was to cry and not to tell anybody and to be cleaning all my clothes all the time.
Q: Did you tell someone or did you keep it for yourself?

A: I did not tell to anybody, I did not tell even to my family, all the day and night I was crying. I keep it for myself for 9 months when I told to the health extension worker my problem.

Q: If the answer is negative: how did you feel keeping this problem for yourself?

A: I just spend the day crying.

Q: What was the reaction of your family?

A: I did not tell to anybody from my family about my problem.

Q: What was the reaction of the other family members and neighbours?

A: My neighbours never knew about that I suffer from fistula; they thought that I had a traditional problem related with the pregnancy.

Q: Did they help you finding a solution to the problem?

A: I do not have relatives so nobody can help me with this problem. My husband did not live with me all the time, he was my second husband and he has another wife so I consider that it was my own problem the fistula not his problem. Also my children were very young to help me.

Q: How long have you been losing urine?

A: After 10 months I got treated in the Hamlin Fistula Hospital.

Q: Who told you about the Hamlin Fistula Hospital in Mekelle?

A: The health extension worker told me that it was a hospital where I could be treated from the fistula.

Q: Did your husband and family support you taking this decision?

A: They did not know about my problem, but my husband went to visit me several times to the hospital. 


\section{d) Personal experiences in the hospital:}

Q: How long have you been in Hamlin Hospital?

A: In total I was one month and half in the hospital.

Q: Were you pregnant when you came here?

A: No I was not pregnant and after the operation I did not have more children.

Q: What do you value the most about your stay in the hospital?

A: When I left the hospital I become a beautiful woman again so I like Hamlin Fistula Hospital a lot.

Q: Were you able to share personal experiences with other women who were there?

A. Yes, we share a lot of experiences, I was feeling understood with other women and I realize that I was not the only one with this problem

Q: If yes: In which experiences have you felt understood and supported by other women who were there?

A: Until I arrived to the hospital I was thinking that it was just my problem but when I arrive and see so many women with the same problem and sometimes with worst problem. In that moment I understood that it was not only me. I was worried before going to the hospital if I was going to be cured but then, after the operation I was fine again.

Q: When you will leave hospital, what are you going to miss the most?

A: I miss everything in the hospital, the food, the clean hospital but what I really appreciate from the hospital is that I was cured again. I gave advice to the women that were waiting for the surgery; I told them not to be worried that they were going to be healthy again.
Q: How do you think is going to be your going back "home"?

A: I was a hairdresser before the hospital, but I did not work while I had the fistula. So when I came back home again, I started working in the hairdresser again, I feel some pain at the beginning but I decided to start the work because my husband was not there anymore. Now I stop working because I am feeling very weak and sick most of the times and I do not feel like working anymore.

Q: Would you like to keep in contact with some of the women you have met here?

A: No I do not speak with any women that I met in the hospital.

e) Personal valuation about social and family in the returning back:

Q: How did your family, friends, neighbours receive you when you returned from the hospital?

A: They give me a very warm welcome when I get back; they make a big coffee ceremony why not, right? I was one month and a half in the hospital. Before I was treated, everybody thought that I had a traditional sickness and that I was never going to be cured. So when they saw me cured and good again, everybody was very happy.

Q: Did you return with your husband and children, to a friend's house, to any relative's house, or did you decide to live alone?

A: I came back home with my children to the same house, but my second husband was not there anymore with us.

Q: What are the most positive changes towards you, you have since perceived after your return from the hospital? (From the family, friends, neighbours...)

A: If somebody is sick nobody love us but when I get back and people realize that I was cured, again everybody loves me, so I lost love of the people when I was suffering nobody care about me. 
Q: What attitudes towards you have not changed and by whom?

A: I did not notice any changes, just that before when I was sick nobody cares about me and now they love me again.

Q: What are the most important changes you have notice in yourself since you came back from the hospital? (Higher self-esteem, selfimage, personal goals, dreams, personal desires...)

A: The first thing is that I feel beautiful again after the surgery. Now I try to start to give advice to pregnant women about my life experiences. I start to make my everyday life, gardening, having coffee ceremonies, going for water...

\section{f) Working together to find solutions:}

Q: How do you think that fistula can be prevented?

A: The most important thing is to deliver in health centre, now fistula is decreasing because there is an important change in the mind of the people and government about it. Another important fact is to end with early marriages (Everybody started to laugh).

Q: And what can be done to avoid social rejection caused by the fistula?

A: The problem of the social exclusion for me it was before when I had the fistula I was alone in my house. But now, thanks to the health extension workers when they realize that a woman does not go so much out of her house they go to see what happens to her. So, now if a woman develops the fistula, they immediately realize and speak with the woman and explain her that there is a solution for that. It is improving a lot this aspect.

Q: What educational or strategies aimed at changing the mentality you think would be useful and are not being used?

A: In the school they have to try to prevent the early marriage and giving a proper education in the school or in the meetings of people, in the church... we need to work on this.

Q: In the area where you live, is there a prevention program?

A: the government, the health extension workers are teaching and preventing to the pregnant women to deliver in the hospitals or health institutions.

Health extension worker: If I see any pregnant woman I advise her to go to the hospital or to any health institution to make the cheeking and also I call to Froini (Healings Hands for Joy) to inform her about it and to take care of her.

Q: If there is, when you realized that you had a health problem and you were suffering its social consequences, did you ask for help?

A: I wait for 9 months until I told to the health extension worker form my village about what was happening to me.

Q: Who was or were the persons more support offered you and how have they helped you?

A: The head extension worker was the person who more helped me with it and the one who told me about the Hamlin Fistula Hospital in Mekelle. Also, the organization of Healing Hands of Joy because helped me as well.

Q: What kind of support (economic, personal, and educational) you have missed and you think it is basic?

A: (thinking...) Education is the best thing for me and I could not have it, if I am healthy I can do any work to have some economic resources to life, I can improve my economy. But in my case I did not have a husband that was helping me economically and I was sick I could not generate any income and I had big economic problems. I received a microcredit from Healing Hands of Joy 2000 birr but only from them, anyone else did not help me economically. But with this money I could start again, but the problem was when I was sick, the husband of my daughter came to me and he sell all the sheep's that I had without 
telling me anything and leaving me without anything, any economic resources. (She started to cry)

Q: What have been the most significant personal things you have given away because of fistula?

A: I lost the love of the people when I was sick and my husband but now I give thanks to God because I am cured again and healthy.

Q: Is there anything you miss of your experience in the Hamlin Fistula?

A: I remember all the good things of the hospital; I have a very good memories.

Q: When you had the operation?

A: It was 6 years ago more or less.
Q: Something else that you want to add to this?

A: We are trying to advice to all pregnant women to deliver at health institutions or hospitals to be safe, but there is a big lack of transportation, for example here in this woreda there is one ambulance so this is a big problem. Before two days we had a problem with a pregnant woman because she was losing blood and we could not have the ambulance because it was in another place, they did not come immediately and it was very difficult. Now the awareness of pregnant woman is increasing a lot thanks to the health extension workers and the government and thanks to them there is a big prevention but there is a big lack of transportation and skill midwife. 


\section{Abba Maharon, 37 years old \\ 09.04.2014 \\ Place: Mynebri \\ Translator: Zufan Ababe}

\section{a) General information:}

Q: How old are you?

A: I am 37 years old

Q: Until what age did you go to school and what grade did you finish?

A: I never went to school.

Q: In which place have you been living for the last 5 years?

A: I have been living in Mynebri the last 5 years.

Q: How old were you when you got married?

A: I got married when I was 20 years old.

Q: How many years older or younger is your husband?

A: My husband is 40 years old, so 3 years older than me.

Q: Was your own choice to marry your husband or did someone else tell you to marry him?

A: It was my own choice to marry my husband, nobody told me to do it, I just wanted to marry him

Q: How many sons or daughters do you have?

A: I had 7 children, 5 of them died after giving birth; now I have a son and a daughter.

Q: Ask for the family members: who else is living in your house?

A: We are living my husband, my son, my daughter and me in this house.

Q: Does your husband work or has worked before?
A: Yes, he works in daily work, maybe sometimes have job and some days that doesn't have.

Q: Did you work or have you been working outside of the house? If yes, ask where and what was she doing.

A: I do not work outside of the house, I cannot work outside of the house because my daughter needs me, and I have to take care of her so I cannot go out to work.

Q: At home, can you describe me all the things you are in charge in your everyday life?

A: At home, I prepare the food, I take care of my daughter, I wash clothes, cleaning the house, bring water...

Q: Valid indicators to establish the economic level: Ask if the home is owned or rented, if they have animals or not (number and type of animals), if they own land for cultivation (approximate size of the field), if the land is rented or bought it, type of crop they produce, if they have manual irrigation or not, if they have running water close to the house or not, electricity, radio at home)

A: Our house is rented; we have animals like hens and cows. We have our own land for cultivation but we rent to another person to make some money. Running water we have very close from the house, 3 minutes walking. Yes we have electricity but we do not have any television or radio.

\section{b) History of motherhood:}

Q: How old were you when you had your first child? (This will be hard to know because there is no birthday culture in Ethiopia and usually do not know how old they are) 
A: I had my children when I was 22 years old. He died when he just have few days.

Q: Where have you given birth? At home, in a health centre, a hospital...

A: I gave birth at health post all the children, my husband wanted it, I prefer at home but finally I gave birth at the health post. Only I had one child at home.

Q: If you gave birth at home, who was attending the birth?

A: The only time that I had the baby at home the birth was attended by a traditional birth attendance.

Q: Did you have any complications during the delivery? If the answer is yes ask: what kind of problem? And what did you do?

A: I had an obstructed labour and several times the baby was dead in the uterus before the birth and others were dead few days later of being born.

Q: How far (approximate time) is your house from the nearest health centre or hospital? And how can you get there?

A: The closest health centre is around 5 kilometres away from my house, so it is not very far.

\section{c) Early symptoms of fistula and social support or rejection:}

Q: From your point of view, what are the consequences of the fistula?

A: Fistula symptoms for me where that I could not go out, I could not work out of the house and as I want, even now that I have been treated 3 times, I am afraid of working because it can appear again.

Q: When did you realize that you were losing urine?

A: I gave birth in the clinic and after I came back home I started to lose urine. I was very afraid in that moment and immediately I spoke with my mom; I was expected to have my period, my menstruation, and not urine! My mom immediately took me to the health centre, but there, they could not identify what was my problem and they send me to Mekelle in Ayder Hospital. When a gynaecologist saw me in this last hospital, he identifies the fistula and he told me that he could not do anything for me but that there was a Hospital where they could treat me. After the first treatment I was fine again, but after 7 years I gave birth again and I developed the fistula one more time. This time ODWACE, Zufan took me directly to the hospital.

Q: What was your first reaction?

A: My first reaction was to be scare and not to be able to understand what was happening to me, but immediately I ask for help to my mom.

Q: Did you tell someone or did you keep it for yourself?

A: I told to my mother first and then I spoke with my husband.

Q: What was the reaction of your family?

A: The first reaction of my family (my mom and my husband) was to take me to the hospital, first to the nearest Health centre and then to Ayder Referal Hospital in Mekelle. My husband immediately realizes that during the delivery I was not good recovered and that's why I developed the fistula.

Q: Did they help you finding a solution to the problem?

A: Yes, they helped me, specially my mother and my husband. My husband also helped me to the private health clinic to see what was happening with me. Then I went to Ayder Hospital and from there they send me to Hamlin Fistula Hospital, this was the first time that I suffer from fistula. The second time, after 4 years of the first fistula, I gave birth again and I developed fistula again, I was suffering this time for 5 years at home, because I could not leave my daughter alone 
and finally Zufan helped me to go to the hospital.

Q: How long have you been losing urine?

A: The first time that I realize that I had a fistula I went immediately to the hospital, but the second time, I wait for 5 years to go to the hospital again because my daughter needed me, she has a brain paralysis, so I had to take care of her. Finally I left her with my mother and I went to the Hospital, but I was very hurry to come back home to be with my daughter.

Q: Who told you about the Hamlin Fistula Hospital in Mekelle?

A: The gynaecologist from Ayder Referal Hospital in Mekelle told me about the hospital.

Q: Did your husband and family support you taking this decision?

A: Yes, they helped me a lot, my mom and my husband, both of them.

\section{d) Personal experiences in the hospital:}

Q: How long have you been in Hamlin Hospital?

A: I suffered a lot with fistula; I had surgery 3 times! The first time I was for 2 weeks in the hospital, the second time I was for 3 weeks and the last time 2 weeks again. When I was treated for the first time they told me that if I was again pregnant $I$ had to go there for the delivery, but I did not do it immediately, I suffered a lot so finally I went to Mekelle hospital to have the baby by caesarean.

Q: Were you pregnant when you came here?

A: No, I was not pregnant, the 3 times that I came to the hospital, I already gave birth, I went after the birth the three times.

Q: What do you value the most about your stay in the hospital?

A: What I really admire from the hospital is the treatment that we received, all the staff working in the hospital was really nice with us. After I was treated in Hamlin Fistula, I was in the Hospital of Mekelle trying to be treated with infusions, but it did not work. In Hamlin fistula hospital they gave us apart from the medical treatment, psychological treatment and also the valance of food was very helpful to recover fast from the surgery.

Q: Were you able to share personal experiences with other women who were there?

A: We share a lot of experiences between of us. For some of them was the first time in the hospital. I told them not to be worried that they will be fine again.

I made very good friends in the hospital, two of them were Tage and Vayuges and I call them sometimes to speak with them.

Q: If yes: In which experiences have you felt understood and supported by other women who were there?

A: We speak about a lot of things and we share a lot of things. I tried a lot to share my experiences at the hospital with the other women, I explain them not to be worried about the surgery because they will be fine again and that they do not have to be worried of having more babies because of it, they could have more babies but always giving birth at hospital with caesarean.

Q: When you will leave hospital, what are you going to miss the most?

When I left the hospital and I came back home I was crying all the time, I really love the woman that I met there, it was a very good experience for us. And also, I really miss the food from the hospital.

Q: How do you think is going to be your going back "home"?

A: I came back from the hospital with my husband and my children. When I came back to Mynebri, Zufan's organization gave me an economical support for the transportation and also to buy an ox.. When I get back, my husband was waiting for me at home and I 
went to my mom's house to pick up my daughter. All of us we started a new life after the treatment.

Q: Would you like to keep in contact with some of the women you have met here?

A: Yes I do, sometime I speak with some friends that I made in the hospital, I miss them a lot!

\section{e) Personal valuation about social and family in the returning back:}

Q: How did your family, friends, neighbours receive you when you returned from the hospital?

A: My mom and my son were here, at home the day that I come back. They cleaned the entire house and my son painted the house before I arrived here. My neighbours were very happy to see me back and good again.

Q: Did you return with your husband and children, to a friend's house, to any relative's house, or did you decide to live alone?

A: I came back home, with my husband and my children.

Q: What are the most positive changes towards you, you have since perceived after your return from the hospital? (From the family, friends, neighbours...)

A: Before I was treated from the fistula I could not go out from my house, I was afraid of going to my neighbour's house for coffee ceremony or to go to the market and the church, I could not go because of the bad smell. I did not know if my neighbours were discriminating me or not because during the fistula period, I was never out of my house, so I do not know. But after the treatment I can do everything again, not heavy work but apart from that almost everything, so I think that I had a big change, and a positive change.

Q: What attitudes towards you have not changed and by whom?
A: I am not sure about it because as I told it before, I was all the time at home so I do not know if my neighbours discriminated me or not.

Q: What are the most important changes you have notice in yourself since you came back from the hospital? (Higher self-esteem, selfimage, personal goals, dreams, personal desires...)

A: Even if I have been treated, I still have problems, not with my health but yes with the health of my daughter. I cannot go out to find a job, I have to take care of her but I can work at home, with hens and the ox and I can have an economic income apart from my husband's economic.

\section{f) Working together to find solutions:}

Q: How do you think that fistula can be prevented?

A: When I get back home from the hospital, ODWACE gave some advices to prevent the social exclusion of the fistula in our area, and that if we knew about any woman who was suffering from fistula, they asked us to give the contact of the organization to these women. Also they told us to tell to the future mom's to go to the hospitals for the delivery; we teach to the community that women have to give birth at the hospital in order to prevent the fistula.

Q: And what can be done to avoid social rejection caused by the fistula?

A: I was not rejected from the community because I was never out of my house during the period that I suffered the fistula. I cannot say that I was excluded; I am never going to know it. I thought for myself, how can I go to visit my neighbours in this situation? I cannot leave the house like this.

During the time that I was in the hospital, my husband use to visit me almost every day.

For the woman that have been rejected from the community, we have to teach to the community that this is not a punishment from 
God, that it is a health problem what we have and that because of it we do not have to be excluded from the community. Maybe one person from their family can suffer the fistula, so we have to help this woman and not exclude them.

For example, Takien (Wukro) I met her in the hospital and she was feeling very rejected from the community, she was feeling very bad with herself and she hide herself a lot, even she did not never tell anything to her husband about the fistula.

For the women that they have been rejected from the community, we have to teach to the community that fistula is not a punishment from God, it is a trauma, and maybe one day a member of your family can suffer it and you have to help her and take her to the hospital.

Q: What educational or strategies aimed at changing the mentality you think would be useful and are not being used?

A: It is very good to teach to the students about the prevention of the fistula, because like that these students can teach to their parents and the community about the fistula and the ways of preventing it, especially for the girls.

Q: In the area where you live, is there a prevention program?

A: Here, we are trying to tell to all women to give birth at the hospital or the nearest health centre around our area. Also we have some ambulances for that and we take pregnant woman to the hospital. The development agent's give us education about family planning and more issues related with the development.

Q: If there is, when you realized that you had a health problem and you were suffering its social consequences, did you ask for help?

A: I ask for help first to my mom, after to the chairperson from Mynebri. She told me about Hamlin Fistula Hospital in Mekelle, Also the women's development group told me that there is a fistula case in the village that she has to go to the Hamlin Fistula to be treated.

Q: Who was or were the persons more support offered you and how have they helped you?

A: The person that more helped me was the health extension worker and the regional women association. They helped me a lot. And of course, my husband, he was the one that took me to the hospital, even when I have to give birth he has encouraging me to go to the hospital but I did not want to go.

Q: What kind of support (economic, personal, and educational) you have missed and you think it is basic?

A: With the fistula, I was not able to work outside of the house and I am still not able to do heavy work inside of the house, so I really miss to have an economic income. So what I really miss is an economic support. I received a microcredit from ODWACE after the operation, 4.000 birr and with it I bought an ox.

Q: What have been the most significant personal things you have given away because of fistula?

A: I was not able to do any social live, I was all the time inside of the house, also that I was not able to work outside of the house to get some economic income.

Q: Is there anything you miss from your experience in the Hamlin Hospital?

A: What I really miss are the friends that I made in the hospital, the food, and the staff from the hospital, everything, I miss everything.

Q: Something else that you would like to tell me?

A: I want to say that I give thanks to the Fistula Hospital and for the support that I received from the organization. For these women that they have not been treated yet, please go to the hospital to get better and to the family members of them please help them to 
the hospital and do not reject them because of fistula, it is not a punishment.

When I was in the hospital, Zufan came to ask me if I wanted to receive an economic support from her organization and first I answered that no, because how it was supposed that I was going to give back the money if I was all the time at home. After some days of thinking about the offer, I changed my mind and I thought that it could be a good idea to buy some animals and work at home and make money to get back after, so like that I have little income and I can change my life.

\section{HUSBAND}

Q: Do you have any suggestion relating with the fistula?

A: First at all, I want to thanks to our government for building the Hamlin Fistula Hospital where woman suffering from fistula can be treated close to their houses, also thanks to ODWACE for giving the economic support for women who have been treated from fistula. I would like to say that there are so many women that they suffer from fistula and that they do not know about the treatment. The prevention program have to improve from the health extension and the development group, they have to continue working on this. Our good government, thank you a lot, before this government, we did not have this political structure and it helps a lot for the development.

Q: And, what do you think about the cases where the husbands get divorced from their wife because they suffer from fistula?

A: I think that it is because their husbands have lack of awareness, fistula it is not a punishment for women, it is not only the problem of the women, is our problem. She suffer from this because she is the one who gave birth, it is our problem, for both. We want to have children and she develops the fistula, so we need treatment for it to be able to continue. I think that the husbands that get divorce from their wife's they have a lack of awareness. 


\section{Letekiros Kebedew, 40 years old \\ 14.04.2014 \\ Place: Myale \\ Translator: Zufan Ababe}

\section{a) General information}

Q: How old are you?

A: My name is Letekiros Kebedew and I am 40 years old

Q: Until what age did you go to school and what grade did you finish?

A: I never went to school.

Q: In which place have you been living for the last 5 years?

A: I was born in Myale and I still live in the same place.

Q: How old were you when you got married?

A: I got married when I was 16.

Q: How many years older or younger is your husband?

A: The difference between my husband and me is 6 years.

Q: Was your own choice to marry your husband or did someone else tell you to marry him?

A: No, it was the choice of my parents.

Q: How many sons or daughters do you have?

A: I have 6 children, 2 girls and 4 boys.

Q: Ask for the family members: who else is living in your house?

A: I life with my children only... my husband died one year ago, he stayed with me during fistula treatment. He had a lot of psychological problems (Zufan told me that her husband use to hit her)

Q: Does your husband work or has worked before?
A: He is dead

Q: Did you work or have you been working outside of the house? If yes, ask where and what was she doing.

A: I never work outside of the house

Q: At home, can you describe me all the things you are in charge in your everyday life?

A: I do not do that much at home, I just prepare the food for my family, I clean the house, I wash the clothes, and I make enjera. Everything at home I do it by myself.

Q: Valid indicators to establish the economic level: Ask if the home is owned or rented, if they have animals or not (number and type of animals), if they own land for cultivation (approximate size of the field), if the land is rented or bought it, type of crop they produce, if they have manual irrigation or not, if they have running water close to the house or not, electricity, radio at home)

A: It is my own house; I have a land for cultivation. I have two oxen for land cultivation and six sheep; I bought them with the economic support that ODWACE gave to me. The cultivation land that $I$ have it is my own land; I cultivate teff to make enjera. I have water next to my house but not in the house. I do not have electricity at home.

\section{b) History of motherhood:}

Q: How old were you when you had your first child? (This will be hard to know because there is no birthday culture in Ethiopia and usually do not know how old they are)

A: I got married when I was 16 years old as I told you and I had my first children after one year of marriage, when I was 17 years old.

Q: Where have you given birth? At home, in a health centre, a hospital... 
A: I gave birth at home, it was 23 years ago and we did not have any access to the hospital and it was common to give birth at home. I gave birth to 8 children but two of them where dead and yes all the deliveries where at home. The last children that I had were dead in my uterus and this was the reason of developing the fistula in my case.

Q: If you gave birth at home, who was attending the birth?

A: A traditional birth attendance was helping me during the delivery, but also my mother, my sister, my neighbour were there during the delivery, helping me.

Q: Did you have any complications during the delivery? If the answer is yes ask: what kind of problem? And what did you do?

A: I had complications during the last delivery. I was on labour for 3 days, I started on Thursday with the delivery and I finished on Saturday. After waiting for three days of delivery, I was throwing up and the child was dead, I had an obstructed labour which produced the fistula. After the last delivery, I realize that I was losing urine. I was not able to see if my bladder was full or not, the urine flows when it wanted. My clothes were dirty and wet all the time; I did not know what was happening to me. I told to my mom what was happening to me.

Q: How far (approximate time) is your house from the nearest health centre or hospital? And how can you get there?

A: The nearest clinic is in our village, if the delivery is good, woman can have the babies there, but if they see that it is going to be a difficult labour they have to go to Mekelle to have the babies. This clinic was opened in 1996 (European calendar)

\section{c) Early symptoms of fistula and social support or rejection:}

Q: From your point of view, what are the consequences of the fistula?
A: For three years I was living with fistula. Everybody was discriminating me because of it. Nobody wanted to be with me or visit me. I feel much rejected during the fistula years. I was not able to leave the house, I could not do things for the community, and I suffer a lot. I was very afraid of leaving the house to go to the market, to the church, or to the coffee ceremonies and I could not work outside of the house

Q: When did you realize that you were losing urine?

A: After the difficult labour, with my $8^{\text {th }}$ delivery I realize that I was losing urine.

Q: What was your first reaction?

A: I was very afraid, I could not understand what was going on, I could not control my own bladder, I could not feel that my bladder was full or not. I had a big pain because of the delivery.

Q: Did you tell someone or did you keep it for yourself?

A: When that happened, I took my clothes and I went immediately to tell to my mother what was happening to me, explaining that I could not control my urine and telling her to help me. Because of the delivery, I had a big pain in my back when I lay down to rest and the urine was flowing.

Immediately when I realize that I was losing urine I thought that it was a punishment from God because I lost the baby, but my neighbour told me that it was not a punishment, it was because the baby that I had was dead inside of me and that was the reason of provoking the fistula. But for me it was a punishment from God.

I developed the fistula before the clinic from Mekelle was opened so, I went for the surgery to Addis Ababa Hospital. The gynaecologist from Mekelle Hospital told me about the hospital where they repair the fistula. I was lucky because at that time in Mekelle was not Hamlin Fistula Hospital so in case that I had to go to Addis I need lot of money for 
transportation. But after one year they opened the Hospital in Mekelle where I was treated. Maybe I am from the first generation of Mekelle's hospital!( she starts to laugh)

Q: What was the reaction of your family?

My family sold a cow to pay the transportation for the hospital.

Q: What was the reaction of the other family members and neighbours?

A: My neighbour told me about the existent treatment for the fistula.

Q: Did they help you finding a solution to the problem?

A: Yes, all of them helped me finding solution to my problem.

Q: How long have you been losing urine?

A: I was for 3 years suffering the fistula.

Q: Who told you about the Hamlin Fistula Hospital in Mekelle?

A: Before me, in the village there was another lady that had the same problem and she was treated in Hamlin Fistula. She talked with my parents and told them that they had to bring me to the hospital. In the hospital they aware us that in case that we know any woman is suffering from fistula we have to tell them to go to the hospital. So my parents took me immediately to the hospital to be treated.

Q: Did your husband and family support you taking this decision?

A: Yes, they helped me with the decision, my mother, my husband everybody.

\section{d) Personal experiences in the hospital Q:}

Q: How long have you been in Hamlin Hospital?

A: I was in the hospital for one month and two weeks because I was anaemic person

Q: Were you pregnant when you came here?
A: No I was not pregnant and the fistula happened with my last pregnancy.

Q: What do you value the most about your stay in the hospital?

A: Before the operation they control my weight and the food that I was eating, they checked my blood. They took care of me and I really appreciate that.

Q: Were you able to share personal experiences with other women who were there?

A: Yes, we shared a lot of things between us, we were discussing about our husbands as well (laughing), like my husband is good, not my husband... some of them told me that their husbands left them because of the fistula. We share a lot of different experiences. Kiros, my friend from the hospital for example had lot of problems with her husband, he divorce her because of the fistula.

Q: When you will leave hospital, what are you going to miss the most?

A: I miss the friends that I made in the hospital and the treatment. I really miss to speak about our feelings. I miss all of it.

Q: How do you think is going to be your going back "home"?

A: There was a nurse that worked in the Hamlin Fistula that took me to the hospital. After the treatment, she came to pick me up from the hospital and we came back home. Everybody was happy to see me back and that I was fine again (laughing). My neighbours were very happy to see me healthy again. Also because when I had the fistula, I could not move my left leg and now I was good again. Everybody was telling me that I was able to walk again and to be with to spend time with family and friends again and walk! Thanks to God and government I am fine again. My neighbours were telling that in Mekelle there was a God that makes women to be good again, Dr. Melaku. 
After I left the hospital, I went two times to visit the hospital and we bring bread that we baked at home. We spoke with women that were going to be treated at that time and we tell them not to be worried, that everything would be good again for them. We kissed everybody, even to Dr. Melaku to say him thanks for your treatment.

Q: Would you like to keep in contact with some of the women you have met here?

A: Yes, I call to the friends that I made in the hospital! One of them told me that when she was going to have a baby, she would call me to go and visit her.

e) Personal valuation about social and family in the returning back:

Q: How did your family, friends, neighbours receive you when you returned from the hospital?

A: They were all of them very happy to see me back and healthy again. They celebrate with me the beginning of my second life.

Q: Did you return with your husband and children, to a friend's house, to any relative's house, or did you decide to live alone?

A: I came back to life with my husband and my children to life.

Q: What are the most positive changes towards you, you have since perceived after your return from the hospital? (From the family, friends, neighbours...)

A: Yes, all of them were very happy to see me back and healthy again. Before the treatment anyone was coming to visit me at home and I was never invited to the other houses. Now again everybody wants to come to visit me and I go to visit them.

Q: Were you feeling excluded when you were suffering the fistula?

A: I knew that I smell bad, so everybody was speaking about me, my neighbours were saying that it was better if I was dead than to be like that, if you have to life with urine all the time is better to die, it is a punishment, and nobody can treat this trauma.

Q: What are the most important changes you have notice in yourself since you came back from the hospital? (Higher self-esteem, selfimage, personal goals, dreams, personal desires...)

A: After I came back from the hospital my dream was to work with the community again and feel part of the community, work in soil and water to generate any economic income. I was able again to be with my neighbours and drink coffee. I was thinking about these things when I came back from the hospital.

\section{f) Working together to find solutions:}

Q: How do you think that fistula can be prevented?

A: The most important thing is to teach to the children about these things; also it is important to avoid the early marriages. Before giving birth we have to go to the hospital.

Chairperson: To change the attitudes of the community we work with the development agents, educating about the harmful traditional practices, if we educate them we can prevent the fistula. We have the development agent meetings every two weeks and we teach and we discuss about early marriage, about pre and post-delivery, saying that it is very important for pregnant women to do the cheeking.

Q: And what can be done to avoid social rejection caused by the fistula?

A: Last month we gave to 400 people the prevention about the fistula because in our village we have 5 cases of fistula (and 3 more not treated) and we have to work on that, not to be rejected from the community and not to be happen anymore early marriages, and delivery at hospital. We educate them not to discriminate women with fistula, teaching that it is not a God punishment for these women, which it is something that any woman can 
suffer and because of it they do not have to be discriminated.

Q: What educational or strategies aimed at changing the mentality you think would be useful and are not being used?

A: The education to change the mentality that we are using is working directly with the community, teaching them about these issues like fistula, early marriage, FGM etc.

Q: In the area where you live, is there a prevention program?

A: Yes, every two weeks the development groups we organize meetings to discuss about fistula and other issues. Meetings are for 400 people more or less for old, young, men, women, for everybody.

Q: If there is, when you realized that you had a health problem and you were suffering its social consequences, did you ask for help?

A: Yes, I ask for help.

Q: Who was or were the persons more support offered you and how have they helped you?

A: My mother and my husband, both of them helped me the most.
Q: What kind of support (economic, personal, and educational) you have missed and you think it is basic?

A: I got the economic support from ODWACE, 2.000 birr. But I miss maybe little bit more of economic support because my husband died one year ago and I am really having economic problems. The prevention education program I got it from the organization Healing hands for joy.

Q: What have been the most significant personal things you have given away because of fistula?

A: I really miss to work with the community in the water and soil conservation, to take care of our lands and to be with the community all together working.

Q: Is there anything you miss from your experience in the Hamlin Hospital?

A: I miss everything, I miss the food, the treatment of the staff from Hamlin Fistula, even the medical treatment, everything. 


\section{Tasfai, 33 years old \\ Date: 17.04.2014 \\ Place: Myale \\ Translator: Zufan Ababe}

\section{a) General information:}

Q: How old are you?

A: I am 33 years old

Q: Until what age did you go to school and what grade did you finish?

A: I did not go to school

Q: In which place have you been living for the last 5 years?

A: I was born in Myale and I still living here

Q: How old were you when you got married?

A: I got married when I was 13 years old

Q: How many years older or younger is your husband?

A: He was 18 years old when we got married, so he is 5 years older than me.

Q: Was your own choice to marry your husband or did someone else tell you to marry him?

A: When I was 10 years old, my parents promised to his parents that we would get married.

Q: How many sons or daughters do you have?

A: I have 3 boys and 1 girl. Two of them are from my first husband, the other two from different boyfriends. The ages are 14, 12, 7 and 4 years old

Q: Who else is living in your house?

A: I live only with my children.

Q: Does your husband work or has worked before?

A: I do not have husband right now
Q: Did you work or have you been working outside of the house? If yes, ask where and what was she doing.

A: I have a coffee house in my house; I work at home and in the coffee house.

Q: At home, can you describe me all the things you are in charge in your everyday life?

A: I do everything at home

Q: Valid indicators to establish the economic level: Ask if the home is owned or rented, if they have animals or not (number and type of animals), if they own land for cultivation (approximate size of the field), if the land is rented or bought it, type of crop they produce, if they have manual irrigation or not, if they have running water close to the house or not, electricity, radio at home).

A: My house is my own home, I got a credit to pay the house, the credit is with interest and I work to pay back that money, because my children are too small to work to help me. I have my own land for cultivation; I rent the land because I do not have any Ox to work on the land so I rent it. Running water is close to my house, 10 minutes walking. I have electricity and yes I have a radio and also an electric pan to make enjera.

\section{b) History of motherhood:}

Q: How old were you when you had your first child?

A: I was 15 years old when I gave birth for the first time and I develop fistula with the first children.

Q: Where have you given birth? At home, in a health centre, a hospital...

A: I gave birth at home, all of them. 
Q: If you gave birth at home, who was attending the birth?

A: Traditional birth attendance was attending the birth.

Q: Did you have any complications during the delivery? If the answer is yes ask: what kind of problem? And what did you do?

A: I had complications with the first delivery, the first child was dead which produced the obstructed labour where I develop the fistula, I was for four days in labour, the children was dead in my uterus and it was dehydrated when it came out, he lose his weight. After that delivery, I did not have any children until 5 years later. My husband also he was sick and he died. At that time there was not Hamlin Hospital in Mekelle, so I had to go to Addis to be treated. I suffer from fistula for one year.

Q: How far (approximate time) is your house from the nearest health centre or hospital? And how can you get there?

A: When there is a complication labour we have to go to Mekelle Hospital. Now we have ambulances but at that time we did not. Also the road that we have now still is very bad.

\section{c) Early symptoms of fistula and social support or rejection:}

Q: From your point of view, what are the consequences of the fistula?

A: I was very young when I develop fistula. I was very young so it was expected to do more things but because of the fistula I was always sitting in my home. I could not even go out to play with my friends, I just wanted to play with them, I was very, very young. So it was very complicated, also to explain about the fistula is very hard for me.

Q: When did you realize that you were losing urine?

A: I realize after the 4 days labour that something was wrong, that I was not able to control my urine; it was going out when it wanted

Q: What was your first reaction?

A: I was very worried about it; I could not understand what was happening to me. Immediately I went to tell to my mother, she did not know what was happening to me and she asked to a friend of her, and she told us that it was because of the difficult labour that I had.

Q: Did you tell someone or did you keep it for yourself?

A: I tell to my mother immediately, also I told to my husband, we were very scared because we did not know what was happening.

Q: What was the reaction of your family?

A: My mother and my brother and sister asked to the community if they knew what was happening to me. Some of them told to my family that it was because I had a difficult labour and that there was a hospital in Addis where I could be treated.

Q: Did your husband help you? And your sons and daughters?

A: Yes, my father and my brother took me to the Hospital in Addis.

Q: How long have you been losing urine?

A: In total I was one year losing urine.

Q: Who told you about the Hamlin Fistula Hospital in Mekelle?

A: When my family and I were asking about the problem, one neighbour told me about the hospital in Addis.

Q: Did your husband and family support you taking this decision?

A: We discus together about it and finally my father and my brother took me to the hospital in Addis.

\section{d) Personal experiences in the hospital:}


Q: How long have you been in Hamlin Hospital?

A: In total I was 2 month in the hospital

Q: Were you pregnant when you came here?

A: No, I was not pregnant, after 4 years I get pregnant again and I had 4 children.

Q: What do you value the most about your stay in the hospital?

A: I do not remember a lot of things because I was very young when I went there and also it was 18 years ago, so I am not able to remember a lot of things about it. My father and my brother helped me and they did a lot of things for me. They were in Addis during the time that I was there; they use to come to visit me.

Q: Were you able to share personal experiences with other women who were there?

A: I was not able to speak Amharic, I just speak Tigrinya, and so I was not able to speak a lot with the other woman. But I remember that we use to discus about our husbands, we complain because it was part of the fault of our husbands to develop the fistula, so then why they were not with us here? Some of them were saying that it was not the fault of the husband, that it was a punishment from God.

Q: When you will leave hospital, what are you going to miss the most?

A: I do not really remember my time there, but I remember that I feel very good at the hospital. I was very far from my house but I remember that I like a lot the food that they cook there.

Q: How do you think is going to be your going back "home"?

A: I came back with my father. When I came back home, my mother, my neighbours, were very happy. They thanks to God that I came back healthy again. My mother was thanking a lot to God, she was very happy. When I came back from Addis, my husband was sick and he died in a short time.

Q: Would you like to keep in contact with some of the women you have met here?

A: At that time, we did not have telephones, so I do not speak with them never again.

\section{e) Personal valuation about social and family in the returning back:}

Q: How did your family, friends, neighbours receive you when you returned from the hospital?

A: All of them were very happy to see me back and healthy again. They thank God because I was back again.

Q: Did you return with your husband and children, to a friend's house, to any relative's house, or did you decide to live alone?

A: I was very young when I got married, so I was living with my husband but in my parent's house, because I was not able to pay our own home, my mother was helping us. After I came back from the hospital in Addis, I was not able to work outside of the house, I was feeling little bit weak, also my husband was very sick and he died very fast. After, with my second husband, I had two children and then I divorce from him.

My youngest child is 3 years and half and he lives with his father and his new wife. His new wife cannot have any children so they decided to take my son to life with them, telling that I already have 3 more children!

Q: Did you feel discriminated when you had fistula?

A: I was never outside of my house, so I was not feeling discriminated, my mother and father were here for me and also my husband, so I do not really feel discriminated. My neighbours were sad because of me, they sometimes come to my house to visit me. Even that, I was never out because I knew that I was going to be discriminated. 


\section{f) Working together to find solutions:}

Q: How do you think that fistula can be prevented?

A: We have to teach to the pregnant women to go to check the pregnancy before and after the delivery. We have to send our children to school to educate them, this is very important to do.

Q: And what can be done to avoid social rejection caused by the fistula?

A: Last month for example, we had training from Healing Hands of Joy for the prevention. There was a woman that was suffering from fistula, and she was discriminated from her community because of it. We have to teach to the community not to discriminate fistula victims, just they have to help her and bring them to the hospital.

Q: In the area where you live, is there a prevention program?

A: Yes, we have some....

Q: If there is, when you realized that you had a health problem and you were suffering its social consequences, did you ask for help?

A: Yes, I ask for help to my family and to my neighbours.

Q: Who was or were the persons more support offered you and how have they helped you?

A: Heath extension workers and the women association have been the persons who more help me.
Q: What kind of support (economic, personal, and educational) you have missed and you think it is basic?

A: I really miss economic support, educational one is already passed, I did not go to hospital and I think that if I was educated, I could do more things. But what I miss is the economical support.

Q: What have been the most significant personal things you have given away because of fistula?

A: My childhood, I was married at a very early age and what I wanted was to play with my friends. Also I could not work outside of the house, I was doing manual things inside of the house but I wanted to work outside of the house and I was not able.

Q: Something else you want to say?

A: We have to educate the community and we are good persons to teach them, because we have suffered a lot. We have to bring fistula women to the hospital to be treated and to be healthy again and to be able to continue with their lives. 


\section{Abrehat Asefa, 25 years old \\ Date: 22.04.2014 \\ Place: Myale \\ Translator: Zufan Ababe}

\section{a) General information:}

Q: How old are you?

A: I am 25 years old.

Q: Until what age did you go to school and what grade did you finish?

A: I did not go to school

Q: In which place have you been living for the last 5 years?

A: I was born here in Myale and I'm still living here.

Q: How old were you when you got married?

A: I do not remember when I got married. What I Know is that 10 years ago I gave birth but the baby was dead, so I think that I got married when I was 13 or 14 years old.

Q: How many years older or younger is your husband?

A: When we got married he was 20 years old, so 7 years older than me more or less.

Q: Was your own choice to marry your husband or did someone else tell you to marry him?

A: It was not my choice to marry him; I was a child when I had to get married

Q: How many sons or daughters do you have?

A: I have two children; the oldest one is now 6years old and the young one 2 years old. But I have been pregnant 3 times; the first baby that I was expecting was dead before it was born.

Q: Ask for the family members: who else is living in your house?

A: I life with my husband and two children.
Q: Does your husband work or has worked before?

A: My husband is a priest and he also works on building houses in our village.

Q: Did you work or have you been working outside of the house? If yes, ask where and what was she doing.

A: I do not work.

Q: And at home, can you describe me all the things you are in charge in your everyday life? A: Everything at home I do it, washing, cooking, cleaning, give food to the children, prepare the enjera... little things at home. Sometimes I also make some decoration.

Q: Valid indicators to establish the economic level: Ask if the home is owned or rented, if they have animals or not (number and type of animals), if they own land for cultivation (approximate size of the field), if the land is rented or bought it, type of crop they produce, if they have manual irrigation or not, if they have running water close to the house or not, electricity, radio at home).

A: We have our own home, right now we are living in our parents' house so we are renting the other house to some people. We do not have any land but yes my parents. We do not have water but yes we have electricity and a radio at home.

\section{b) History of motherhood:}

Q: How old were you when you had your first child? (This will be hard to know because there is no birthday culture in Ethiopia and usually do not know how old they are)

A: I had my first children when I was 15 years old, but it was dead. My second son I had when I was 18 years old. 
Q: Where have you given birth? At home, in a health centre, a hospital...

A: I gave birth at home the first time

Q: If you gave birth at home, who was attending the birth?

A: My mom was attending the delivery. I was in labour for 3 days, the baby was dead and before the baby come out the urine started to flow. My mom told me that because the baby was drinking my urine it was dead. And it was suffocated; maybe it was because of that or for another reason. It was then when I develop the fistula. I went to the Fistula Hospital and they told me that in case that I was going to have another baby, I had to go back to the hospital for the delivery. And I had other babies in the hospital by caesarean.

Q: Did you have any complications during the delivery? If the answer is yes ask: what kind of problem? And what did you do?

A: Yes, I had complications during the delivery.

c) Early symptoms of fistula and social support or rejection:

Q: From your point of view, what are the consequences of the fistula?

A: I was for 3 month suffering from fistula, I was all the time in my house, I was not able to go out of the house and at that moment I was 14 or 15 years old so I just wanted to play in the street with my friends, enjoy with them. That was very bad.

Q: When did you realize that you were losing urine?

A: After 3 days of giving birth, I realize that I was not able to control my urine. So immediately I told to my mother what was happening to me. She was very afraid as well. She did not know what it was. I told to my husband as well about my problem and after one month they took me to Mekelle Hospital to see a gynaecologist. He told me that I had to wait 3 months to be treated but that he was going to treat me. After 3 months I went and I was treated. Then, one month later I went for the cheeking and he told me that it was better if I go to Hamlin Fistula Hospital in Addis. At that time the clinic of Mekelle was not opened. I went to Addis with my husband, in the hospital they told me that I had to be in Addis for three months so my husband came back home.

My husband is a priest so he was helping me with it because he cannot get married again! Our religion forbids that they can get married more than one time. So he helped me to Addis and then he came back to Myale.

In the hospital, they advised me that if I was pregnant again and that $I$ had to go to the hospital to gave birth.

Q: What was your first reaction?

A: I was very scared because I could not understand what was happening to me

Q: Did you tell someone or did you keep it for yourself?

A: First I told to my mother and after to my husband

Q: What was the reaction of your family?

A: My mom was very scared and also my husband. They did not know what was happening to me, they could not understand anything.

Q: Did your husband help you? And your sons and daughters?

A: Husband helped me to go until Addis for the surgery.

Q: How long have you been losing urine?

A: In total 3 or 4 months.

Q: Who told you about the Hamlin Fistula Hospital in Mekelle?

A: The gynaecologist from Mekelle Hospital told about the Hamlin Fistula Hospital in Addis

Q: Did your husband and family support you taking this decision? 
A: Yes, also my husband was the one who helped me until Addis.

\section{d) Personal experiences in the hospital:}

Q: How long have you been in Hamlin Hospital?

A: 3 months I was in the Hospital

Q: What do you value the most about your stay in the hospital?

A: They treat me so well, I stop losing urine and I am very, very happy because of that. I was missing a lot my family back home but I was thinking all the time that when I got back home I would be able to spend time with them out of my house.

Q: Were you able to share personal experiences with other women who were there?

A: Yes, we were a lot of women, from Oromia, Amara region...we wanted to share our experiences but it was very difficult because of the language, I could not speak Amharic, just Tigrinya. Even that I love the girls in the hospital, we had a very good time together.

Q: When you will leave hospital, what are you going to miss the most?

A: I miss the all hospital, the food, the treatment, people, everything, the clean place and bed...

Q: How do you think is going to be your going back "home"?

A: My husband went to pick me up to Addis and he helped me to come back to Myale. My family and my neighbour were very, very happy to see me back home and healthy again

Q: Would you like to keep in contact with some of the women you have met here?

A: No we did not have telephones at that time, it is really sad, because also now I am able to speak little bit of Amharic!

\section{e) Personal valuation about social and family in the returning back:}

Q: How did your family, friends, neighbours receive you when you returned from the hospital?

A: They receive me very, very warm welcome. My mother, my father, my neighbour all of them was very happy to see me back home and healthy again!

Q: Did you return with your husband and children, to a friend's house, to any relative's house, or did you decide to live alone?

A: I went back with my husband to live, as I explain before, he is a priest so he can got married more than once.

Q: What are the most positive changes towards you, you have since perceived after your return from the hospital? (From the family, friends, neighbours...)

A: Everybody was coming back to visit me at home.

Q: What are the most important changes you have notice in yourself since you came back from the hospital? (Higher self-esteem, selfimage, personal goals, dreams, personal desires...)

A: My dream was that after the treatment when I was backing home to be with everyone again. I am the wife of the priest so I have to be with people and when I had the fistula I could not do anything, just to be at home alone.

\section{f) Working together to find solutions:}

Q: How do you think that fistula can be prevented?

A: The most important thing is that when we get pregnant to go to the hospital. We have to educate the pregnant women together and give them advice to go to the hospital before the delivery. 
Q: And what can be done to avoid social rejection caused by the fistula?

A: St. Mary help us to give birth and when he come to help us we have to go with him to the health centre... we have to teach the community that the discrimination is not good. I was not feeling discriminated because I was all the time at home.

Q: What educational or strategies aimed at changing the mentality you think would be useful and are not being used?

A: Those who are treated already we have to teach to the community about our life experiences. Also the health extension workers have to teach to the community to give birth in health centres. Also we development agents have to teach the community about fistula and for the prevention of fistula.

Q: Is it enough prevention for you?

A: Also we have to teach to the students about the prevention and non-discrimination of fistula victims.

Q: In the area where you live, is there a prevention program?

A: Yes, health extension workers and specially the development agents work on that.

Q: Who was or were the persons more support offered you and how have they helped you?

A: Methim (chairperson) was the one who help me most and after her my husband. She gave me all information about the Hamlin Fistula, education, and prevention. She helped me the most.
Q: What kind of support (economic, personal, and educational) you have missed and you think it is basic?

A: What I really miss is education. I can discuss about everything with my husband and my economic is good but what I really miss is education and we have to change it. I got the economic support from ODWACE and with it I bought a cow with it.

Q: What have been the most significant personal things you have given away because of fistula?

A: I wanted to have education and I could not do it because I was married very early and I suffer fistula at a very early age, if not I would love to be able to study.

Q: Is there anything you miss from your experience in the Hamlin Hospital?

A: To live in the hospital!! (She started laughing)

Q: Something else?

A: I want to say to that women's that are suffering from fistula that they have to go to be treated and that they will be better again. 


\section{Hatsed Mehari, 23 years old}

Date: 24.05.2014

Place: Mekelle

Translator: Zufan Ababe

\section{a) General information:}

Q: How old are you?

A: I am 23 years old.

Q: Until what age did you go to school and what grade did you finish?

A: I went to school until grade 6

Q: In which place have you been living for the last 5 years?

A: Now I am living in Mekelle, but until 2 years ago I was living in Myale. Now I live in Mekelle with my husband.

Q: How old were you when you got married?

A: When I was 16 years old I got married

Q: How many years older or younger is your husband?

A: My husband now is 30 years old, so 7 years older than me. But my first husband when I got married he was 27 years old, so 11 years older than me.

Q: Was your own choice to marry your husband or did someone else tell you to marry him?

A: It was not my choice to marry my first husband; it was my parent's choice. But my second husband it was my choice to marry him.

Q: How many sons or daughters do you have?

A: I have one daughter of 2 years old.

Q: Ask for the family members: who else is living in your house?

A: I live with my daughter and my second husband.
Q: Does your husband work or has worked before?

A: My husband is working with his brother and they sell the oil.

Q: Did you work or have you been working outside of the house? If yes, ask where and what was she doing.

A: I do not work.

Q: At home, can you describe me all the things you are in charge in your everyday life?

A: At home also!! I do not work!!!

Q: But, can you explain me what kind of things you do at home?

A: I clean the house, I prepare the enjera, the food, I wash the clothes...

Q: Valid indicators to establish the economic level: Ask if the home is owned or rented, if they have animals or not (number and type of animals), if they own land for cultivation (approximate size of the field), if the land is rented or bought it, type of crop they produce, if they have manual irrigation or not, if they have running water close to the house or not, electricity, radio at home).

A: My house is rented in Mekelle and we have a land in Myale that the government give to us to build a house, but we do not have it for cultivation. Yes we have water in the house in Mekelle and also electricity.

\section{b) History of motherhood:}

Q: How old were you when you had your first child?

A: I got married for the first husband when I was 16 years old and I had my first child at 17 years old. 
Q: Where have you given birth? At home, in a health centre, a hospital...

A: I gave birth at home

Q: If you gave birth at home, who was attending the birth?

A: During the delivery traditional birth attainder was with me. And she was the one who take out the dead baby out.

Q: Did you have any complications during the delivery? If the answer is yes ask: what kind of problem? And what did you do?

A: I had complicated delivery; I was on labour for three days. I started on Saturday until Monday, and of course the baby was dead and because of the prolonged labour I develop the fistula. Until Tuesday I was not able to urine and I had a big pain and they take me to the clinic. I realize that I could not control my urine anymore.

Q: How far (approximate time) is your house from the nearest health centre or hospital? And how can you get there?

A: More or less it was when I gave birth on 2006 ; it was around $6 \mathrm{~km}$ away from my house.

\section{c) Early symptoms of fistula and social support or rejection:}

Q: From your point of view, what are the consequences of the fistula?

A: Because of the urine that I was not able to control it, I had a big infection in my legs. I suffered a lot because of the fistula. I went to live back with my family again, there were two rooms, in one room all my family and in the other one just me. Anyone came to visit me because of the bad smell; only my sister was taking care of me. In the clinic they advised me to clean my body and the room as much as I could, so my sister was doing that for me.

I was inside of the room for 3 months because I was not able to go out, also because the urine was hurting a lot in the infection, I was not able to walk! It was like to have fever, the urine is acid and with the infection it was very, very painful.

Q: When did you realize that you were losing urine?

A: Immediately, after the delivery, on Tuesday already I was losing urine and I was with fistula for 3 months and I was in the bed all the time.

Q: What was your first reaction?

A: Immediately I told to my sister, she immediately saw my bed that it was wet. So first we went to the clinic close to my village and from them they send us to Mekelle Hospital. In Mekelle hospital they directly send me to Hamlin Fistula Hospital. There they told me that I just gave birth 4 days ago, so that I had to wait for 3 month for the surgery and to wait at my home. They cannot treat us immediately after the birth; we need to wait 3 months until we recover from the delivery. The doctor advised me to use dippers because of the infection.

Q: Did you tell someone or did you keep it for yourself?

A: I told to my sister but not to my husband. My sister was the one who told him about what was happening to me.

Q: What was the reaction of your family?

A: As soon as I told to my sister, we saw my bed totally wet, so we went immediately to the hospital. I could not understand what was happening to me and also my sister.

Q: Did you think that it was a punishment?

A: I do not know I really was not able to understand what was happening to me. I was only 17 years old and apart from losing the urine I had a big pain.

Q: What was the reaction of the other family members and neighbours?

A: One woman of my neighbour when she enter in our house, she said that the smell was very bad. My sister every day was washing my 
body and my room. She used a perfume and incense in my room. They did not know anything about what was happening to me, we never told them about my problem

Q: Did they help you finding a solution to the problem?

A: My sister yes, she immediately helped me to the hospital.

Q: Did your husband help you? And your sons and daughters?

A: The first time that I went to the clinic, I went by traditional ambulance. After three months, there was a nurse who took me with my sister and my husband to Hamlin Fistula Hospital. In that period my husband was next to me but after the treatment, I decided to not to continue with my husband anymore because I was not able to have sexual relations for 3 months so I divorce him. During the period of the fistula, I was living with my sister while my husband was in our own home, living alone.

Q: How long have you been losing urine?

A: Totally 3 months, immediately I went to the hospital where they advise me that for the surgery I had to wait 3 months after the delivery.

Q: Who told you about the Hamlin Fistula Hospital in Mekelle?

A: When I went to Mekelle Hospital to check what was happening to me, they refer me directly to Hamlin Fistula Hospital, they told me in Mekelle that there was a Hospital where they could treat me.

Q: Did your husband and family support you taking this decision?

A: Yes they did, but after the surgery in Hamlin Fistula Hospital, I decided not to continue with my husband because I was not able to have sexual relations for 2 or 3 months. So I was afraid and I divorce him.

\section{d) Personal experiences in the hospital:}

Q: How long have you been in Hamlin Hospital?

A: I was there for one month and one week

Q: What do you value the most about your stay in the hospital?

A: The beds were very good, the bedclothes were very clean, the food was really good, and the water everything was clean and good. Also the workers were kind and nice with us, they treat us really well!

Q: Were you able to share personal experiences with other women who were there?

A: When I was there, most of the women were from Amhara region, so I was not able to speak with them because I only speak Tigrinya! And when I was trying to speak Amharic, all of them were laughing at me! We had fun, even if we were not able to have deep discussions.

Q: When you will leave hospital, what are you going to miss the most?

A: I get us to the hospital very quickly! When I came back to my house I could not adapt to it! I really miss the hospital and it was very hard to come back home.

Q: How do you think is going to be your going back "home"?

My sister came to the hospital and we walk until Myale (20 or $25 \mathrm{~km}$ ), my husband did not come to the hospital.

Q: Would you like to keep in contact with some of the women you have met here?

A: No I do not keep in contact with anyone, I wish I could but the language barrier was a big problem for us. 
e) Personal valuation about social and family in the returning back:

Q: How did your family, friends, neighbours receive you when you returned from the hospital?

A: Everybody was very happy to see me back and healthy! My neighbours came to visit me to my sister's house but we did not have a coffee ceremony, because my sister was with me and she already helped me so I did not want her to do it. But some neighbours came to visit me, so we all were happy.

Q: Did you return with your husband and children, to a friend's house, to any relative's house, or did you decide to live alone?

I came back to my sister's house to live. The doctors told me not to have sexual relations for 6 months and after that to use contraceptives for two years because were dangerous to get pregnant. So I was very worried about my husband, how he cannot have sex in 6 months and then no children in 2 years? So, it was better to divorce him.

Q: What are the most positive changes towards you, you have since perceived after your return from the hospital? (From the family, friends, neighbours...)

A: With my family, with my neighbours and with my community I was feeling better. I was not able to do hard work, like carry water but if not I was back again to my everyday life.

Q: What are the most important changes you have notice in yourself since you came back from the hospital? (Higher self-esteem, selfimage, personal goals, dreams, personal desires...)

A: After the surgery, my main dram was to be able to move to Mekelle and no to the village.. I wanted to move to the city. Also to divorce my husband, we were angry all the time, we were discussing all the time, I did not want to marry him, and my parents want that for me. So my other dream was to divorce my husband. So what I wanted was to live in
Mekelle, working in any coffee house or cleaning any house and to divorce my now exhusband and I did it! So I leave my husband and I came to Mekelle, I was working in a house like serving, so I had a salary and a place to live.

\section{f) Working together to find solutions:}

Q: How do you think that fistula can be prevented?

A: Pregnant women have to give birth in health centres and we have to take care before and after the delivery, go to make checks to see how is going the pregnancy.

Q: And what can be done to avoid social rejection caused by the fistula?

A: We have to give education to the community, to discuss with them and to teach them that fistula is not reason for the social rejection.

Q: What educational or strategies aimed at changing the mentality you think would be useful and are not being used?

A: The development group/ army they are working on this. Every 5 home in a village make a group and they discus about fistula, pregnancy, health centres... they have a program were 5 of them discuses and then the leader will discuss with another five group... so all the village has the chair person who will be the representative person of the village. All of them advice the pregnant women's and they follow her to be sure that nothing happen to them.

This is a very good strategy for education. Also there are groups for men in every village.

Q: In the area where you live, is there a prevention program?

A: As I explain it before, yes there is a prevention program working in all or most of the villages. It started 3 years ago and it was the initiative of our government. 
Q: If there is, when you realized that you had a health problem and you were suffering its social consequences, did you ask for help?

A: Yes, I ask for help to my sister, she helped me.

Q: Who was or were the persons more support offered you and how have they helped you?

A: My sister, she took care of me all the time.

Q: What kind of support (economic, personal, and educational) you have missed and you think it is basic?

A: I miss economic support. I had the economic support of ODWACE and I bought a cow with that money. It had a baby but now it ate a lift toxic and is dead. Now I got money from Healing Hands of Joy. Now I want to open a shop to work there, but is little bit difficult but we will see!

Q: What have been the most significant personal things you have given away because of fistula?

A: At that time when I was all the time in the bed because I could not move, my dream was to come to Mekelle!

Q: Is there anything you miss from your experience in the Hamlin Hospital?

A: I miss everything from the Hospital, the experience that they gave me, also how to clean my clothes! Everything, also the food, I learn how they made food in the hospital and now I can do it in my house!

Q: Something else that you will like to tell me?

A: What can I say? Help to the fistula victims to have again a normal life please. And you Liher, continue helping to other woman please! 


\section{Hailul 26 years old}

Date: 25.04.2014

Place: Maeza, local coffee house

Translator: Zufan Ababe

\section{a) General information:}

Q: How old are you?

A: I am not sure about my age, I was born in 1980 in Ethiopian calendar, so you will have to calculate the age... 26 years old.

Q: Until what age did you go to school and what grade did you finish?

A: I went to school until grade 4.

Q: In which place have you been living for the last 5 years?

A: I was born next to Myale in a village but last 5 years I was living in Myale

Q: How old were you when you got married?

A: I got married when I was 18 years old.

Q: How many years older or younger is your husband?

A: I do not know my own age, so I have no idea how old is my husband!!! He was born in 1977 in Ethiopian calendar so he is 3 years older than me.

Q: Was your own choice to marry your husband or did someone else tell you to marry him?

A: It was my choice to marry him, first my parents and his parents speak and then they came to ask me if I was agreeing to marry him.

Q: How many sons or daughters do you have?

A: I have only one daughter.

Q: Ask for the family members: who else is living in your house?

A: We live three of us in the house.
Q: Does your husband work or has worked before?

A: My husband work in the land, he takes the stones to build the houses later.

Q: Did you work or have you been working outside of the house? If yes, ask where and what was she doing.

A: I do not have any work.

Q: At home, can you describe me all the things you are in charge in your everyday life?

A: In home I only do: enjera, cook the food, clean the house, take care of my daughter and husband, wash clothes... everything.

Q: Valid indicators to establish the economic level: Ask if the home is owned or rented, if they have animals or not (number and type of animals), if they own land for cultivation (approximate size of the field), if the land is rented or bought it, type of crop they produce, if they have manual irrigation or not, if they have running water close to the house or not, electricity, radio at home).

A: It is our own house and we have our own land but we rent it and we had shared the crop with other family. The crop changes every day, teff... We do not have any electricity in our house. We have water close to our house.

\section{b) History of motherhood:}

Q: How old were you when you had your first child? (This will be hard to know because there is no birthday culture in Ethiopia and usually do not know how old they are)

A: After 2 years of getting married I had my first children, so more or less with 19 or 20 years old.

Q: Where have you given birth? At home, in a health centre, a hospital... 
A: I had 2 days of labour and they carry me to Mekelle Hospital by local stretchers. At that time there was no ambulance. The baby was ok and I was fine too. But the problem happen with the second pregnancy, I was for one day in labour at home but the health extension worker was with me during that delivery, when she saw that I was having complications she took me to Mekelle hospital. The midwife told me that the baby was dead and I develop the fistula. I realize immediately that I could not control the urine.

Q: How far (approximate time) is your house from the nearest health centre or hospital? And how can you get there?

A: Mekelle, 25 kilometres away from Myale in my first pregnancy. In the second one, we already have a health clinic in Myale.

\section{c) Early symptoms of fistula and social support or rejection:}

Q: From your point of view, what are the consequences of the fistula?

A: When the gynaecologist in Mekelle Hospital saw me, they refer me immediately to Hamlin Fistula Hospital. Dr. Melaku told me that he would treat me after 3 months, so I had to go back home and to drink lot of water. In our culture, when a woman gave birth, we have to wait one month or two months until we go to visit the new mother and specially for the rich people, so the new mom have to be inside of the house during that months. All people though that after my delivery I never go out because of that. Anybody thought that I develop a fistula. I suffer a lot; I was not able to go out, no to work and not able to walk.

Q: When did you realize that you were losing urine?

\section{A: After the delivery}

Q: What was your first reaction?

A: I was not able to understand what was happening to me, my baby was not there anymore and I was losing urine. One neighbour told me about fistula and that there was a treatment. My husband encourages me, not to be worry about it that I was going to be fine. My now ex-husband told me, after the meeting with Dr. Melaku that not to worry, that even if we have to pay, he will take care and we would go to Ayder Hospital to be treated before the 3 months that I was supposed to wait. But in Ayder Hospital they told us to go to Hamlin, after that and with the help of my ex-husband we went to a private clinic, but there also told us to go to Hamlin, so yes, he helped me a lot.

Q: Did you tell someone or did you keep it for yourself?

A: I told to my sister and later to my now ex husband and she immediately took me to the hospital.

Q: What was the reaction of your family?

A: My husband and sister took me to the hospital as soon as they realize what was happening to me.

Q: What was the reaction of the other family members and neighbours?

A: My parents were very sad when they knew it, they thought that it was a punishment and they could not believe that it could be treated. They thought that it was a punishment because I lost the baby!

My neighbour heard about what was happening to me when I was in the Hamlin Fistula Hospital, they never heard about fistula. My family protect me; they did not tell anything to the community to protect me.

Q: Did they help you finding a solution to the problem?

A: Yes they did.

Q: Who told you about the Hamlin Fistula Hospital in Mekelle?

A: In Mekelle Hospital, then Ayder Hospital and in private Hospital told me about the Hamlin Hospital. 
Q: Did your husband and family support you taking this decision?

A: Yes, all my family support this decision.

\section{d) Personal experiences in the hospital Q:}

Q: How long have you been in Hamlin Hospital?

A: In total I was in the hospital one month.

Q: What do you value the most about your stay in the hospital?

A: Everything was good, food, the water, the bed, the workers, I was very happy over there. It is a really nice place.

Q: Were you able to share personal experiences with other women who were there?

A: We were like sisters! We share lot of different experiences and we discus about lot of different things! Most of them were far from Mekelle. I made two very good friends and one of them told me that her husband divorced her because of the fistula and that she had a big discrimination in her community. The other one told me that her husband went with another woman because she was suffering from fistula and she was not able to have sexual relations.

Q: When you will leave hospital, what are you going to miss the most?

A: I wanted to come back to see my daughter and my husband but I was very sad because I knew that I was never going to see the friends and specially the 2 friends that I made in the Hospital, so I was very sad because of that.

Q: How do you think is going to be your going back "home"?

A: My husband came to pick me up to the hospital and we walk back to Myale together.

Q: Would you like to keep in contact with some of the women you have met here?
A: No, I do not have phone and most of them also, so we do not keep in contact with each other.

\section{e) Personal valuation about social and family in the returning back:}

Q: How did your family, friends, neighbours receive you when you returned from the hospital?

A: They make the local drink; my husband's mother and my sister came to visit us. Everybody was very happy, we were celebrating that I was born again! All people give me present. Everybody was very happy and they could not believe that I was treated.

Q: Did you return with your husband and children, to a friend's house, to any relative's house, or did you decide to live alone?

A: I came back with my husband and children.

Q: What are the most positive changes towards you, you have since perceived after your return from the hospital? (From the family, friends, neighbours...)

A: Before the treatment, anyone knew anything about what was happening to me. After the treatment, I came back to my normal life in the community.

Q: What are the most important changes you have notice in yourself since you came back from the hospital? (Higher self-esteem, selfimage, personal goals, dreams, personal desires...).

A: Before the treatment I promise to St. Mary, St. George, St. Michael... that I will give her twelve candles and I give for them, I was very happy I was health and back with my family again and to work inside of the house again. I was very happy.

\section{f) Working together to find solutions:}

Q: How do you think that fistula can be prevented? 
A: We give birth at home and we need to avoid this to avoid the fistula, we have to go early to the hospitals to give birth. If we develop the fistula, we have to go as soon as possible to the hospital as well to be treated.

Q: And what can be done to avoid social rejection caused by the fistula?

A: We have to teach to the community members about the fistula because they do not know what it is and because of that they reject us. So is important to educate them and women like me, the one's that we have been treated are the best ones to teach them.

Q: What educational or strategies aimed at changing the mentality you think would be useful and are not being used?

A: After when I came back from the Hamlin Fistula, I started to educate, to aware pregnant woman. Also it is important to teach in school, because one day the girls will become mothers so we need to prevent at early age.

Q: In the area where you live, is there a prevention program?

A: Every month, day 27 is holiday in Ethiopian calendar for Saints. The development group make a program and they invite us to teach the community, we gave birth at home and this is the reason of fistula, so we have to avoid this.

Q: If there is, when you realized that you had a health problem and you were suffering its social consequences, did you ask for help?

A: Yes, to my husband, the health extension worker when she hears about my problem, she came to my house and she told me to drink a lot of water, to wash my body... she told me that after the treatment I was going to be fine again. She came to visit me every 2 weeks to see and to encourage me. I really appreciate how much she helped me.

Q: Who was or were the persons more support offered you and how have they helped you?
A: My husband, the health extension worker and a woman who was already treated from fistula, she gave me lot of advices.

Q: What kind of support (economic, personal, and educational) you have missed and you think it is basic?

A: I got the economic support from Healing Hands of Joy 2.400 birr. I bought a cow and it gave birth. What I miss is education and if I have an opportunity I would like to continue studding.

Q: Is there anything you miss from your experience in the Hamlin Hospital?

A: I miss everything in the hospital, I miss my friends, the good food, the clean beds, the treatment everything! 


\section{Aregawit Mibratu, 35 years old}

Date: 28.05.2014

Place: Maeza, local- coffee house

Translator: Zufan Ababe

\section{a) General information:}

Q: How old are you?

A: I am 35 years old

Q: Until what age did you go to school and what grade did you finish?

A: No, I never went to school

Q: In which place have you been living for the last 5 years?

A: I have been living in Myale for my all live

Q: How old were you when you got married?

A: I was 15 years old when I get married

Q: How many years older or younger is your husband?

A: When I get married he was 28 years old. So 13 years older than me.

Q: He is much older than you!!

A: No, just a little bit....

Q: Was your own choice to marry your husband or did someone else tell you to marry him?

A: Yeah, it was not my choice; my parents chose it for me...

Q: And how were you feeling with 15 years old and already married?

A: In our culture, our parents chose the husband. I did not know anything about that man. My parents were rich, so they gave to my husband's family 8 cows for present. My father bought my husband...My father was working a lot and when he gave 8 cows to my husband as present, my husband was not able to take care of them and all of them died, also he died, 15 years ago.

Q: How many sons or daughters do you have? A: I have two daughters; one is 18 years old and the young one 16 years old. They were students but now they stop studding.

Q: Ask for the family members: who else is living in your house?

A: I live with two of my daughters; my husband died 15 years ago

Q: Does your husband work or has worked before?

A: He is dead

Q: Did you work or have you been working outside of the house? If yes, ask where and what was she doing.

A: I work in my house, with the animals, no outside of the house. I rent the land that I own to have little bit of money, because I do not have any ox to work with, so I rent it.

Q: At home, can you describe me all the things you are in charge in your everyday life?

A: I do almost everything at home; I clean, I wash, I prepare the food, go to the market. Normally my daughters help me doing these things.

Q: Valid indicators to establish the economic level: Ask if the home is owned or rented, if they have animals or not (number and type of animals), if they own land for cultivation (approximate size of the field), if the land is rented or bought it, type of crop they produce, if they have manual irrigation or not, if they have running water close to the house or not, electricity, radio at home). 
A: I have my own home, my husband built it, I have a land that now I rent it. I have very, very close water from my house but I do not have electricity at home. I have a radio with battery. I got 2.000bir from ODWACE and 2.000 birr from Healing Hands of Joy and I bought some sheep's. Dogs ate 6 of my sheep's, one of them it was pregnant...I suffer a lot because now I do not have anything again and I pay back the money to Healing Hands of Joy.

\section{b) History of motherhood:}

Q: How old were you when you had your first child?

A: I was 16 years old when I had my first baby

Q: Where have you given birth? At home, in a health centre, a hospital...

A: Home. When I was pregnant, in the $8^{\text {th }}$ month I was very sick, at home without moving. For one month I had big pain. When I was on labour I had a lot and big pain. I was on labour for 3 days. I gave birth at home and I develop the fistula. I suffer a lot during the delivery, I was in shock, I do not remember anything, and when I gave birth I was not able to understand anything. My mom had to explain me what happened.

When I realize that I was losing urine, I thought that in few days it was going to stop immediately that it was something related with the delivery. After 3 months, it did not stop so I went to Mekelle Hospital and I told to the doctors that I had stomach ache and pain in my back, fever, I did not tell anything to the doctors, I was very shy to tell them about it and they gave me some tablets.

After two years of the first baby, I had another baby and again at home, and in the labour, my mother and my sister were helping me. After the second delivery, I was feeling very tired and the urine become very flow. I wait 15 years with fistula. I was sick at bed and the chairperson and the health extension worker came to my house and they ask me about the symptoms that the fistula had and I told them that yes, so they explain me about fistula and that it could be treated that a lot of women had it and that after the treatment could have a normal life again.

Every day I use to wash my clothes and I use the incense for the bad smell. I also use perfume not to have a bad smell.

Q: How you were feeling about it? It will have to be hard not to tell anyone about it...

A: Yes, very hard, I was all the day crying. I was not able to do almost anything. When I was with my friends drinking coffee or speaking, I use to start crying in front of them. They asked me lot of time, why are you crying? And I never told them anything. Because if I told anyone that I lose urine, I knew that the community was going to discriminate me.

Q: If you gave birth at home, who was attending the birth?

A: My mother was during the delivery helping me.

Q: Did you have any complications during the delivery? If the answer is yes ask: what kind of problem? And what did you do?

A: I had a big pain during the delivery.

\section{c) Early symptoms of fistula and social support or rejection:}

Q: Did you tell someone or did you keep it for yourself?

A: I did not tell anyone what was happening to me, I was very afraid. Every day I was washing my clothes, the urine was dropping little by little. Even to the doctor in Mekelle I did not tell him anything. I was very very afraid!

Q: If the answer is negative: how did you feel keeping this problem for yourself?

A: I was crying all the time. All my friends were asking me why I was crying and I told them that nothing. It was hard to keep it for myself but I knew if I told to someone, they 
were going to discriminate me, so it was better not to tell to anyone.

Q: And finally how did you go to the hospital? A: Health extension worker and the chairperson helped me. I told them my problem and my brother took me to the hospital in Mekelle.

Q: What was the reaction of your family?

A: After they know it, my brother helped me to go to the hospital.

Q: From your point of view, what are the consequences of the fistula?

I was very afraid of telling to the people what was happening to me, because I knew that I was going to be rejected from society.

\section{d) Personal experiences in the hospital:}

Q: How long have you been in Hamlin Hospital?

A: totally two months.

Q: What do you value the most about your stay in the hospital?

A: It was very good food, our clothes were clean, the treatment was very good, and in general everything was good.

Q: Were you able to share personal experiences with other women who were there?

A: There were a lot of women from western, from south and we discus about our problems. And I realize that I was not the only one that was for so many years with fistula. Some community members were discriminating us and I told to them that I never told anything about my problem, I used to wash my clothes all the time. I understand that fistula women have bad smell but are not a reason for discrimination.

We discus a lot about this things... it was very nice.
Q: When you will leave hospital, what are you going to miss the most?

A: I miss everything from the hospital. Even in my dreams I dreamt that I am there again!

Q: How was your coming back "home"?

A: My sister son was driver, so he drive me until the car's road. After that my sister and me we walk until Myale.

Q: Would you like to keep in contact with some of the women you have met here?

A: I have some phone numbers of women in the hospital but it doesn't work. Even if I do not speak with them, I am thinking about them all the time, if they are fine etc.

\section{e) Personal valuation about social and family in the returning back:}

Q: How did your family, friends, neighbours receive you when you returned from the hospital?

A: My father when I got home, he kill a sheep to celebrate that I was back, also because I was sick so I had to eat to become strong again. It was a big ceremony. I was eating meet for two weeks.

My mother also was thanking God, she could not understand why if I was good that happened to me.

Q: Did you return with your husband and children, to a friend's house, to any relative's house, or did you decide to live alone?

A: No husband died. So I live with my daughters.

Q: What are the most positive changes towards you, you have since perceived after your return from the hospital? (From the family, friends, neighbours...)

A: Before the treatment, I was crying all the time, and now I stop crying, I do not have any mental disturbance now. I am not shy anymore; I can go everywhere and be with everyone again. 
Q: What are the most important changes you have notice in yourself since you came back from the hospital? (Higher self-esteem, selfimage, personal goals, dreams, personal desires... )

A: Now I am OK and I can do a lot of things, also my daughters are young now so they can help me with different things, especially because I am thinking on opening a coffee house so they can help me.

\section{f) Working together to find solutions:}

Q: How do you think that fistula can be prevented?

A: When a woman gets pregnant, we have to eat lots of nutrient foods take a rest and go to the doctor to check the pregnancy. One of the consequences of fistula is not to eat all kind of nutrients and also not to do hard work. We have to advice pregnant women for these things.

I started from my home, with my daughters to teach them these things; I speak with them about early marriages, saying that it is not good to marry before 18 years, because they can see what happened to me because of that.

I also give awareness in the community; I go home to home speaking with pregnant women and saying to them that they have to have the babies in health centres. Some of community people laugh at me, saying that I did not develop the fistula because I did not give birth at home. I answer to them that my father sold me for 8 cows, I was not educated, and also gave birth in my home, and because all of this things I develop the fistula. Nowadays every woman have to go to give birth the health centre, we cannot see more woman suffering from fistula.

Q: And what can be done to avoid social rejection caused by the fistula?

A: I was hidden because of fistula, but my neighbour also had the same problem and all the community was saying that she had a very bad smell. All the community discriminate her. I was telling to the neighbours not to do that because anyone can suffer it. We need to educate the community to avoid this discrimination.

Q: What educational or strategies aimed at changing the mentality you think would be useful and are not being used?

Q: In the area where you live, is there a prevention program?

A: The development group is doing a really good work in the prevention area. The day $27^{\text {th }}$ of month in Ethiopia calendar, they do education programs.

Q: And, do you think that in the schools we have to teach about it?

A: I did not go to school but it is important to be aware about the reproductive health, HIV... nowadays it is improving a lot the awareness.

Q: If there is, when you realized that you had a health problem and you were suffering its social consequences, did you ask for help?

A: No until 15 years of suffering it...

Q: Who was or were the persons more support offered you and how have they helped you?

A: The chairperson from my village told me about Hamlin, she give me lot of advices, she really help me.

Q: What kind of support (economic, personal, and educational) you have missed and you think it is basic?

A: Right now there is a woman in Hamlin fistula, before she had suffer a lot of years with it, she was hidden like me, she was in the prison and finally they decided to take her to Hamlin Hospital to treat her (we all laugh).

Anyway, I tell to the woman that are suffering from fistula, that they do not have to suffer, that there is a treatment and we have to go and get well again. There are so many reasons from these women not to be treated, they are afraid... we have to convince them to go and to get well good again. 
I miss and I have so many economic supports specially, now maybe my daughters can help me to open a coffee house.

Q: What have been the most significant personal things you have given away because of fistula?

A: I was not able to carry heavy things, and I'm still afraid of doing heavy work.

Q: Is there anything you miss from your experience in the Hamlin Hospital?

A: Everything, especially the love that they give me, they treat me like family. The hospital is the reason of having a light live, before the treatment I was living in a dark live and now I can do almost everything. The fistula and the social exclusion have to stop.

Q: Something else that you want to tell us?

A: Told to student not to marry before 18 . And the prevention has to improve more and more because we have to finish with fistula, next generation must learn from us, we have to educate them, if we educate them they are not going to marry before 18 years old and also they will give birth in health centres, so we have to work on this. 


\section{Tesfay, 42 years old}

Date: 02.05.2014

\section{Place: Healing Hands of Joy, Mekelle}

Translator: Goitom

\section{a) General information:}

Q: How old are you?

A: My name is Tesfay and I am 42 years old.

Q: Until what age did you go to school and what grade did you finish?

A: No I did not go to school

Q: In which place have you been living for the last 5 years?

A: Near Shire.

Q: How old were you when you got married?

A: I was 16 years old when I got married

Q: How many years older or younger is your husband?

A: I am not sure, but I knew that he was older than me.

Q: Was your own choice to marry your husband or did someone else tell you to marry him?

A: My family choice to marry him.

Q: How many sons or daughters do you have?

A: I have 3 daughters and 4 sons.

Q: Ask for the family members: who else is living in your house?

A: I live with my son and daughters.

Q: Did you work or have you been working outside of the house? If yes, ask where and what was she doing.

A: I use to work outside of the house, doing farm activities when I can, if not I was in charge of the households.
Q: At home, can you describe me all the things you are in charge in your everyday life?

A: I do everything at home, make the enjera, prepare the food, wash clothes, and clean the house....

\section{b) History of motherhood:}

Q: How old were you when you had your first child?

A: I had my first baby when I was 19 years old

Q: Where have you given birth? At home, in a health centre, a hospital...

A: I gave birth at home to all of them

Q: If you gave birth at home, who was attending the birth?

A: The elder women from my neighbourhood were helping me during all the deliveries.

Q: Did you have any complications during the delivery? If the answer is yes ask: what kind of problem? And what did you do?

A: I did not have any complications until the last delivery; I had an obstructed labour with the last baby, which make me the fistula.

Q: How far (approximate time) is your house from the nearest health centre or hospital? And how can you get there?

A: At that time, when I had the babies, it was 5 hours of walking distance the closes hospital, so for a pregnant woman it was difficult to get there.

\section{c) Early symptoms of fistula and social support or rejection:}

Q: From your point of view, what are the consequences of the fistula? 
A: It was a big problem to have the fistula, I was excluded from the community and I feel like I was alone with this problem. There were few people came to visit me but just few, most of the community people hate me and did not want to know anything about me.

Q: When did you realize that you were losing urine?

A: During the obstructed labour, people take me to the hospital during the night time that we walk for more that 8 hours what at day light you can do it in 6 hours. I do not remember exactly when I realize about the urine, but it was the same day that I had my last children.

Q: What did you think about it, were you scared?

A: At that time I was very scared, I could not understand what was happening to me. I thought that it was just my problem, that other women never had a fistula, I was the only person in the world that this happened.

Q: Did you tell someone or did you keep it for yourself?

A: I was in the hospital when that happened, so the gynaecologist refers me from Shire hospital to Adigrat Hospital. In Adigrat Hospital they realize that I had a fistula, so they send to me to Addis Ababa Hamlin Fistula. At that time, Mekelle's Hamlin Hospital was under construction that's why I had to go until Addis.

(She start speaking louder) In the beginning, in Shire Hospital, my husband was with me, so he immediately knew about it and he helped me to Adigrat Hospital.

Q: What was the reaction of your family?

A: My husband was scare as well but he stayed with me and he helped me from Shire to Adigrat Hospital.

Q: Who told you about the Hamlin Fistula Hospital in Mekelle?
A: In Adigrat Hospital when they realize that I had a fistula they send me to Addis.

\section{d) Personal experiences in the hospital Q:}

Q: How long have you been in Hamlin Hospital?

A: I was in the hospital for 3 months in Addis.

Q: What do you value the most about your stay in the hospital?

(She speaks lowly)

After I go to Addis Ababa Hamlin Hospital, I was there 3 months there and I got the medical treatment. But after 3 months, I started to lick again, so I was not totally cured. When they saw it they give me money for the transportation back home and they told me to come back after 6 months. I came back to my village I stayed for 6 months there and I came back to Addis again. I was in the hospital for one month and I got the medical treatment. I never recover totally from the fistula, because I still losing little bit urine, anyway, comparing with what I had at the beginning I cannot complain about the result of the medical treatment.

I really like it Addis Fistula Hospital, everything was good in the Hospital, the treatment, the clean hospital, the food everything!

Q: Were you able to share personal experiences with other women who were there?

A: We have a very good time! As I told you before, I thought that fistula was only my problem and when I saw lots of woman with the same problem I was so relied. I was all the time speaking with the other women about our past life, I share lots of things with them and I feel lucky to be able to share things with them.

Q: How do you think is going to be your going back "home"?

A: When I came back home, my husband was very happy to see me healthy again. But only him, the other community members and some 
of my relatives they were not that happy with me.

Q: Why???

A: Even for our community, when a woman have a baby by caesarean the community members are not happy with it because if you have to have a baby it has to be without any medical treatment, that's against of the traditions! And to change this traditions are very difficult.

Q: Would you like to keep in contact with some of the women you have met here?

A: I would like to but at that time we did not have the phone so it is difficult to keep in touch with them, I do not know how they will be now!

\section{e) Personal valuation about social and family in the returning back:}

Q: Did you return with your husband and children, to a friend's house, to any relative's house, or did you decide to live alone?

A: Yes with husband

Q: What are the most positive changes towards you, you have since perceived after your return from the hospital? (From the family, friends, neighbours...)

A: I really think that I have positive changes. Yes, comparing with before and after treatments. Now I am doing better. But, I still have some problems with some community members because they treated me badly when they knew that I had fistula and I still do not have good relationship with them.

Q: What happened?

(She starts to speak louder)

A: The reason of not having a good relationship is because at the beginning when they knew that I had a fistula, they treated me very bad, they wanted to see me dead. And when I came back treated they did not even say me anything. Also the women from my community, they were speaking behind my back in a bad way...I am treated already but it seem that I have to continue with the punishment.

Q: What attitudes towards you have not changed and by whom?

A: Some community members did not treat me well and I still do not speak with them.

\section{f) Working together to find solutions:}

Q: How do you think that fistula can be prevented?

A: (Louder) The health extension workers are following the future moms and they are doing a very good work. They visit the women in their houses and they control when they are going to have the baby... They also advice to the future moms to come early to the health centre to have the baby.

Also there is an ambulance in our woreda for example donned by the Red Cross. At this time is working a lot to end with fistula.

Q: And what can be done to avoid social rejection caused by the fistula?

A: (Louder) I think that it is better to forget about the bad situations. Nowadays the people that treat me badly because of fistula, I do not care about them; I leave them behind of me...

Q: In the area where you live, is there a prevention program?

A: There is a prevention program but is not satisfactory at all, there is still discrimination against fistula women, we have to work on this. The women that are formed in Healing Hands of Joy are working hard to fight against the discrimination and also to try to change the mentality of giving birth at home and to go to health clinics at time.

Q: Who was or were the persons more support offered you and how have they helped you?

A: My husband, he helped me a lot during the fistula period. 
Q: What kind of support (economic, personal, and educational) you have missed and you think it is basic?

A: I did not get any support, no economic, no personal, and no educational. I just received economic help for the transport, to go and come back to Addis and the treatment. This is my first week in Healing Hands of Joy one week ago. Now I am taking this training on prevention for a month and to be able to teach my community. After that I will have an economic support to start a business or to buy some animals to improve my economical income. But it is very important and necessary to give teach and give different supports, like economical, educational and psychological.

Q: Something else you want to say?

A: At this time I am not totally cured, I want to speak with sister Frewini about my medical condition. Maybe I can be treated again and finally be \%100 cured from fistula. 


\section{Gidey, 28 years old}

Date: 05.05.2014

Place: Healing Hands of Joy, Mekelle

Translator: Senait

\section{a) General information:}

Q: How old are you?

A: I am 28 years old

Q: Until what age did you go to school and what grade did you finish?

A: No I did not go to school

Q: In which place have you been living for the last 5 years?

A: I live around Shire, in a village close to it.

Q: How old were you when you got married?

A: I got married when I was 13 years old

Q: How many years older or younger is your husband?

A: Now he is 40 years old and I am 28 years old so, 12 years older than me.

Q: And you still with the same husband?

A: He divorces me because of the fistula. Then after my treatment, I got married with another boy but after a period I divorce him because of personal reasons. After a period I decided to try again a relationship with my first husband and I'm still with him now.

Q: Was your own choice to marry your husband or did someone else tell you to marry him?

A: The first marriage it was arranged between the two families, I was very young to understand what was happening there...

Q: How many sons or daughters do you have?

A: In my first pregnancy I had the fistula and my baby dead because of the obstructed labour, after that my first husband divorced me. After the fistula and with my second husband I had two more babies with my second husband, not with the first one.

Q: Ask for the family members: who else is living in your house?

A: I live with my husband and the two children.

Q: Does your husband work or has worked before?

A: My husband is a farmer

Q: Did you work or have you been working outside of the house? If yes, ask where and what was she doing.

A: Yes, I make enjera and I sold to the people next to my house, in my neighbourhood

Q: At home, can you describe me all the things you are in charge in your everyday life?

A: My husband is a farmer, so most of the time I am home doing households, and making enjera to sell it

\section{b) History of motherhood:}

Q: How old were you when you had your first child?

A: When I was 16 , but the baby was dead because of the obstructed labour.

Q: Where have you given birth? At home, in a health centre, a hospital...

A: I gave birth at home in the first delivery it was when I develop the fistula. The next two times I went to Shire Hospital to give birth because we need to give birth by caesarean so we need to go to the hospital.

Q: If you gave birth at home, who was attending the birth? 
A: Traditional birth attendance was attending the birth, they do not have any medical studies, they just learn by seeing others.

Q: Did you have any complications during the delivery? If the answer is yes ask: what kind of problem? And what did you do?

A: I was on delivery for 3 days in my first delivery. I had a prolonged labour, which produced me the fistula.

Q: How far (approximate time) is your house from the nearest health centre or hospital? And how can you get there?

A: It is very far! In our culture to give birth in a health centre is a very bad thing, the community did not allow me to go to the hospital to have the next two babies.

\section{c) Early symptoms of fistula and social support or rejection:}

Q: From your point of view, what are the consequences of the fistula?

A: In my case I had a lot of difficulties. I had a lot of physical problems, lots of pain. In my case as well, my husband when he realizes that what kind of problem I had, he immediately divorced me. Thanks that my parents were there to support me...

Q: When did you realize that you were losing urine?

A: I realize after the prolonged labour that I started to lose urine. I was with fistula more or less for one year.

At the beginning I was very confuse, why this happen to me? I thought that I was cursed and my family the same, they thought the same. My father heard something that there was a medical treatment for it. But, we did not have any money to pay for it, we are poor, so I decided to sell my gold jewellery to go to Shire Hospital. From there they refer me to Hamlin Hospital. After that and once I was in the Hospital, they told me that I did not have to pay for anything so I was very happy!!!
Q: What was your first reaction?

A: I was so scared; I thought that I was cursed, I was just crying all the time!

Q: Did you tell someone or did you keep it for yourself?

A: The first person that I told was my father.

Q: What was the reaction of your family?

A: My father told me not to worry that we would find a solution. My husband told me that he did not want to be with me....

Q: Who told you about the Hamlin Fistula Hospital in Mekelle?

A: The doctor from Shire Hospital saw what my problem was so he told me to go to Mekelle for the treatment

\section{d) Personal experiences in the hospital:}

Q: How long have you been in Hamlin Hospital?

A: I was for one month and half in Hamlin.

Q: What do you value the most about your stay in the hospital?

A: Everything was perfect, but the most the surgery, I was cured after the medical treatment and when I get back to my village I was equal with the other people.

Q: Did your community support you when they realize what you had?

A: Most of them they helped me, they were bringing me food because saying that I had to be strong to recover but they did not know what was happening really to me.

Q: Were you able to share personal experiences with other women who were there?

A: At the beginning, before join the Hamlin Hospital I thought that it was just my problem. When I get there and I saw how many women were there, I feel relied; I thanked God because I was not the only one. We share lots of things between us, it was really good! 
Q: When you will leave hospital, what are you going to miss the most?

A: I miss how they take care of us, the food, the clean beds, and the support that they give to me.

Q: Would you like to keep in contact with some of the women you have met here?

A: I have some phones of women that I met there, but at that time I did not have a phone, now I have so I really have to call them and tell them that I am fine!

Q: How was your going back "home"?

A: Everybody was very happy to see me healthy and back again. My friends thought that I was going to live forever with the fistula because they did not know that there was a medical treatment for that. When I came back all of them were very happy and at the same time surprise. They immediately told me to go to the market, to the church with them and I was feeling so happy to do this kind of activities again.

Also my brother and sister came to celebrate my come back, they gave me as present a chicken so we celebrate my come back in my parent's house.

\section{e) Personal valuation about social and family in the returning back:}

Q: Did you return with your husband and children, to a friend's house, to any relative's house, or did you decide to live alone?

A: I came back to live with my parents again, I did not go back with my husband.

Q: What are the most positive changes towards you, you have since perceived after your return from the hospital? (From the family, friends, neighbours...)

A: I was stressed with the fistula and I was not feeling like being with people. The community try to help me to find solutions about the health centres. I did not have any money to pay to go to the health centre but the women association was collecting money for me to go to the hospital, so I think that they treat me very well comparing with another cases.

Q: What are the most important changes you have notice in yourself since you came back from the hospital? (Higher self-esteem, selfimage, personal goals, dreams, personal desires...)

A: With the fistula, for one year I was feeling very bad, stressed, not happy, paranoid I thought that everybody was speaking bad about me. After the surgery, everything moves from my head, I was feeling comfortable again with myself and with the others.

\section{f) Working together to find solutions:}

Q: How do you think that fistula can be prevented?

A: At this time, I know that a pregnant woman has to go to give birth to a health centre, also that we have to start early with the antenatal care and controlling when we are going to have the babies.

I already start to teach to the community, I was going to the houses of pregnant women in my area and told them to go to give birth to the health centres! They told us to teach community in Hamlin fistula Hospital. When I graduate in Healing Hands of Joy I will continue with this work.

Q: And what can be done to avoid social rejection caused by the fistula?

A: I will try to educate all the community saying that Fistula is curable and that we do not have to discriminate these women! Opposite, we have to find solutions for them.

Q: What educational or strategies aimed at changing the mentality you think would be useful and are not being used? In schools for example.

A: I think that there is not and it would be very necessary.

Q: In the area where you live, is there a prevention program? 
A: There are women's development group and they are working on this, they try to find pregnant women and they advice her to go to the hospital or clinic to give birth, also to go and have antenatal care.

Q: Who was or were the persons more support offered you and how have they helped you?

A: My father, he helped me a lot.

Q: What kind of support (economic, personal, and educational) you have missed and you think it is basic?

A: I did not get any economic, educational support. Now In Healing Hands of Joy I will receive education and also personal and economic support and I want to buy some sheep's to work with them and to generate some economic income.

I was treated one year before, and I really miss this education and economic support from an organization. I heard about HHoJ in a workshop that they organize in Shire. After that, midwifes and health extension workers came to my house and they told me if I wanted to join the organization for a month of training and I just say yes!

Q: Something else that you will like to tell me?

A: I am very interested in the training of Healing Hands of Joy and I will do the best to teach in my community about what I learn here and try to change the mentality of giving birth at home. 


\section{Abrehet, 36 years old \\ Date: 07.05.2014 \\ Place: Healing Hands of Joy \\ Translator: Senait}

\section{a) General information:}

Q: How old are you?

A: I am 36 years old

Q: Until what age did you go to school and what grade did you finish?

A: No, I never went to school.

Q: In which place have you been living for the last 5 years?

A: Before Shire, in a village.

Q: How old were you when you got married?

A: I got married when I was 14 years old.

Q: How many years older or younger is your husband?

A: When we got married he was 24 years old, so he is 10 years older than me.

Q: Was your own choice to marry your husband or did someone else tell you to marry him?

A: It was an agreement between our parents; I did not decide anything, also because I could not understand anything...

Q: How many sons or daughters do you have?

A: I have 7 children; 3 girls and 4 boys

Q: Ask for the family members: who else is living in your house?

A: Yes, I live with my husband and with all my children.

Q: Does your husband work or has worked before?

A: Yes, my husband is a farmer.
Q: Did you work or have you been working outside of the house? If yes, ask where and what was she doing.

A: No, I never work outside of the house, sometimes, I help to my husband because he is a farmer but apart from that no. I am at home, taking care of the children, cleaning the house, preparing the food....

\section{b) History of motherhood:}

Q: How old were you when you had your first child?

A: I had my first children when I was 18 years old

Q: Where have you given birth? At home, in a health centre, a hospital...

A: Only the last one I gave birth in the health centre, the other 6 children I have at home.

Q: And in which delivery you develop the fistula then?

A: I develop the fistula at the $6^{\text {th }}$ pregnancy, after the fistula I had the last baby and I went to the health centre for that because in Hamlin Fistula Hospital told me that if I had another baby I had to give birth in a health centre.

Q: If you gave birth at home, who was attending the birth?

A: Most of the time my mother and my closest relatives were in the delivery but when they saw that I was having some complications they called to the traditional birth attendance.

Q: Did you have any complications during the delivery? If the answer is yes ask: what kind of problem? And what did you do? 
A: I had complications on the $6^{\text {th }}$ delivery; I had a prolonged labour were I was 3 days in labour.

Q: How far (approximate time) is your house from the nearest health centre or hospital? And how can you get there?

A: The closest health centre is 2 hours walking distance, there are no good roads to go there...

c) Early symptoms of fistula and social support or rejection:

Q: From your point of view, what are the consequences of the fistula?

A: I was for 3 months with fistula, at that time, my neighbours reject me but I was lucky with my family, they support me. After that, I went to health post centre and from there they refer me to Hamlin in Mekelle.

Q: When did you realize that you were losing urine?

A: I think that it was after 7 days of the delivery.

Q: What was your first reaction?

A: I was very shock, I could not understand anything...I was crying all the time because I thought that I was going to die.

Q: Did you tell someone or did you keep it for yourself?

A: No, immediately I told to my husband what was happening to me. He did not know anything about fistula but even that he tried to support me and he encourages me to be strong.

I told to everybody about it, to all people that came to visit me to try to get information about it.

Q: Finally, how did you know about the treatment and the hospital?

A: I could not walk when I had the fistula, so I thought that something happened to my life, I discus with my husband and with my family and all of us we decided to go to the health centre. When a health worker saw me, they immediately recognize that it was a fistula and they refer me to Hamlin fistula Hospital.

Q: What was the reaction of your family?

A: They immediately took me to the hospital

Q: Did your husband help you? And your sons and daughters?

A: My husband yes.

Q: How long have you been losing urine?

A: In total, 3 months.

Q: Who told you about the Hamlin Fistula Hospital in Mekelle?

A: In the health centre

\section{d) Personal experiences in the hospital:}

Q: How long have you been in Hamlin Hospital?

A: I was there for one month.

Q: What do you value the most about your stay in the hospital?

A: I am never going to forget about the surgery there, I was born again.

Q: Were you able to share personal experiences with other women who were there?

A: We share all our life experiences in the hospital. Everybody was speaking about their past lives and sharing experiences. After the surgery and when I realize that the fistula was because prolonged labour and not giving birth in a health centre, I tried to encourage all pregnant women in my area to go to health centre to give birth. I convince some women to go to heath centre to give birth!!! I am really happy about that. 
Q: When you had the surgery?

A: 3 years ago

Q: Would you like to keep in contact with some of the women you have met here?

A: I took all the phones from the workers and also from women! Some time I call to Dr. Melaku, I miss them a lot.

e) Personal valuation about social and family in the returning back:

Q: How did your family, friends, neighbours receive you when you returned from the hospital?

A: All the people were very happy and I was very happy too!

Q: did you have coffee ceremony?

A: Of course, we made a big ceremony with food and drinks! Of course, we were celebrating that I was born again.

Q: Did you return with your husband and children, to a friend's house, to any relative's house, or did you decide to live alone?

A: Yes with my husband and children, they were very happy to see me good again.

Q: What are the most positive changes towards you, you have since perceived after your return from the hospital? (From the family, friends, neighbours...)

A: I have a lot of positive changes, for 3 months I was in a big depression, even if my family and my friends helped me with my children and preparing the food but I was very depressive! After the surgery I am very happy again, I can meet my friends, I can go to the market, to the church without worrying about the urine.

\section{f) Working together to find solutions:}

Q: How do you think that fistula can be prevented?
A: We have to give birth at health centre. We have to have the antenatal care because we are not sure about what kind of position has the child or at what day we will have the delivery, so to avoid this things we need to have the antenatal care and we can avoid as well the fistula.

Q: And what can be done to avoid social rejection caused by the fistula?

A: We need to educate the community, saying that anyone can have the fistula and that it can be treated and cured and that is not a reason of discriminating anyone!!

Q: What educational or strategies aimed at changing the mentality you think would be useful and are not being used? Do you think that the schools need to teach it?

A: Is very, very important to work in the schools, I feel very sorry because I never heard about fistula and I think that if we teach in the schools everybody will know about it and we won't make a big problem like we do it now.

Q: In the area where you live, is there a prevention program?

A: The women development army is educating all the community, they teach about fistula and also about maternal health!

Q: So, when you finish the training here, you will join them?

A: Of course I will (she start smiling).

Q: Who was or were the persons more support offered you and how have they helped you?

A: My mother and my husband, both of them helped me a lot.

Q: What kind of support (economic, personal, and educational) you have missed and you think it is basic?

A: I was very worried to be in Hamlin Hospital, because my children and my husband were alone, without anyone taking 
care of them. It was very hard time. I would appreciate some help on that. Now I will get economic support from Healing Hands of Joy and I am planning to buy some sheep's because my children are young and they can help me with it!!!

Q: What have been the most significant personal things you have given away because of fistula?

A: At the beginning, when I had the fistula, I thought that I need money to go to the hospital and for the treatment. I got a loan to go there but when I get there Hamlin Hospital explain me that I do not need any money for that, everything was free. My husband and my mother spend all the money, so now I am having some problems to return this money back!

Q: Something else that you want to say me? A: No, I think I told you everything! 


\section{Zufan Ababe, director of ODWACE in Tigray}

Date: 20.03.2014

\section{Place: Women Association of Tigray, Mekelle}

\section{c) General information about}

\section{ODWACE:}

Q: When was created this NGO in Ethiopia, which was it purpose and who were the promoters of this initiative?

A: It was Established 1987, its name was NCTP (National Committee of Traditional Practices of Ethiopia). The Promoters were volunteers, especially health professionals and when it was established NCTP it was under Ministry of Health and the Promoters were health professionals, agriculture, ministry of education and more 11 members, that right now I do not remember. In 1986 was established for the Ministry of Health and in 1987 has already its own office.

Q: Was there a social demand to create it and who were them?

The social demand was coming from social workers and volunteers from community from the society. They were the one's asking for it.

Q: How does this NGO work? Could you explain its functioning staff, training politic of staff, financial resources, social acceptance, and support of public administration.

A: This NGO works with some objectives encourages traditional practice and the other one to discharge or to already use traditional practices, it works with the government, with NGO's local and International's. Also different local and international NGO's support us, like Safe the Children, UNICEF. Haurralde Fundazioa. Most of them they are international.

\section{Q: Socially in Mekelle, in Tigray region is it very known?}

A: Yes, in Tigray very known. This is the branch office, the donor's contact with us for support. We work with different target groups, sometimes also with the government. (Thinking...). Our policy is to work against Traditional practices that are harmful for women. We try to stop these traditional practices. We work with religious leaders, schools and practices like the one's FGM (female genital mutilation), uvula cutting, we make to be aware of these practices, to stop this practices that are very dangerous. They are the ones who have to be aware of these practices. Also children in school are very important, because we train them and them they go home and teach their parents and neighbours about it.

Q: To whom is your work address?

A: Religious leaders, education, all of them that I told you before.

Q: How many workers do you have? 
A: In all Tigray, it depends on the donors, some donor's they work in 5 different zones of Tigray. From the central to the south except the, west and northwest. Actually we don't have any workers in the woreda and zone but we are working with partners especially with WAT so we use their employees. For example when we want to go to aware some target groups, the women association (WAT) facilitates the community, using their workers do that.

Q: How do people get to know your NGO and how can women of rural areas of the region of Tigray contact you?

A: As I explain you, we are in contact with different association, or women's groups, or development groups. We work with different organizations.

Q: What are the major difficulties that exist on your work? (Low income, lack of trained staff in gender issues, dispersed rural area with limited access, resistance by traditional beliefs, etc.).

A: Main problem for our office is the transportation, low budget as well, at national level of our office in Tigray is better comparing with other regions, but we have a big problem with traditional practices, specially in the rural area, like uvula cutting is high almost the $90 \%$ in children. So for the all community our budget is very low. In the community there are many challenges, because they do a lot of years of this area.
Q: And the FGM it is very common in Tigray?

A: Yes, is not as much as in other regions but it is very known, so we have to work to finish with it, our mains objectives are zero tolerance for the FGM.

\section{Q: Reason of OVULA cutting, why?}

A: When we ask for the mothers the reason, they said that they cannot swallow well, it gives infection and it blocks the passing the way, so if they cut it, they think that this problem will finish. We teach them that uvula has its own function and that it does not have to be cut. If they continue thinking that they have to cut, we advise them to go to the doctor to do it. For example, I have three children and we did not cut. But most of mother thinks that if the uvula is not cut, their children can die.

Q: During the time NGO has been working, what changes have occurred?

A: The changes of HTP cannot be measure because. We know that it has been a positive change, these changes are because of all the people who work with us, there are lot of changes, our surveys say that there is a change in the practice but also in the knowledge and in the attitude. Slowly we are getting good changes in FGM, early marriages in Tigray. Practically we are seeing these changes but slowly.

Q: What are the main challenges to achieve to reduce the rate of fistula? 
A: The main challenge is the tradition because it discriminates women. One good example is women who suffer from fistula. If a woman says that she has a fistula, directly is discriminated, so she is afraid and she hides herself. Because of there is no awareness about it, or if there is it is not too much. She or these women do not know that it is because of an obstructed labour that this happen, she or they think that they have not been good with God, that she is not a good person and that she is punished for God. So because it is a punishment, she cannot tell to anyone. We are working on this, and I think slowly things are changing, there is a bigger awareness between women about it and they know about the hospital and that they can have a surgery without being worried about paying it.

It is really related then with the religious believes to hide, to be ashamed of them. But now, most of women are giving birth in hospitals, is changing it.

\section{b) Work Strategies:}

Q: Could you explain which are your NGO's strategies and intervention area?

A: Our NGO as I explain we are working in all Tigray,

Q: Do you work in schools with students? Should schools increase awareness among their students sensible about fistula?

A: We give training for student in school clubs like HIV clubs, girl clubs and so, even we establish HTP (Harmful Traditional
Practice) clubs in some schools in Mekelle in 11 different schools, 5 years ago. I remember a girl she developed a fistula, and after this training that we give, she knew what to do, she came to the hospital and was treated and now is ok. When we give this training in schools, they go to their houses and they teach to their parents and neighbours and even to that people that are prepared to cut their uvula. They try to aware them from cutting. Also for the early marriages, they know who is prepared to marry so they go to speak with the club leaders and teachers and they discuss with the parents to try to stop it.

Q: When women suffer of fistula, what is your action protocol?

A: Our organization for the fistula victims with WAT we find fistula victims and we give money for the transportation or me myself I go to their place and I bring them to the Fistula Hospital. After the treatment, we pay the cost of transport and we give them a training and economic support, psychological support as well with the training. The economic support is about 4000 birr (160 euros).

When these women know that something is wrong, they cannot discuss with the neighbours because they smell very bad. Even they are not able to go to church because of the smell so they are in their home all the time. Normally they sit down in the stone, like that their clothes do not get wet with the urine. They cannot go to the go to the market, to visit their neighbours, to 
the church or to coffee ceremonies; they are all the time home and alone.

Q: So then, who contact with you?

A: They contact us through women development groups, we give the awareness when we are training them for the HTP and we tell them that when they know that there is a fistula case to contact us. We give our telephone number and our address and most of the time, directly they contact with me. I go to their place, I am not a health professional but I listen to their stories and problems and I help them to the hospital. I give them dippers to use it in the bus and new clothes. I help them until the hospital.

Q: What aspects of your intervention program could be improved? You were telling me about transport...something else?

A: We cannot go to the rural area because of sometimes it has difficult access. There are so many fistula victims and we want to train them for prevention, is better than treat them, of course once that the damage is done, they need surgery but always prevention is better. Prevention can help more. So if we get the support from our head office I have to go to the remote area and train and aware them. They tell me that there are so many cases, so if we can we have to go there and aware them to decrease fistula victims.

Q: Describe the situation surrounding women with fistula (economy/family/ educational/social, etc.)?
A: The fistula victims normally are more in rural areas because they cannot get to the health centre, which normally are far from their houses. The main reason of fistula is the obstructed labour and they cannot get to the hospital.

Women are in labour for more than 12 hours even 2 or 3 days sometimes!!! So, they develop the fistula. Family is another problem and also education and economic problems. They do not have a proper nutrition and they do a lot of work, in our country when you read some studies, woman can work between 13 to 17 hours every day!!! And it is a heavy work, carrying water, wood, is amazing how much a woman can work...

Q: From your point of view, what is the most devastating issues (personal, familiar and social) arising from fistula?

A: Normally they have lots of children and low economic resources.

Q: Relating to fistula, are there differences between rural and urban areas between women suffering from fistula? And comparing with other regions of Ethiopia?

A: As I have heard from Hamlin Fistula Hospital, the prevalence comparing with other regions they said that there is a high prevalence in Tigray. 1,6\% Tigray and $1 \%$ at national level in fistula prevalence. Actually, more women come to the hospital so the number increase. 


\section{c) Return to everyday life:}

Q: Once these women leave the hospital, does your NGO facilitate any financial support, or are there organizations/ institutions that provide some form of financial aid in case they have to start with a "new" life?

A: Actually, in our region most husbands do not divorce from their wife's, but they have a low economic resource. First at all, when we bring a woman to the hospital and after she is treated and they go to the support we give money for the transport and after we give another economic resource to buy a cow, or sheep's. We give them around 4000 birr (160 euro). We also give trainings, and we follow them, we evaluate them that they are in a good situation. 48 women get our financial from Spain from Haurralde Fundazioa.

Q: Do you do follow-up these women after hospital discharge?

A: Yes they do.

Q: Does this NGO offer some type of training to these women to be agents of change and for helping other women who are going through the same situation?

A: They get a training to help other women.

Q: Something else that you want to tell me?

A: They suffer for a lot of years, some of them for 10 or 20 years, so all of this is because there is a lack of awareness. If they are aware about it, they can come to the hospital to be treated. And we have to go to the religious leaders, to ask for help.

Even for a woman is very difficult to life with urine. We still have to do a lot, we are expected to do a lot and we do just a little piece of it, especially in the rural areas. Of course, there are developments groups in the rural areas and always fistula victims can ask for help to them. We have to work on prevalence. After they are treated we feel very happy for them, you can see a big change in their lives. 
